\title{
ELABORAÇÃO E AVALIAÇÃO DA EFICÁCIA DO SISTEMA DE PONTOS DE UM INSTRUMENTO DE ORIENTAÇÃO ALIMENTAR COMO FERRAMENTA PARA INTERVENÇÕES DIETÉTICAS EM INDIVÍDUOS HIPERLIPIDÊMICOS
}

EDELI SIMIONI DE ABREU

Tese de Doutorado apresentada ao Departamento de Nutrição da Faculdade de Saúde Pública da Universidade de São Paulo para obtenção do Grau de Doutor.

Área de concentração:

Nutrição

Orientadora:

Profa.Assoc. Elizabeth A. F. S. Torres

São Paulo

2003 
Autorizo, exclusivamente para fins acadêmicos e cientificos, a reprodução total ou parcial desta tese, por processos fotocopiadores.

Assinatura:

Data:

$43810 / 2003$ doc 
"A ciência da nutrição e suas aplicações são de repercussão mundial. Soluções para os problemas de nutrição parecem ser vitais para uma melhora de longo alcance na saúde pública, para a prevenção de doenças e para o progresso do bem-estar da humanidade."

H. J. HEINZ /I 


\section{DEDICATÓRIA}

Por ordem de entrada

Ao Mauricio

“... because l've got you under my skin..."

Ao José Mauricio e Henrique "...l hear the angels calling out your names..." 


\section{AGRADECIMENTOS}

À Profa. Assoc. Elizabeth Aparecida Ferraz da Silva Torres por sua amizade e paciência que, como orientadora, transformou o tão temido doutorado, numa agradável fase de aprendizado.

Ao Prof. Titular Carlos Augusto Monteiro que muito contribuiu com seu entusiasmo e dedicação à pesquisa, ajudando-nos com sugestões que só enriqueceram esse trabalho.

À Profa. Titular Dulcinéia S. P. Abdalla por suas competentes sugestões.

À Profa. Dra. Regina Mara Fisberg por sua competência como nutricionista e professora e pelo estímulo desde o início dessa trajetória.

Ao Prof. Dr. Raul Dias dos Santos Filho pelo apoio, gentileza e disponibilidade em ajudar. Grata pelas observações.

À Profa. Assoc. Sônia Tucunduva Philippi e à Profa. Dra. Betszabeth Slater Villar pelas sugestões e por estarem sempre dispostas a ajudar.

À Faculdade de Medicina da Fundação do $A B C$ e Disciplina de Endocrinologia, na pessoa do Professor Titular: Dr. Fadlo Fraige Filho, pela gentil acolhida que ofereceu condições para a realização desse trabalho.

Ao Prof. Dr. Daniel Gonçalves Lerário, tão esforçado e disposto a ajudar, pelo auxílio no levantamento dos dados.

À nutricionista Márcia A. L. Nacif, por sua amizade, porto seguro que me acolheu em momentos dificeis, que me estimulou, deu sugestões.

À amiga Mônica G. N. Spinelli pelo apoio incondicional, paciência e sugestões tão pertinentes. 
À Eluza Maria Gomes pela revisão cuidadosa que refletiu mais uma vez a sua amizade.

Às sempre amigas Ana Carolina Almada Colucci e Renata Furlan Viebig pelo auxilio na confecção do summary.

Às colegas Renata, Margarete e Luzi que não mediram esforços para que esse trabalho viesse à luz.

Ao Ricardo Penacchi de Camargo pela amizade e auxilio na formatação do sistema de pontos.

Aos pacientes que voluntaria e humildemente participaram dessa pesquisa, sem imaginar o quanto estavam colaborando com a ciência da nutrição.

A todos os indivíduos dislipidêmicos, cujo sacrifício em manter uma dieta hipogordurosa, me proporcionaram a motivação para concluir esse trabalho.

$\grave{A} \mathrm{CNPq}$, que financiou esta pesquisa.

A todos que colaboraram e me apoiaram e espero agradecer pessoalmente.

À Lucileide e Gilvanda, colaboradoras diligentes, que com competência e paciência me auxiliaram nas tarefas domésticas e se dedicaram aos meus filhos.

À Diva, minha mãe e Henriqueta, minha avó, que sempre acreditaram no estudo como a melhor herança.

À minha familia: ao Maurício pelo apoio de sempre e principalmente nesse período e aos meus filhos de quem roubei tantos momentos e agora espero recompensá-los.

A Deus, a quem devo tudo e muito mais. 


\section{ÍNDICE}

1 INTRODUCÃO 1

1.1 Envelhecimento populacional 2

1.2 Epidemiologia das doencas cardiovasculares 4

1.3 Fatores de risco associados ao aparecimento de doenças

cardiovasculares 6

1.4 Dietas e dislipidemias 8

1.5 Aterogênese 9

1.6 Alimentação e lipidemias 13

1.7 Potencial aterogênico dos alimentos 16

1.8 Metabolismo lipidico 18

1.9 Classificação das dislipidemias 21

1.10 Tratamento das dislipidemias 22

1.10.1 Tratamento dietético nas dislipidemias 22

1.10.2 Farmacoterapia nas dislipidemias 24

1.11 Indice de Colesterol/Gordura Saturada (CSI) 25

1.12 Guias alimentares $\quad 27$

1.13 Fundamentos do comportamento alimentar 29

1.14 Estudos experimentais ou de intervenção 31

1.15 Justificativa $\quad 32$

2 OBJETIVOS 33

2.1 Objetivo Geral 33

2.2 Objetivos Específicos 33

3 MÉTODO 34 
3.1 Delineamento do estudo

3.2 Elaboração do sistema de pontos 34

3.2.1 Lista de alimentos

3.2.2 Tamanho das porcōes

3.2.3 Cálculo de CSI 36

3.2.4 Como contar os pontos 37

3.2.5 Alimentação balanceada

3.2.6 Correcões e ajustes no sistema de pontos 39

3.3 Estudo piloto 41

3.3.1 População e local de estudo 41

3.3.2 Amostragem 42

3.3.3 Critérios de seleção e exclusão 42

3.3.4 Coleta de dados 43

3.3.5 Variáveis de estudo $\quad 43$

3.3.6 Desenho do estudo piloto 44

3.3.7 Procedimentos metodológicos 45

3.4 Aspectos Éticos 51

3.5 Análise estatistica dos dados 52

3.5.1 Análise descritiva

3.5.2 Análise inferencial_ 53

4 RESULTADOS $\quad 57$

4.1 Elaboração do sistema de pontos 57

4.2 Sistema de pontos para colesterol e gordura no sangue 60

4.3 Estudo piloto $\quad 87$

4.3.1 Caracterização da população e dos grupos controle e estudo $\quad 87$

4.3.2 Análise do perfil dos individuos do grupo controle e estudo $\quad 93$ 
5 DISCUSSÃO

5.1 Elaboracão do sistema de pontos $\quad 104$

5.2 Estudo piloto 126

5.2.1 Caracterização da população $\quad 111$

5.2.2 Análise do perfil dos individuos do grupo controle e estudo $\quad 119$

5.2.3 Análise do perfil dos individuos do grupo controle e estudo $\quad 120$

6 CONCLUSÃO $\quad 127$

7 REFERENCIAS $\quad 128$

ANEXOS _ A1

ANEXO 1 Dieta Tradicional para portadores de dislipidemias $\quad$ A2

ANEXO 2 Instrumento para Coleta de Dados A3

ANEXO 3 Of. COEP/067/01 A4

ANEXO 4 Termo de Consentimento Livre e Esclarecido A5

ANEXO 5 Análise de residuos A6 


\section{LISTA DE ABREVIATURAS}

\begin{tabular}{ll} 
SIGLA & DESCRIÇÃO \\
AHA & American Heart Association \\
C & Colesterol \\
CI & Indice de colesterol (cholesterol index) \\
CID & Código Internacional de Doenças \\
CSI & Indice de colesterol/gordura saturada (cholesterol/saturated-fat index) \\
CT & Colesterol total \\
DAC & Doença arterial coronariana \\
DP & Desvio Padrão \\
ECNT & Enfermidades Crônicas Não Transmissiveis \\
EDTA & Etilenodiaminotetracético \\
EUA & Estados Unidos da América \\
FM-FuABC & Faculdade de Medicina da Fundação do ABC \\
FSP & Faculdade de Saúde Pública \\
HDL & Lipoproteina de alta densidade \\
ICS & Índice de colesterol/gordura saturada \\
IMC & índice de Massa Corporal \\
IBGE & Instituto Brasileiro de Geografia e Estatistica \\
LDL & Lipoproteina de baixa densidade \\
LDLox & Lipoproteina de baixa densidade oxidada \\
MRFIT & Multiple Risk Factor Interventional Study \\
MS & Ministério da Saúde \\
\hline
\end{tabular}




$\begin{array}{ll}\text { N } & \text { Número de individuos } \\ \text { NRC } & \text { National Research Council } \\ \text { OMS } & \text { Organização Mundial da Saúde } \\ \text { P } & \text { Ácido graxo polinsaturado } \\ \text { R-24h } & \text { Recordatório de } 24 \text { horas } \\ \text { S } & \text { Ácido graxo saturado } \\ \text { SBC } & \text { Sociedade Brasileira de Cardiologia } \\ \text { SBD } & \text { Sociedade Brasileira de Diabetes } \\ \text { STARS } & \text { St Thomaz' Atherosclerosis Regression Study } \\ \text { TSH } & \text { Hormônio Estimulante da Tireóide } \\ \text { USDA } & \text { United States Department of Agriculture } \\ \text { USP } & \text { Universidade de São Paulo } \\ \text { VET } & \text { Valor Energético Total } \\ \text { VLDL } & \text { Lipoproteina de muito baixa densidade }\end{array}$




\section{LISTA DE FIGURAS}

Figura 1: $\underline{C T}$ sérico e morte por DAC em 361.662 homens com 35 a 57 anos, do estudo MRFIT, por 6 anos de seguimento 4

Figura 2: Representação diagramática do processo de formação da lesão ateromatosa 10

Figura 3: Ateromas da aorta torácica descendente 12

Figura 4: Ateroma da artéria coronária $(25 x)$ 12

Figura 5: Aspecto histológico do ateroma (120 x) 12

Figura 6: Esquema metabólico das lipoproteínas plasmáticas 14

Figura 7: Passos para a elaboração de Guias Alimentares 29 


\section{LISTA DE QUADROS}

Quadro 1: Recomendações dietéticas para o tratamento de hipercolesterolemias 23

Quadro 2: Dados estimados da população a utilizar o sistema de pontos e necessidades energéticas 39

Quadro 3: Valores de referência dos lipides séricospara individuos com 20 anos de idade ou mais 49

Quadro 4 : Classificação para IMC 50

Quadro 5: Testes utilizados para comparações dos Grupos e demais variáveis 55 


\section{LISTA DE TABELAS}

Tabela 1: Coeficiente de correlação dos cálculos de CSI em relação à escolaridade dos participantes da pesquisa. Ourinhos, 2002 60

Tabela 2: Características sócio-demográficas dos individuos hiperlipidêmicos, segundo Grupo. Ambulatório de endocrinologia da FM-FuABC, Santo André, 2002. 88

Tabela 3: Distribuição da média e desvio-padrão dos indivíduos hiperlipidêmicos, segundo Idade e Grupo. Ambulatório de endocrinologia da FM-FuABC, Santo André, 2002. 89

Tabela 4: Distribuicão da média e desvio-padrão dos individuos hiperlipidêmicos, segundo Altura e Grupo. Ambulatório de endocrinologia da FM-FUABC, Santo André, 2002. 90

Tabela 5: Distribuição da média e desvio-padrão dos indivíduos hiperlipidêmicos, segundo as variáveis diagnósticas e Grupo. Ambulatório de endocrinologia da FM-FuABC, Santo André, 2002.

Tabela 6: Distribuição dos individuos hiperlipidêmicos, segundo a presença de comorbidades e Grupo. Ambulatório de endocrinologia da FM-FuABC, Santo André, 2002. 92

Tabela 7: Distribuição dos indivíduos hiperlipidêmicos, segundo o uso de medicamentos e Grupo. Ambulatório de endocrinologia da FM-FuABC, Santo André, 2002. 
Tabela 8: Resultados inferenciais dos testes entre as comparações dos

Grupos e demais variáveis. Ambulatório de endocrinologia da

FM-FuABC, Santo André, 2002.

94

Tabela 9: Resultados inferenciais dos testes entre os Grupos, segundo

as medidas observadas no início da pesquisa. Ambulatório de

endocrinologia da FM-FUABC, 2002

95

Tabela 10: Reducão percentual das variáveis diagnósticas dos individuos

hiperlipidêmicos, segundo Grupo. Ambulatório de endocrinologia

da FM-FuABC, Santo André, 2002.

97

Tabela 11: Resultados inferenciais dos testes entre os Grupos, segundo a

Reducão das medidas observadas. Ambulatório de endocrinologia

da FM-FUABC, 2002

98 


\section{LISTA DE GRÁFICOS}

Gráfico 1: Distribuição da ldade e da Redução percentual de CT, segundo

Grupos. Ambulatório de endocrinologia da FM-FuABC, 2002 100

Gráfico 2: Distribuição da Reducão percentual de IMC e da Redução percentual de $C T$, segundo Grupos. Ambulatório de endocrinologia da FM-FUABC, 2002. 100

Gráfico 3: Distribuicão da Circunferência abdominal e da Redução

percentual de $\mathrm{CT}$, segundo Grupos. Ambulatório de

endocrinologia da FM-FUABC, 2002 101

Gráfico 4: Distribuicão Sexo e da Reducão percentual de CT, segundo

Grupos. Ambulatório de endocrinologia da FM-FuABC, 2002 101

Gráfico 5: Distribuição Raça e da Redução percentual de CT, segundo

Grupos. Ambulatório de endocrinologia da FM-FuABC, 2002 102 


\section{RESUMO}

Abreu ES. Elaboração e avaliação da eficácia do sistema de pontos de um instrumento de orientação alimentar como ferramenta para intervenções dietéticas em indivíduos hiperlipidêmicos. São Paulo; 2003. [Tese de Doutorado - Faculdade de Saúde Pública da USP].

Dados da literatura confirmam a existência de substâncias dietéticas que são aterogênicas e promotoras de doenças cardiovasculares, tais como conteúdos elevados de colesterol e gordura saturada. O que fica difícil mensurar é o poder aterogênico ou mesmo hipercolesterolêmico dos alimentos. Assim, a utilização de um sistema de pontos de fácil compreensão e manejo poderia auxiliar os indivíduos na escolha de alimentos saudáveis. Esse trabalho teve como objetivo elaborar um instrumento de orientação alimentar e avaliar sua eficácia como ferramenta para intervenção dietética para individuos com hiperlipidemias. Foi um estudo realizado em duas etapas: elaboração do sistema de pontos com pontuação de índice de Colesterol/Gordura Saturada (CSI) e um estudo piloto de desenho experimental com duração de três meses. Esse protocolo de pesquisa comparou dois grupos. $O$ grupo estudo seguiu a dieta proposta pelo sistema de pontos e o grupo controle que foi orientado por impresso com alimentos permitidos e proibidos. Os resultados demonstraram que foi elaborado, com sucesso, um instrumento de orientação alimentar denominado Sistema de Pontos para Controle de Colesterol e Gordura no Sangue. Essa ferramenta se apresentou como de rápida aplicação e de fácil compreensão, com eficácia absoluta em relação à dieta tradicional para dislipidemias, em relação às medidas de peso, IMC, circunferência abdominal, colesterol total, LDL e prática de atividade física e eficácia relativa quanto às medidas de HDL, VLDL e Triglicérides.

Descritores: Índice de Colesterol/Gordura Saturada (CSI). Guias Alimentares. Lipideos. Dislipidemias. 
Abreu ES. Elaboração e avaliação da eficácia do sistema de pontos de um instrumento de orientação alimentar como ferramenta para intervenções dietéticas em indivíduos hiperlipidêmicos. [Elaboration and evaluation of points system food orientation instrument efficacy as a tool for dietetic interventions on hypercholesterolemic individuals.] São Paulo (BR); 2003. [Tese de Doutorado Faculdade de Saúde Pública da USP].

Literature data confirms the existence of atherogenic dietary substances and promoters of cardiovascular disease, they are high levels of dietetic cholesterol and saturated fat. However, it is difficult to measure the food's atherogenic or even hypercholesterolemic power. Thus, an easily comprehensive food guide could help individuals on choosing healthy foods. This work aimed to elaborate a food orientation instrument and evaluate his efficacy as a tool for dietetic intervention of hiperlipidemic individuals. It was a study developed in two steps: elaboration of points system with punctuation of Cholesterol/saturated fat Index (CSI) and a pilot study of experimental design with duration of three months. This protocol compared two groups: the study group, that followed the proposal diet from the points system and the control group that was oriented by a text contenting allowed and prohibited foods. The results demonstrated that the points system food orientation instrument to control cholesterol and fat in blood plasma was successfully elaborated and presented as a fast application and easy comprehension, with absolute efficacy than traditional diets for dyslipidemic individuals, than weight measures, BMI, waist circumference, total cholesterol, LDL a physical activity, and relative efficacy when compared to HDL, VLDL a triglycerides.

Descriptors: Cholesterol/Saturated Fat Index (CSI). Food Guides. Lipids. Dyslipidemia. 


\section{INTRODUÇÃO}

Atualmente, o mundo enfrenta novos e intensos desafios na área da saúde. Entre eles, destaca-se o decorrente aumento da expectativa de vida, ou seja, a população mundial vivencia uma situação especial de envelhecimento. Tal processo propicia maior exposição de crescente número de pessoas a uma série de fatores de risco, o que pode desencadear a elevação da incidência de enfermidades crônicas não transmissiveis (ECNT), de tratamento dispendioso, em que se destacam a doença cardiovascular, as neoplasias, a osteoporose e os estados de demência (MARUCCI 1992).

Os fatores de risco para ECNT têm origem genética e sofrem influências ambientais. No que tange às influências ambientais, podemos destacar o tabagismo, que è o fator de risco número 1 (NCEP 2001), o estilo de vida, o uso de drogas, o álcool e os hábitos alimentares.

A dieta habitual é apontada como elemento fundamental de análise dos determinantes da susceptibilidade para o aparecimento de doenças crônicodegenerativas não transmissiveis.

A partir do estabelecimento de estudo prospectivo dos fatores de risco para doença aterosclerótica na população de Framingham nos Estados Unidos, em 1956 (FRIEDMAN e KIMBALL 1986, ANDERSON e col. 1987) e do clássico estudo dos "Sete Paises" (KEYS 1970) ficou definitivamente demonstrado o papel do colesterol 
e das gorduras saturadas como fatores de risco e sua correlação com aterosclerose.

O que fica difícil mensurar é o potencial aterogênico ou mesmo hipercolesterolemizantes dos alimentos. Para auxiliar 0 entendimento da contribuição dos conteúdos de colesterol e gordura saturada dos alimentos para aterogênese, foi desenvolvido por CONNOR e col. (1986), um índice de colesterol/gordura saturada (CSI - cholesterol/saturated-fat index) que pode ser utilizado para comparar diferentes alimentos e preparações, além de auxiliar na avaliação do consumo diário dos individuos.

\subsection{Envelhecimento populacional}

O processo biológico de envelhecimento, que é universal e inevitável, è determinado pela interação entre fatores genéticos e ambientais.

A Organização Mundial da Saúde (OMS) conceitua envelhecimento como "um processo fisiológico que começa na concepção e ocasiona mudanças caracteristicas para a espécie durante todo o ciclo de vida" (PASCHOAL 1996).

Desde meados do século $X X$, a expectativa de vida da espécie humana vem aumentando mais do que em toda a história pregressa da humanidade (RAMOS 1993). Isso se deve a vários fatores que incluem a educação, o aumento da renda per capita, a mudança do perfil epidemiológico das doenças, a expansão dos serviços de saúde, além do avanço tecnológico, entre outros. 
O prolongamento da vida acarreta mudanças nos padrões de morbimortalidade na população mundial. Entretanto, o ritmo do progresso não tem sido uniforme em todos os paises. Para os paises em desenvolvimento, onde a expectativa de vida é menor, 60 anos é a idade de transição das pessoas para o segmento idoso da população (PASCHOAL 1996).

Nos paises desenvolvidos, o crescimento da população idosa vem sendo estudado há vários anos. Nos Estados Unidos da América (EUA), por exemplo, esse segmento vem crescendo, desde 1960, de forma mais intensa do que a população mais jovem (LOBO 1994).

De fato, no Brasil o cenário não é diferente. Estudos que analisaram a transição demográfica, na população brasileira, desenvolvidos nas últimas décadas, constataram o crescimento do segmento idoso da população como conseqüência da queda da mortalidade e declínio da fecundidade (BERQUÓ e LEITE 1988, CAMARGO e SAAD 1990).

Esse aumento acentuado, particularmente nos paises em desenvolvimento, dos quais faz parte o Brasil, traz conseqüências dramáticas para a economia e para a sociedade (PAPALÉO 1996). Do ponto de vista econômico, aumenta a população aposentada, classificada como não produtiva, sobrecarregando a população economicamente ativa, onerando o sistema de previdência social e aumentando a importância do papel da família no suporte social ao idoso, além do impacto maior na repartição dos parcos recursos existentes, surgindo novas necessidades de demandas. 
As estimativas indicam que, no País, a faixa etária acima de 60 anos chega a 8,3\% da população - cerca de 13 milhões de pessoas (FUNDAÇÃO IBGE 2000) e com tendência a aumentar (RAMOS 1993).

\subsection{Epidemiologia das doenças cardiovasculares}

A doença arterial coronária atinge, principalmente, a população dos países desenvolvidos e teve sua incidência aumentada a partir de meados do século $\mathrm{XX}$ (BLEIL 1998). Dados epidemiológicos enfatizam a relação entre níveis plasmáticos de colesterol e suas frações, com a incidência desse tipo de doença (MARTINS e col. 1996, CONNOR 1999).

Figura 1: $\underline{\text { CT sérico e morte por DAC em } 361.662 \text { homens com } 35 \text { a } 57}$ anos, do estudo MRFIT, por 6 anos de seguimento.

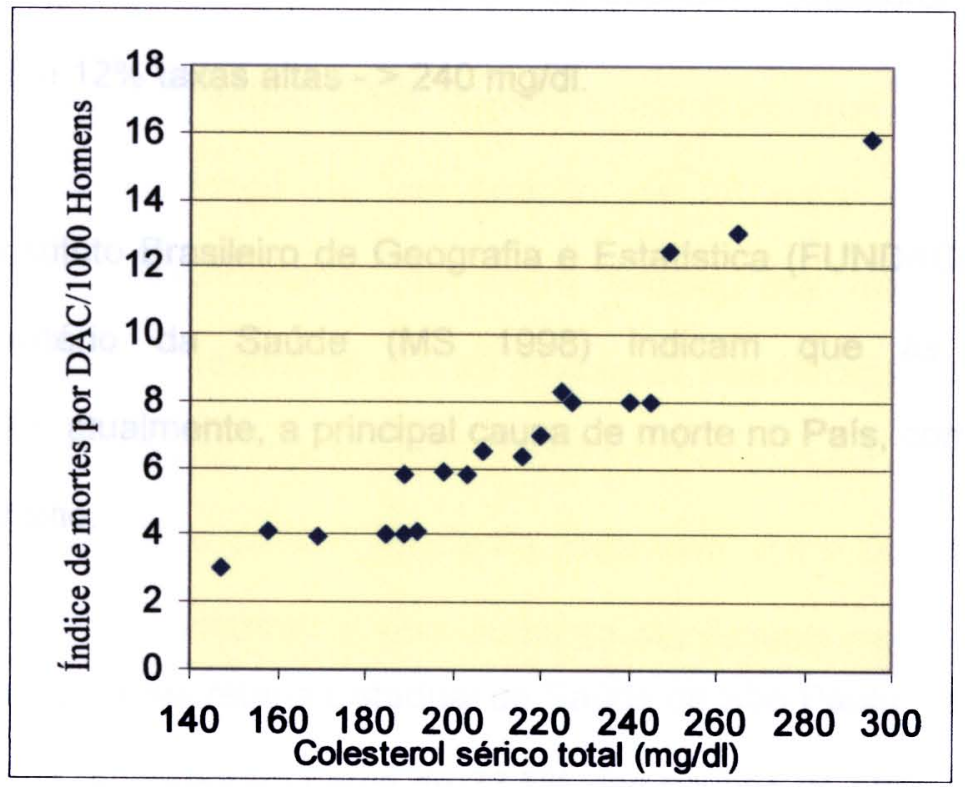

Fonte: Adaptado de MARTIN e col. (1986) 
Evidências epidemiológicas prévias, obtidas a partir de pesquisa que envolveu mais de 360.000 homens no Estudo de Intervençāo de Múltiplos Fatores de Risco (MRFIT - Multiple Risk Factor Interventional Study), sugeriram que o nivel de colesterol total estava associado à taxa de mortalidade por DAC (MARTIN e col. 1986, LaROSA e col. 1990), como é apresentado na Figura 1.

No Brasil, a partir da década de 1940, começou a ocorrer uma inversão entre a prevalência de doenças infecciosas e parasitárias e as doenças do sistema circulatório (MS 1983, LOTUFO 1993, BLEIL 1998). E, apesar da importância do colesterol como fator de risco, alguns autores declaram que, no Brasil, nada se conhece sobre as dislipidemias em termos populacionais (LUZ e col. 1990, FORTI e col. 1997); o que existem são estudos focando grupos ou populações especificas (GIANNINI e col. 1988, DIOGUARD e col. 1994, LESSA e col. 1997, NICOLAU e col. 1998, FISBERG e col. 2001). No entanto, a Sociedade Brasileira de Cardiologia (SBC 1996) afirma que $42 \%$ dos brasileiros apresentam colesterol acima do normal - > 200mg/dl e $12 \%$ taxas altas - > $240 \mathrm{mg} / \mathrm{dl}$.

Dados do Instituto Brasileiro de Geografia e Estatistica (FUNDAÇÂO IBGE 1996) e do Ministério da Saúde (MS 1998) indicam que as doenças cardiovasculares são, atualmente, a principal causa de morte no País, com mais de 300.000 mortes por ano.

Segundo dados da Secretaria Estadual de Saúde de São Paulo, as doenças do sistema circulatório representam cerca de $33,5 \%$ das causas de óbito no Estado (SES/SP 2001). 
No entanto, o desenvolvimento de doenças cardiovasculares é caracterizado por um longo período de latência, seguindo um curso assintomático prolongado, que caracteriza a história natural de enfermidades crônicas nāo transmissiveis, porém envolvem uma multiplicidade de fatores de risco complexos (LESSA 1997).

\subsection{Fatores de risco associados ao aparecimento de doenças cardiovasculares}

Muitos são os estudos que tentam identificar os fatores envolvidos na gênese das enfermidades cardiovasculares. A obesidade é apontada como um fator de risco importante no desenvolvimento de uma série de doenças e no aumento da morbimortalidade em adultos e idosos (LERÁRIO e col. 2002). Estudos realizados por BJONTORP (1995) sugerem que a obesidade está altamente associada a doenças cardiovasculares.

Não obstante, em estudos sobre consumo alimentar que compararam inquéritos domiciliares, ao longo de um período de 26 anos (MONDINI e MONTEIRO 1994) e, posteriormente, em outro estudo, por mais 12 anos (MONTEIRO e col. 2000), constatou-se que as mudanças nos hábitos alimentares dos brasileiros vêm rapidamente substituindo o problema da escassez pelo excesso dietético. No Brasil, o aumento da prevalência da obesidade, entre adultos, ocorre em todos os estratos sócioeconômicos, com aumento significativo nas famílias de baixa renda (MONTEIRO e col. 1995a), uma transição no estado nutricional da população pouco encontrada em paises em desenvolvimento (MONTEIRO e col. 1995b). 
Várias investigações relacionaram fatores de risco à doença arterial coronariana (DAC), tais como, hipertensão arterial, tabagismo, elevada concentração de colesterol total (CT) no plasma e diabetes mellitus. Nenhum estudo descarta o fator de inatividade física e obesidade como precipitantes ao aparecimento da doença, quando associados a outros fatores de risco (KEYS 1970, JOHANSSON e col. 1996, JEPPENSEN e col. 1998).

O perfil de saúde cardiovascular elaborado pelo National Cholesterol Education Program (NCEP 2001) aponta como fatores de risco ao aparecimento de doenças cardiovasculares:

- idade e sexo: o risco de doença cardiovascular aumenta de acordo com a idade, principalmente a partir dos 45 anos para homens e dos 55 anos para mulheres. O sexo masculino apresenta maior risco para esse tipo de doença em, praticamente, todas as faixas etárias;

- história familiar: o parentesco de primeira relação com individuos que apresentaram doença cardiovascular prematura representa outro fator de risco;

- tabagismo: indivíduos que não são tabagista ou que deixaram de fumar estariam diminuindo o risco de doenças cardiovasculares;

- hipertensão arterial sistêmica: para a prevenção de doenças cardiovasculares, recomenda-se que os niveis pressóricos mantenhamse inferiores a $140 / 90 \mathrm{mmHg}$;

- HDL-colesterol: o nivel sérico de HDL-colesterol inferior a $40 \mathrm{mg} / \mathrm{dl}$ representa um risco para o aparecimento e desenvolvimento de doença cardiovascular, enquanto que a partir de $60 \mathrm{mg} / \mathrm{dl}$ é considerado fator de proteção, com poder de anular algum fator de risco positivo; 
- LDL-colesterol: há três categorias de riscos que modificam os niveis recomendados de LDL-colesterol. Na presença de doença arterial coronariana já instalada - < $100 \mathrm{mg} / \mathrm{dl}$; na presença de dois ou mais fatores de risco dos citados acima - $<130 \mathrm{mg} / \mathrm{dl}$; e, na presença de até um desses fatores de risco $-<160 \mathrm{mg} / \mathrm{dl}$.

Outros autores apontam, ainda, como fatores de risco para a doença cardiovascular o aumento do fibrinogênio na coagulação sangüínea, levando à trombogênese (NEVES 1997); a obesidade representada por alto Índice de Massa Corpórea (IMC), aumento do perimetro abdominal e do percentual de gordura corporal (RAMOS DE MARINS e col. 2001); sedentarismo (WILCOX e col. 2000); etnicidade (SUNDQUIST e col. 2001, LERÁRIO e col. 2002); uso de certos medicamentos, como os contraceptivos orais (LOTTENBERG e col. 2002); fatores psicossociais, que levam ao estresse (JUÁREZ e col. 2000); e, fatores dietéticos (KRIS-ETHERTON e YU-POTH 1997, FORNÉS e col. 2000, KRIS-ETHERTON e col. 2001, FORNÉS e col. 2002).

\subsection{Dietas e dislipidemias}

Entre os fatores de risco dietéticos para as dislipidemias e aterogênese pode-se citar o baixo consumo de substâncias antioxidantes, destacando-se os carotenóides (RIMM e col. 1993), as vitaminas E (STAMPFER e col. 1993) e C (VANDENLANGENBERG e col. 1996) e o selênio (KWITEROVICH JR 1997); o uso de cafeina (LANE e col. 1994); o consumo não moderado de bebidas alcoólicas (MOREIRA e col. 1996); o elevado consumo de gorduras saturadas, colesterol e sal, contrastando com o baixo consumo de gorduras insaturadas - mono e 
poliinsaturadas (JACOTOT 1991, ASCHIERIO e col. 1996) e de fibras alimentares (JENKINS e col. 1998).

Estudos epidemiológicos e experimentais têm demonstrado uma relação causal entre dietas com significantes quantidades de alimentos de origem animal, que encerram quantidades consideráveis de gorduras saturadas e colesterol, e, a ocorrência de doenças cardiovasculares, principalmente pelo aumento de LDLcolesterol no sangue (KEYS 1970, KATO e col. 1973, ERSHOW e col. 1981, TUNSTALL-PEDOE 1988, KUSHI e col. 1995, HU e col. 1999, HU e col. 2000).

KEYS em 1965, jả identificou a relação entre ácidos graxos saturados com a elevação do colesterol sérico. São considerados aterogênicos aqueles que não possuem cadeia curta, com mais de 10 átomos de carbono, entre eles estão o ácido láurico, encontrado no óleo de coco; o ácido mirístico, encontrado em gorduras de origem animal e no óleo de coco; e, o ácido palmítico, encontrado nas gorduras animais e no azeite de dendê.

\subsection{Aterogênese}

Segundo SCHIMITZ e col. (1991) a aterogênese é caracterizada por uma sucessão de desordens nas camadas intima e média das paredes dos vasos, sendo que o metabolismo desordenado das gorduras é apontado como um agente causador desse distúrbio. Dentre as desordens nas paredes dos vasos, estão o aumento da permeabilidade do endotélio, infiltração de monócitos, proliferação de células musculares lisas adjacentes, agregação plaquetária e acúmulo de lipídeos. O colesterol livre e ésteres de colesterol, triglicérides, ceróide, ferro e cálcio são 
gradualmente depositados nas áreas envolvidas e elementos fibrosos invadem a placa em crescimento (Figuras 2, 3, 4 e 5).

A Figura 2 ilustra, por meio de um diagrama, a formação da placa de ateroma nos vasos sangüíneos.

Figura 2: Representação diagramática do processo de formação da lesão ateromatosa.

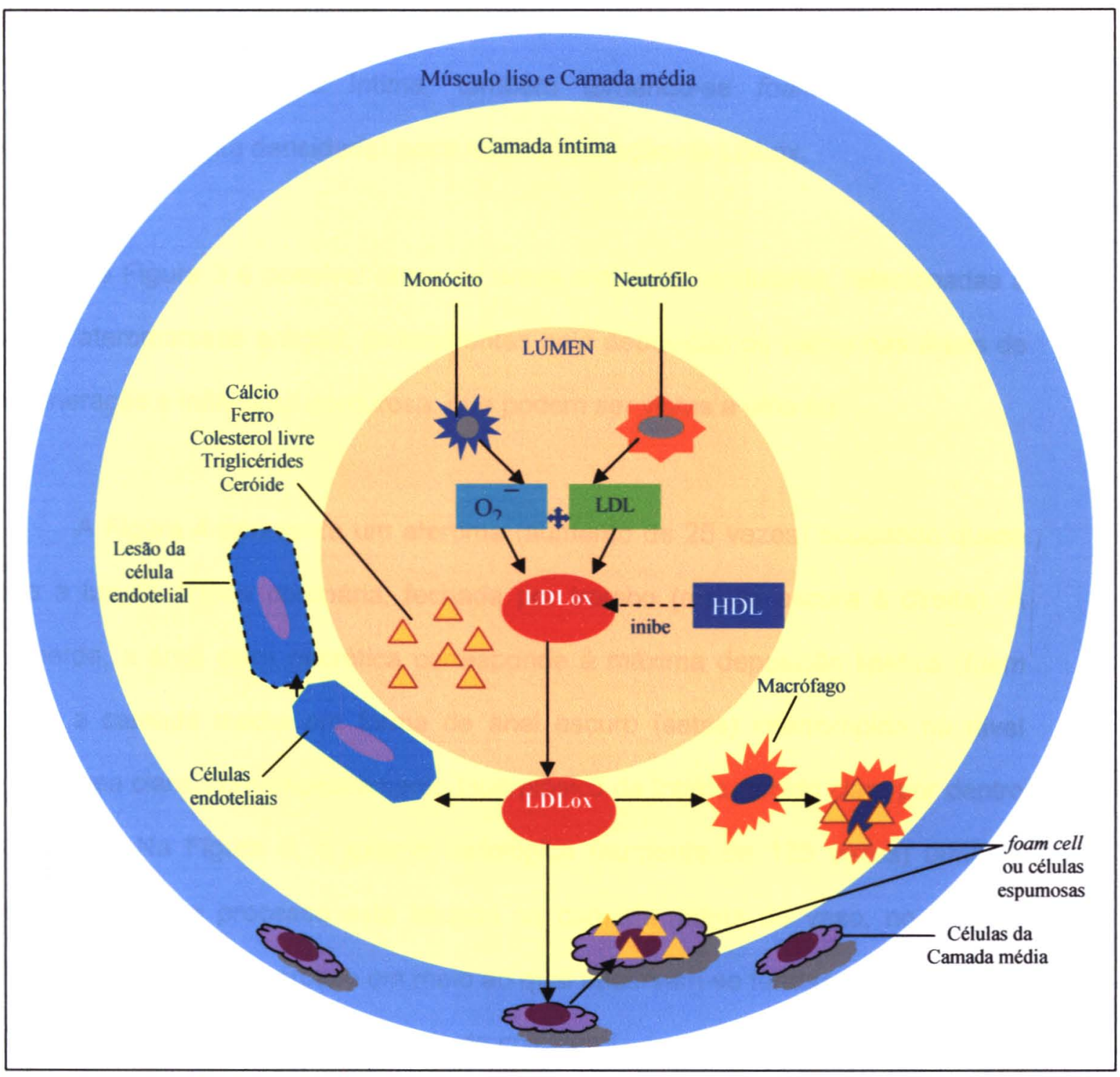

Fonte : Adaptado de BITTENCOURT JR e SENNA (2002) 
$\mathrm{Na}$ Figura 2, os leucócitos (monócitos e neutrófilos) produzem espécies ativas de oxigênio, que provocam a oxidação das partículas de LDL (Lipoproteína de baixa densidade), transformando-se em LDLox (oxidized low density lipoprotein), que atuam sobre as células endoteliais, provocando lesão e formação de moléculas de adesão. Isso facilita a migração dos monócitos para a camada íntima dos vasos. Os monócitos são transformados em macrófagos e, sob ação das LDLox, passam a acumular colesterol e ésteres de colesterol, triglicérides, ceróide, ferro e cálcio (representados pelas partículas amarelas) tornando-se foam cells ou células espumosas. As células da musculatura lisa do vaso, ainda por ação da LDLox, migram para a camada intima, também tornando-se foam cells. A HDL (Lipoproteina de alta densidade) pode inibir a formação da LDLox.

Na Figura 3 é possível observar áreas elevadas, nodulares, relacionadas a lesões ateromatosas antigas, proeminentes pela deposição de cảlcio nas áreas de degeneração e infiltração gordurosa, que podem ser vistas a olho nu.

A Figura 4 apresenta um ateroma (aumento de 25 vezes) ocupando quase toda a luz da artéria coronária, fechada por trombo (massa escura à direita). À esquerda, a área clara necrótica corresponde à máxima deposição lipidica (foam cells), a camada média em forma de anel escuro (setas) interrompido no nivel dessa área clara, com espessamento hiperplásico da intima (tecido claro por dentro da média). Na Figura 5, o exame histológico (aumento de 125 vezes) também demonstra que o processo está situado na camada íntima do vaso, no qual se verifica um processo necrótico em meio ao qual observam-se fendas fusiformes que são as imagens negativas dos cristais de colesterol. 
Figura 3: Ateromas da aorta torácica descendente.

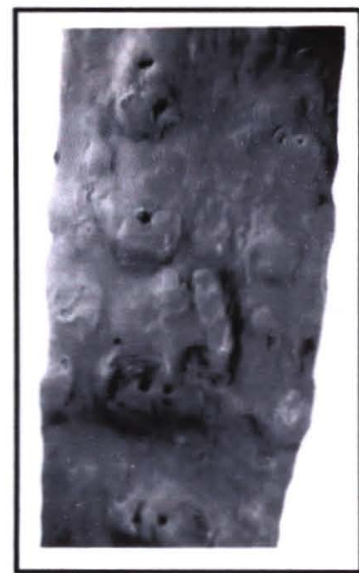

Fonte: Diapositivo cedido por Dra. Nádia Barbosa Moreno

Figura 4: Ateroma da artéria coronária $(25 \mathrm{x})$.

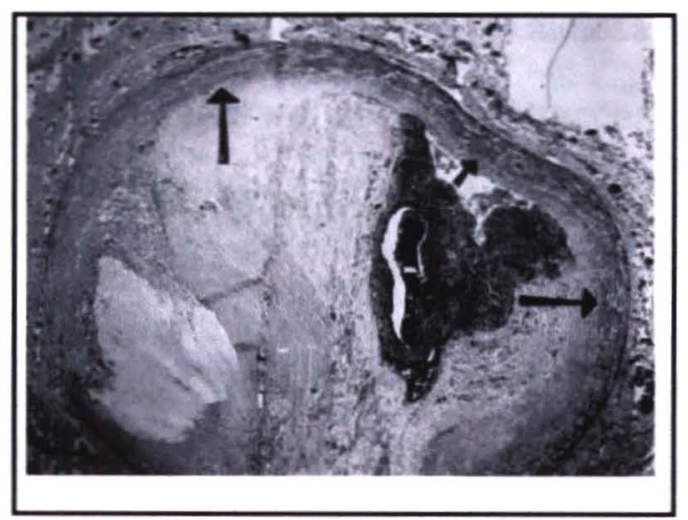

Fonte: Diapositivo cedido por Dra. Nádia Barbosa Moreno

Figura 5: Aspecto histológico do ateroma (120 x).

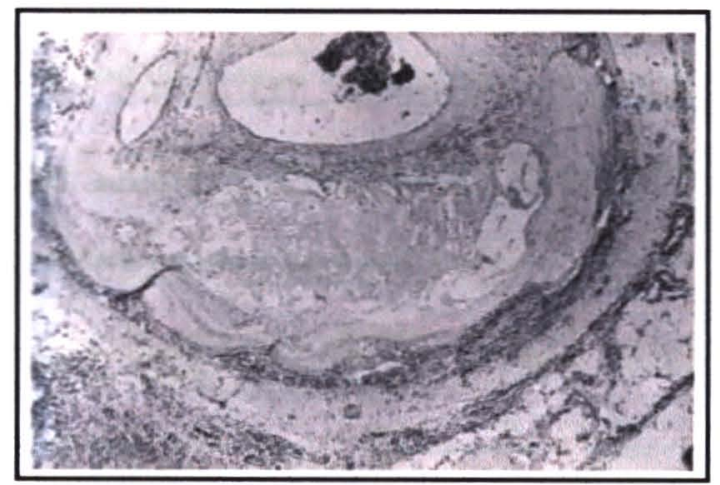

Fonte: Diapositivo cedido por Dra. Nádia Barbosa Moreno 


\subsection{Alimentação e lipidemias}

Classicamente, a primeira conduta a ser adotada no tratamento das hiperlipidemias é a intervenção dietética, indicada isoladamente ou associada a medicamentos (SANTOS 1999). Vale ressaltar que a dieta exerce papel fundamental na prevenção e controle desses distürbios e das doenças a eles relacionados (KRIS-ETHERTON e YU-POTH 1997, FORNÉS e col. 2000, KRISETHERTON e col. 2001, FORNÉS e col. 2002).

As dislipidemias são definidas como distúrbios do transporte dos lipídeos que resultam de anormalidades metabólicas na sintese ou degradação das lipoproteinas plasmáticas, que alteram as concentrações dos seus diferentes componentes na circulação (NCEP 1994, NCEP 2001).

A Figura 6 apresenta o metabolismo esquemático das lipoproteínas plasmáticas, por meio das vias exógena e endógena e transporte reverso do colesterol.

O resultado final do processo exógeno de transporte é levar os triglicérides provenientes da dieta ao tecido adiposo e o colesterol ao fígado. A via endógena estabelece um ciclo, pelo qual a LDL (lipoproteína de baixa densidade) leva o colesterol aos tecidos extra-hepáticos, retornando à LDL a partir desses tecidos por meio da HDL (lipoproteina de alta densidade). 
Figura 6: Esquema metabólico das lipoproteínas plasmáticas.

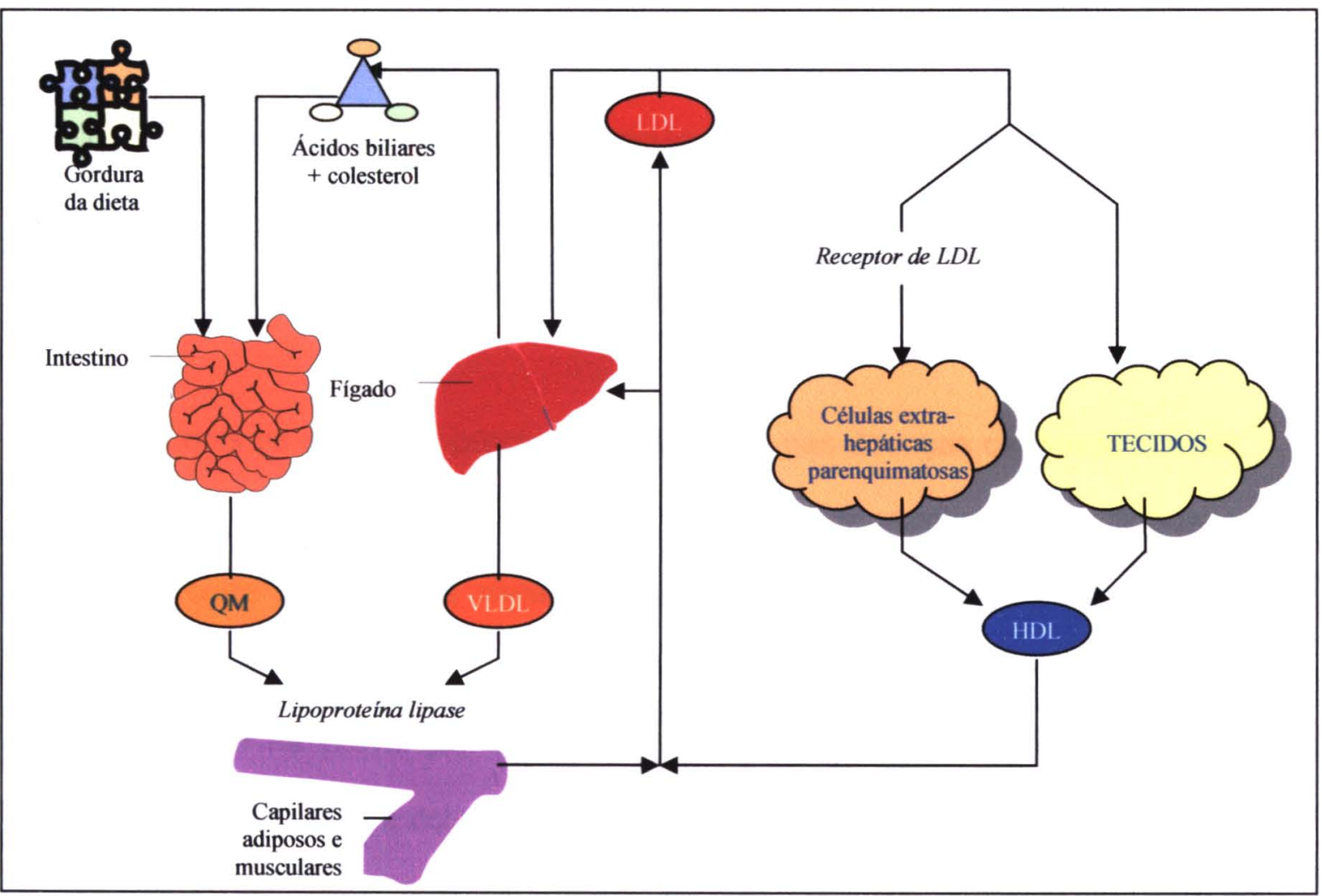

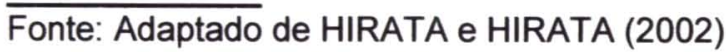

Legenda: $\mathrm{HDL}$ = lipoproteína de alta densidade, $\mathrm{LDL}$ = lipoproteína de baixa densidade, $\mathrm{QM}=$ quilomicrons, $\mathrm{VLDL}=$ lipoproteína de densidade muito baixa.

Quando os níveis séricos das lipoproteínas estão acima dos valores de referência (vide Quadro 3 no item método), a dislipidemia é chamada de hiperlipidemia, se estiverem abaixo dos valores determinados, é denominada hipolipidemia. A hipercolesterolemia ocorre pelo aumento do colesterol total e/ou de LDL-colesterol e a hipertrigliceridemia pela elevação dos triglicérides (NCEP 2001, SBC 2001).

A importância clínica da hiperlipidemia reside na comprovada relação que essa alteração metabólica mantém com o aparecimento de doença arterial coronariana (QUINTÃO 1992, NEVES 1997, ARVANITOMYNNIS e col. 2000), que por sua vez é responsável pelo aumento da morbidade e mortalidade de origem 
isquêmica (RABELO e MARTINEZ 1998, WILLETT 1998). No entanto, essa associação não é precisa, pois individuos com indices normais de colesterol total podem ser vítimas desse tipo de doença. O LDL-colesterol é um preditor melhor definido de risco para doença cardiovascular, bem como o HDL-colesterol que apresenta evidente correlação inversa com a prevalência dessas doenças, mas a magnitude dessa correlação não se pode precisar (RABELO 2000).

São dois os principais processos envolvidos nas doenças cardiovasculares: ateroma, relacionado com efeitos de longa duração e trombogênese, ligada a eventos de curta duração que afetam o estilo de vida, como os que estimulam a agregação plaquetária (NEVES 1997). No primeiro caso, a dieta tem papel primordial, tanto na prevenção como no controle (CONNOR e CONNOR 1993, RODRÍGUEZ HERRERA e col.1996, GUITIÉRREZ FUENTES 1998).

Com base nas investigações, estudos de intervenção terapêutica foram realizados para demonstrar que o tratamento efetivo das hiperlipidemias é capaz de impedir o desenvolvimento de lesões ateroscleróticas nas artérias coronárias, alterar sua evolução, diminuir o desencadeamento de eventos clínicos e aumentar a sobrevida (KATO e col. 1973, SANTOS 1999).

Essa intervenção terapêutica, que visou modificar o estilo de vida, deu-se por medidas como: dietoterapia, atividade física programada, relaxamento $e$ abandono do tabagismo (HOOPER e col. 2000).

Muitos estudos utilizam apenas o emprego da dieta como terapia de intervenção. Nesse caso, merecem destaque os estudos Leiden e STARS - St 
Thomaz' Atherosclerosis Regression Study (ARNTZENIUS e col. 1985, WATTS e col. 1992).

Sabe-se que os hábitos alimentares de uma população são fatores determinantes para o seu estado de saúde. Tem sido sugerido pela literatura, por estudos experimentais e epidemiológicos, que pessoas com dietas tipicamente ocidentais deveriam alterar seus hábitos alimentares para prevenir doenças coronarianas e outras manifestações ateroscleróticas (KATO e col. 1973, AHA 2000).

Os programas de prevenção primária de DAC nos Estados Unidos, desde 1950, chamam a atenção tanto para a questão da composição de gordura da dieta, como do excesso energético. Recomenda-se como intervenção corrigir o elevado consumo de gordura saturada e colesterol, evitar o excesso calórico e manter o peso ideal (CONNOR e col. 1992, SASAKI 2000) e, na verdade, essas recomendações vigoram até o momento (NRC 1998, AHA 2000, WHO 2002).

\subsection{Potencial aterogênico dos alimentos}

Embora a epidemiologia nutricional, como estudo formal, seja uma área recente, a observação de que alguns aspectos da dieta poderiam influenciar na ocorrência de doenças em seres humanos data de periodos mais remotos dentro da história (TORRES 2000).

Sendo a alimentação uma das principais formas de controle das lipidemias e, uma vez que o colesterol dietético não representa um fator 
hipercolesterolemizante considerável, isoladamente, é necessário conhecer os outros componentes da dieta que podem colaborar para esse controle (KEYS 1965, RODRIGUES HERRERA e col. 1996).

O potencial hiperlipemiante e aterogênico dos alimentos está relacionado ao seu conteúdo de colesterol e gorduras saturadas, bem como ao total energético da dieta (CONNOR e col. 1986, LOTTEMBERG 1997, YU-POTH 2000). Por outro lado, os alimentos possuem outros componentes, cujo papel na redução das lipidemias tem sido estudado exaustivamente. Destacam-se entre eles: fibras - solúveis e insolúveis, certas proteinas vegetais, vitaminas, alguns antioxidantes naturais, além de certos lipideos - ácidos graxos mono e poliinsaturados (RICHARD 1987, ARTAUD-WILD 1993).

Os lipídeos são importantes componentes dos alimentos que, além de suas propriedades nutricionais, conferem caracteristicas especificas de sabor e textura, realçando a qualidade sensorial (BLUNDELL 1995). São formados basicamente por moléculas de triglicérides, mas que se apresentam por diversas composições de ácidos graxos (MURRAY e col. 2000).

Um dos fatores dietéticos mais discutidos e associados ao aumento do colesterol sérico é o elevado consumo de gorduras saturadas e a baixa relação dos ácidos graxos poliinsaturados $(P)$ com os saturados $(S)$ - relação $P / S$ (KALLITHRAKA e col. 2000). Uma baixa relação PIS aumenta os niveis séricos de colesterol total e suas frações, diminuindo a fração HDL e aumentando os triglicérides, enquanto alta relação P/S provoca efeito inverso (ROLLS 2000). 
Esse mecanismo deriva dos efeitos dos ácidos graxos da dieta no metabolismo de lipoproteínas, como segue (BITTENCOURT JR e SENNA, 2002):

- ácidos graxos saturados - diminuem a atividade do receptor hepático de LDL, aumentando o colesterol plasmático;

- ácidos graxos monoinsaturados - diminuem a LDL, mas não alteram a HDL, aumentam a atividade do receptor de LDL hepático e diminuem a oxidação de LDL plasmática;

- ácidos graxos poliinsaturados - diminuem a oxidação de LDL plasmática, podendo reduzir a HDL e aumentar a atividade do receptor hepático de LDL.

Os lipideos dietéticos, e os demais nutrientes a eles associados, exercem importante e critico papel na saúde e na fisiologia do organismo humano. Para que ocorra a melhor utilização dos nutrientes lipossolúveis é necessária uma digestão e absorção satisfatórias dos triglicérides da dieta (LICHTENSTEIN 1998).

Portanto, é interessante entender um pouco do mecanismo de absorção e utilização dos lipideos no organismo humano.

\subsection{Metabolismo lipidico}

A fraçāo lipidica é constituída dos seguintes componentes encontrados nos alimentos: os triglicérides - formados por ácidos graxos e glicerol, os fosfolipideos, o colesterol, os ésteres de colesterol e uma pequena fração de ácidos graxos livres, além das vitaminas lipossolúveis e seus compostos relacionados - carotenóides, tocotrienóis e tocoferóis, principalmente alfa-tocoferol (MURRAY e col. 2000). Os 
lipídeos dietéticos são formados principalmente por óleos e gorduras, cuja maior parte é formada por triglicérides, os quais fornecem energia.

A hidrólise dos triglicérides ingeridos é iniciada quando o alimento mastigado entra em contato com a lipase faringeana. A degradação lipolítica de triglicérides em ácidos graxos livres e mono e diglicerideos começa no esôfago e continua no estômago. A região principal para digestão e absorção dos triglicérides é o intestino delgado. A lipase pancreática é a enzima mais importante ligada à digestão dessas gorduras, a lipase intestinal tem um papel reduzido. A lipase pancreática hidrolisa essas gorduras em glicerol e ácidos graxos ou monoglicerídeos. O intestino delgado, além de representar a porta de entrada dos ácidos graxos e colesterol dietéticos, também sintetiza os quilomicrons (DIETSCHY 1997).

Os triglicérides de cadeia longa entram na célula da mucosa como monoglicerídeos, ácido graxo e glicerol. Os monoglicerideos são reconvertidos a triglicérides pela adição de dois ácidos graxos ativados. Os triglicérides sintetizados agora são "empacotados" nos quilomicrons, e em uma menor quantidade em lipoproteinas de densidade muito baixa (VLDL), que deixam a célula e entram nos vasos linfáticos, esvaziam na veia subclávia esquerda através do ducto torácico (NELSON e COX 2002).

Os triglicérides de cadeia média e curta podem entrar na célula da mucosa intactos, em parte hidrolisados (di e mono) e como ácidos graxos e glicerol. Os glicerídeos sofrem lipólise intracelular e deixam a célula mucosa como ácidos graxos e glicerol. Esses entram na veia porta que os leva diretamente ao fígado. Tornou-se evidente o importante papel exercido pelos lipideos no funcionamento normal de uma célula. Eles não só servem como formas de reserva de energia, 
mas também participam intimamente da estrutura da membrana das células e suas organelas (MURRAY e col. 2000, NELSON e COX 2002). Os lipideos participam direta ou indiretamente em diversas atividades metabólicas, tais como (DIETSCHY 1997, NELSON e COX 2002):

a) ativadores de enzimas: algumas enzimas necessitam de frações lipidicas para serem ativadas, como é o caso das fosfolipases que hidrolisam fosfolipideos, desempenhando funçōes importantes nos processos fisiológicos e patológicos na inflamação, isquemia, agregação plaquetária e hipersensibilidade aguda;

b) componentes do sistema de transporte de elétrons da mitocôndria: há evidências de que a cadeia de transporte de elétrons nas membranas internas da mitocôndria está mergulhada em um meio de fosfolipideos. O transporte de um próton do espaço intermembrana para a matriz é gerado pela fosforilação oxidativa;

c) precursores de prostaglandinas: os ácidos graxos essenciais também são precursores de prostaglandinas, compostos semelhantes aos hormônios amplamente distribuidos nos tecidos, que produzem vários efeitos metabólicos.

d) regulacão do metabolismo do colesterol: os ácidos graxos essenciais são importantes por ter um papel significativo na regulação de vários aspectos do metabolismo de colesterol, transporte, transformação em produtos metabólicos, e excreção final de alguns desses produtos. O figado exerce papel essencial no balanço de colesterol do organismo e na concentração da maioria das lipoproteinas no plasma, tanto pela sintese, como pela excreção. Cerca de $75 \%$ da LDL é removida da circulação e se ligam aos receptores celulares resultando em um complexo LDL-receptor, a captação das LDL induz à redução dos receptores dessas particulas e inibe a atividade da enzima hidroxi-metil-glutaril: coenzima $\mathrm{A}$ redutase (HMGCoA redutase), enzima decisiva na biossíntese do colestrol, e que, ativa a acil-coenzima $A$ : colestrol acil transferase (ACAT), que esterifica o colesterol. A sintese e a degradação de colesterol ocorrem simultânea e 
continuamente, porque o suprimento e a eliminação do colesterol da dieta não são, por si só, completamente eficazes na regulação dos niveis séricos de colesterol. É excretado pela sua conversão em sais biliares, que são subseqüentemente liberados no intestino delgado, ou pela conversão em esteróis neutros. Esse ciclo entero-hepático do colesterol e ácidos biliares serve para regular, por meio de uma retroalimentação negativa, a sintese de colesterol no fígado.

\subsection{Classificação das dislipidemias}

As III Diretrizes Brasileiras sobre Dislipidemias e Diretrizes de Prevenção da Aterosclerose do Departamento de Aterosclerose da Sociedade Brasileira de Cardiologia de 2001 classificam as dislipidemias de duas formas (SBC 2001):

classificação laboratorial:

- hipercolesterolemia isolada: aumento do colesterol total $(>240 \mathrm{mg} / \mathrm{dL})$ e/ou de LDL-colesterol (>160mg/dL);

- hipertrigliceridemia isolada: aumento dos triglicérides ( $>200 \mathrm{mg} / \mathrm{dL})$;

- hiperlipidemia mista: aumento do colesterol total $(>240 \mathrm{mg} / \mathrm{dL})$ e dos triglicérides $(>200 \mathrm{mg} / \mathrm{dL})$;

- diminuição isolada do HDL-colesterol (<40mg/dL) ou associada a aumento dos triglicérides (>200mg/dL) ou LDL-colesterol (>160mg/dL).

classificação etiológica:

- dislipidemias primárias: de origem genética, homozigótica ou heterozigótica.

- dislipidemias secundárias: causada por outras doenças ou uso de midicamentos como: hipotireoidismo, diabetes mellitus, sindrome nefrótica, 
insuficiência renal crônica, , obesidade, alcoolismo, ictericia obstrutiva, uso de altas doses de diuréticos, betabloqueadores, corticosteróides, anabolizantes.

\subsection{Tratamento das dislipidemias}

Como citado anteriormente, os meios utilizados para o tratamento das dislipidemias, mais especificamente, das hiperlipidemias, envolvem dois tipos de abordagem: a dietoterapia isoladamente ou a intervenção dietética associada à farmacoterapia (RABELO e MARTINEZ 1998).

\subsubsection{Tratamento dietético nas dislipidemias}

A dietoterapia tem suas bases de aplicação bastante conhecidas e estabelecidas dentro de sólidos principios científicos. A trigliceridemia pode ser reduzida pelo controle de açúcares simples, álcool e energia da dieta. A redução na ingestão de colesterol e gordura saturada podem ativar os receptores de LDL, aumentando o catabolismo dessas lipoproteínas (SANTOS 1999).

A American Heart Association (AHA) propōe duas dietas, uma aconselhável para a população em geral e outra para o tratamento dietético da hipercolesterolemia. As caracteristicas dessas dietas encontram-se no Quadro 1 (AHA 2000).

No entanto, os cálculos dessas dietas são complexos para o paciente e até mesmo para o pessoal de saúde. Assim, se fosse elaborado um instrumento de fácil compreensão para uso do pessoal que trabalha na promoção da saúde, bem 
como para pacientes, poderia se tornar uma ferramenta para intervenção dietética de ampla aplicação (ZILVERSMIT 1979).

Quadro 1: Recomendacões dietéticas para a população em geral e para o tratamento de hipercolesterolemias.

\begin{tabular}{|c|c|}
\hline Nutrientes & $\begin{array}{cc}\text { Ingestão } & \text { Recomendada } \\
\text { Para: } & \text { Para: } \\
\text { População em Geral } & \text { Hipercolesterolemia } \\
\end{array}$ \\
\hline Gordura total & $<30 \%$ das calorias totais \\
\hline Ácidos graxos saturados & $7-10 \%$ das calorias totais $<7 \%$ das calorias totais \\
\hline Ácidos graxos poliinsaturados & Até $10 \%$ das calorias totais \\
\hline Ácidos graxos monoinsaturados & De 10 a $15 \%$ das calorias totais \\
\hline Carboidratos & 50 a $60 \%$ das calorias totais \\
\hline Proteínas & 10 a $20 \%$ das calorias totais \\
\hline Colesterol & $<300 \mathrm{mg} / \mathrm{dia}$ \\
\hline Calorias & Para manter e atingir o peso desejável \\
\hline
\end{tabular}

Fonte: AHA (2000)

O controle das dislipidemias depende do grau de aderência do paciente ao tratamento. Para melhor adesão à dieta, essa deve se aproximar ao máximo possivel da habitual, devendo ser nutricionalmente adequada e agradável ao paladar (AHA 2000).

Dessa forma, o paciente deverá receber instruções sobre a seleção, quantidade, preparo e substituições dos alimentos (LEBRUNIE e col. 1997), mas, o que se observa nos tratamentos dietoterápicos tradicionais (Anexo 1), é que o paciente recebe um impresso com "alimentos permitidos" e "alimentos proibidos" (ZILVERSMIT 1979). 
Nesse caso, se o individuo puder, com auxilio de uma tabela, gerenciar sua alimentação, sentindo-se um agente de mudança de seus hábitos e tornando-se um aliado ao tratamento, poderia levar a um melhor resultado em relação ao que se tem conseguido com tratamentos dietoterápicos tradicionais (CONNOR 1992)

\subsubsection{Farmacoterapia nas dislipidemias}

As drogas utilizadas no tratamento das dislipidemias podem ser divididas em dois grandes grupos: aquelas que controlam as trigliceridemias e as que têm um efeito mais significativo sobre a colesterolemia (LEVINE e col. 1995, MANNINEN e col. 1998).

As estatinas são as drogas mais efetivas para a redução da colesterolemia e, foram descobertas em 1976 (ENDO e col. 1976). São poderosos hipolipemiantes que, além dessa capacidade, conferem uma série de outros beneficios como preservar e melhorar a função endotelial (LEFER e col. 2001).

As estatinas estão indicadas no tratamento de pacientes com hiperlipidemia primária e dislipidemia mista como adjuvante à dieta. São, ainda, indicadas no tratamento da hipercolesterolemia familiar homozigótica (EAST e col. 1988).

Após a determinação do perfil lipidico, deve ser feita uma tentativa para controlar os niveis elevados de colesterol por meio de medidas conservadoras e mudanças no estilo de vida - perda de peso em individuos com excesso de peso, dieta hipogordurosa, atividade fisica, abandono do tabagismo, antes de iniciar a terapia medicamentosa (ITFPCHD 1992, LADEIA 1998). 
Em um estudo de MANSUR e col. (2001) foi demonstrado que a prescrição de estatinas para pacientes com doença coronariana e hiperlipidemias, no Brasil é ampla, no entanto, a aderência do mesmo está longe de ser satisfatória, pelo alto custo da medicação. As III Diretrizes Brasileiras sobre Dislipidemias (SBC 2001) apontam como objetivo de recomendação da droga, a redução do colesterol dependendo dos valores lipídicos e do risco de eventos coronarianos do paciente.

A Sociedade Européia de Aterosclerose (ITFPCHD 1992), bem como a Americam Heart Association (AHA 2000) recomendam intervenção dietética associada à mudança no estilo de vida, mesmo que concomitantemente à farmacoterapia.

O Segundo Consenso Uruguaio sobre Dislipidemias (SUA 1999) recomenda diretrizes de tratamento baseadas no correto diagnóstico nutricional, na prescrição de ácidos graxos insaturados e na incorporação definitiva dos antioxidantes naturais.

\subsection{1 Índice de Colesterol/Gordura Saturada (CSI)}

O papel dos lipideos nas hiperlipidemias e o potencial aterogênico dos alimentos são áreas de investigação que preocupam os cientistas há várias décadas. Já na década de 1960, baseados em dados de uma equação de regressão desenvolvida por KEYS (1965), FETCHER e col. (1967) planejaram uma tabela em que computavam o efeito dos alimentos no teor de colesterol sérico, além de outros autores como HEGSTED (1965), MATTSON e col. (1972), WHITE e 
HAVENSTEIN (1976) e ZILVERSMITT (1979) que foram revisando e aperfeiçoando a equação matemática.

Em 1979, ZILVERSMIT propôs o $\mathrm{Cl}$ - indice de colesterol dos alimentos, representado por equaçōes de regressão da seguinte forma:

$$
\mathrm{Cl}=1,01+(\mathrm{S}-0,5 \mathrm{P})+0,05 \mathrm{C}
$$

Onde,

$\mathrm{S}=$ quantidade de ácido graxo saturado $(\mathrm{g}) / \mathrm{P}=$ quantidade de ácido graxo poliinsaturado $(\mathrm{g}) / \mathrm{C}=$ quantidade de colesterol $(\mathrm{mg})$.

Esse indice foi proposto para mostrar o efeito absoluto das porçōes individuais dos alimentos no nivel de colesterol sérico. Dessa forma, um baixo score significa uma alta capacidade de redução das hiperlipidemias.

O maior obstáculo para a utilização desses indices é que alimentos que possuem alto teor de ácidos graxos poliinsaturados apresentam indices negativos, enquanto alimentos com teores de gorduras próximos de zero apresentariam um índice igual a zero, dando a incorreta impressão que não é necessário limitar o uso de gordura poliinsaturada. Partindo-se desse pressuposto, seria razoável consumir altos teores de colesterol e gordura saturada na dieta, desde que eles fossem combatidos com altas quantidades de ácidos graxos poliinsaturados. Na verdade, o que é matematicamente possivel não possui plausibilidade biológica (TORRES 2000).

Dessa forma, CONNOR e col. (1986) propuseram alterar a equação para: 
$\mathrm{CSI}=(1,01 \times \mathrm{g}$ de gordura saturada $)+(0,05 \times \mathrm{mg}$ de colesterol $)$

Com o novo indice, os autores perceberam uma correlação de $r=0,78$, com mortalidade por doenças isquêmicas em homens de 55 a 64 anos, em 40 paises (CONNOR e col. 1986). Além disso, essa ferramenta já foi testada e validada, sendo considerada por estudo realizado na Universidade de Washington, como simples e precisa (MITCHELL e col. 1996).

Com o objetivo de elaborar uma tabela de alimentos normalmente consumidos, TORRES (2000) selecionou os valores calóricos dos alimentos e calculou os respectivos CSIs, para que se pudesse utilizar esses dados em futuras dietas preventivas ou de intervenção para DAC.

\subsection{Guias alimentares}

Uma dieta saudável pode ser resumida em: variedade, moderação e equilibrio. Para facilitar o emprego desses principios, Atwater em 1894, descreveu sobre a necessidade de desenvolver guias alimentares para a orientação dos indivíduos, na seleção de seus alimentos para consumo, em um trabalho realizado para o United States Department of Agriculture (USDA). A partir de então, foram propostos vários guias, para diferentes grupos populacionais e com formatos variados (WELSH e col. 1992).

O guia alimentar é um instrumento que orienta a escolha correta dos alimentos. Por meio de sua utilização adequada, pode-se usufruir uma saúde 
melhor e reduzir as chances de contrair determinadas doenças (MNHW 1988, PHILIPPI e col. 1999).

A proposta de elaboração de guias alimentares tem como objetivo transformar conhecimentos cientificos em conceitos claros, práticos e de fácil compreensão, transformando, assim, os valores inseridos nos nutrientes, em alimentos e dietas adequadas a uma dada população (SHAMAH e col. 1997, NEUMANN e col 2000, MS 2002).

O conteúdo dos guias se modifica de acordo com o desenvolvimento da ciència e as novas concepçōes sobre alimentos, doenças e populaçōes a que se destinam (WELSH e col. 1992). Os guias devem se fundamentar na alimentação habitual da população (KOENING e ELMADFA 1999), ser claros, concretos e previamente validados (PEÑA e MOLINA 1998).

$\mathrm{Na}$ Figura 7 são demonstrados os passos necessários para 0 desenvolvimento de guias alimentares.

Validar um instrumento significa conferir valor ao mesmo, ou seja, confirmar se ele realmente tem o potencial a que se propõe. Os resultados de um estudo de validação podem ser usados como base para ajustes no instrumento ou para sua adoção (WILLETT 1998). Nesse processo, se aplica a unidade didática a uma amostra da população alvo, com o objetivo de se conhecer o grau de entendimento que o grupo tem sobre o que é apresentado e proposto. 
Figura 7: Passos para o desenvolvimento de quias alimentares.

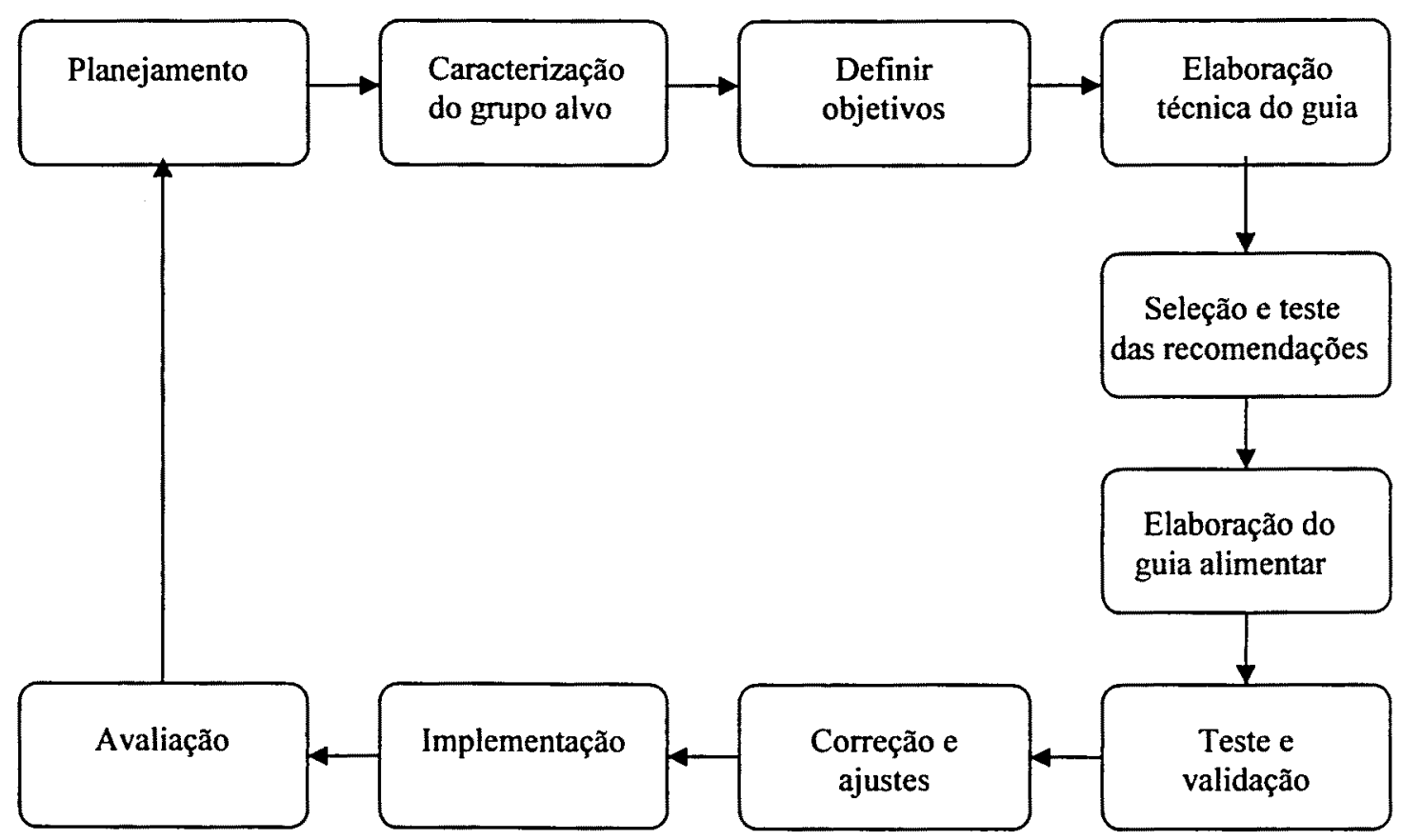

Fonte: Organización Panamericana de la Salud (PEÑA e MOLINA 1998).

Todo instrumento de promoção da saúde deve ser validado para que se possa medir a sua eficácia.

Estudos realizados nos Estados Unidos constataram que a adesão ao guia alimentar da pirâmide de alimentos diminuiu o risco de doenças crônicas em homens e mulheres (McCULLOUGH e col. 2000a e McCULLOUGH e col. 2000b).

\subsection{Fundamentos do comportamento alimentar}

O comportamento alimentar é um dos fatores condicionantes mais próximos do estado nutricional do individuo, pois corresponde não apenas aos chamados hábitos alimentares, como a todas as práticas relativas à alimentação, estando fortemente condicionado à disponibilidade de alimentos (SHAMAH 1997, BOOG 1998). 
o comportamento alimentar pode ser estudado em três niveis: cognitivo, afetivo e situacional (BOOG 1998).

O componente cognitivo corresponde ao que 0 individuo sabe sobre alimentação e nutrição e que pode influenciar em maior ou menor grau seu comportamento alimentar. Assim, para modificar hábitos alimentares é importante educar e orientar a população, porém isso não é tarefa fácil. Exige uma profunda análise dos determinantes da conduta que se deseja modificar e aplicar as medidas necessárias (SHAMAH 1997).

Um estudo realizado pelo USDA que desenvolveu um İndice de Alimentação Saudável, observou que a educação e o grau de instrução dos americanos influenciam na escolha de alimentos (USDA 1995).

É óbvio que o componente cognitivo por si só nāo modifica o comportamento alimentar, depende-se, ainda, da personalidade e das necessidades psicológicas e socioculturais do individuo. Nesse caso, o componente afetivo pode desempenhar um papel de maior influência que o cognitivo. Além disso, o conhecimento nem sempre é compativel com as condiçōes do meio em que vivemos. Há sempre que se verificar o componente situacional (MOTTA e BOOG 1984).

Porém, a aquisição do conhecimento é o ponto inicial do processo de mudança de comportamento; daí a sua importância nos programas educativos. Este é o primeiro passo e insubstituivel para a consecução de melhores niveis de saúde. 


\subsection{Estudos experimentais ou de intervenção}

O objetivo de um estudo experimental é avaliar a eficácia de qualquer intervenção, seja ela preventiva, curativa ou reabilitadora (ROUQUAYRIOL 1986).

De modo geral, a experimentação em epidemiologia poderá ser feita por meio da manipulação de populações humanas ou de animais. No primeiro caso, os fatores são introduzidos ou suprimidos em comunidades previamente conhecidas e os resultados são medidos (FORATINI 1996).

Esse estudo caracteriza-se por manipular a população diretamente em relação ao fator que está sendo estudado. Para tanto, os indivíduos são divididos e classificados, de forma aleatória, em dois conjuntos, designados como grupo estudo e grupo controle, nos quais são analisados fatores de risco ou medidas preventivas que se queiram estudar ou avaliar (ROUQUAYRIOL 1986, FORATINI 1996).

O alcance populacional desse tipo de estudo é muito variável. No que concerne ao tamanho da amostra de prova, é evidente que um dos critérios a ser seguido diz respeito à incidência do agravo que será objeto da medida em estudo. Isto é, para elevado grau de exposição, mais reduzido será o número de pessoas engajadas no estudo. Há que se considerar também os aspectos éticos, avaliandose os possiveis riscos que a intervenção suponha. Mas em nenhum dos casos, podem ser superiores aos seus beneficios (TARASUK e BROOKER 1997). 


\subsection{Justificativa}

De acordo com o quadro da situação de doenças crônicas, descrito anteriormente, cuja prevenção e controle dependem, em grande parte da dieta e, principalmente, da adesão do paciente a ela, pode-se dizer que hả grande dificuldade em se modificar hábitos alimentares, fundamentalmente quando não se possui um instrumento apropriado. Assim, se houvesse um guia alimentar de fácil compreensão, a adoção de novas práticas seria facilitada, o que poderia fomentar e melhorar a saúde da população, bem como prevenir doenças relacionadas ao consumo excessivo de gorduras saturadas e colesterol. 


\section{OBJETIVOS}

\subsection{Objetivo Geral}

Elaborar um instrumento de orientação alimentar e avaliar sua eficácia como ferramenta para intervenção dietética para indivíduos com hiperlipidemias.

\subsection{Objetivos Especificos}

- Elaborar um sistema de pontos para orientação alimentar de individuos hiperlipidêmicos, utilizando-se o indice de colesterol/gordura saturada (CSI) em alimentos.

- Avaliar a eficácia do sistema de pontos, em um estudo piloto, pela verificação das mudanças nos índices antropométricos e bioquímicos dos individuos. 


\section{MÉTODO}

\subsection{Delineamento do estudo}

O delineamento desse estudo foi realizado em duas etapas:

- elaboração do instrumento de orientação alimentar para indivíduos com hiperlipidemias;

- o estudo piloto - estudo de desenho experimental ou de intervenção (ROUQUAYRIOL 1986).

\subsection{Elaboração do instrumento de orientação alimentar}

Para elaboração da estrutura do instrumento de orientação alimentar foi necessário o desenvolvimento das seguintes fases:

- $1^{\mathrm{a}}$ fase: elaboração de uma lista de alimentos para constituir o sistema de pontos;

- $2^{a}$ fase: estabelecimento do tamanho das porções em medidas caseiras para cada alimento;

- $3^{a}$ fase: cálculo de CSI de cada alimento da listagem, de acordo com as medidas caseiras, para lhe conferir a pontuação;

- $4^{a}$ fase: elaboração da mensagem de como contar os pontos;

- $5^{a}$ fase: estabelecimento de uma relação da escolha de alimentos com uma alimentação balanceada. 
Assim, foi elaborado um instrumento com um sistema de pontos em medidas caseiras, no qual se criou uma listagem de alimentos que receberam pontuações para índice de colesterol/gordura saturada (CSI).

\subsubsection{Lista de alimentos}

Para o desenvolvimento do sistema de pontos, utilizou-se uma lista de alimentos desenvolvida por FORNÉS (1998) em um estudo que utilizou dados secundários, com vistas a observar o padrão alimentar e os lipídeos séricos da população de um municipio da região metropolitana de São Paulo. Em seguida, esses dados foram confrontados com os da última POF - Pesquisa de Orçamento Familiar 1996/97 (IBGE 2001) a fim de identificar se algum alimento importante para o consumo não havia sido contemplado pela lista em questão.

Após a obtenção desses alimentos, elaborou-se uma nova lista para constituir o sistema de pontos, de modo a contemplar todos os alimentos apontados como integrantes da dieta habitual desses indivíduos, adicionando-se a eles outros alimentos disponiveis no mercado, que podem ser consumidos com menor freqüência. Desse modo, tentou-se cobrir a maioria dos alimentos que eventualmente possam integrar a dieta desses individuos (MITCHELL 1996).

\subsubsection{Tamanho das porções}

Para o estabelecimento do tamanho das porções em medidas caseiras de cada alimento, utilizaram-se as recomendações da Agência Nacional de Vigilância Sanitária (ANVISA 2001), para rotulagem de alimentos, por serem exigidas pela legislação e estarem em maior contato com o consumidor (GRACIANO e col. 
2000). Para os alimentos que não foram referenciados pela ANVISA, utilizou-se a lista de alimentos, com as respectivas medidas caseiras e em gramas, da Pirâmide alimentar: guia para escolha dos alimentos (USP 1999).

Essas medidas caseiras foram transformadas em quantidades representadas por gramas, para a realização dos cálculos, mas mantidas em medidas caseiras na listagem de alimentos do sistema de pontos, pela facilidade de compreensão e de cálculo pela população.

\subsubsection{Cálculo de CSI}

O CSI foi calculado pela metodologia citada por CONNOR e col. (1986) pela da seguinte fórmula:

$\mathrm{CSI}=(1,01 \times \mathrm{g}$ de gordura saturada $)+(0,05 \times \mathrm{mg}$ de colesterol $)$

Por esse score, um indice baixo significa uma alta capacidade de redução das hiperlipidemias (CONNOR e col. 1989).

No Brasil, são raros os dados sobre composição de alimentos, quando existem são compilações de tabelas estrangeiras, que não refletem as preparações brasileiras e, também necessitam ser aperfeiçoadas (SEVENHUYSEN 1994). Portanto, o aporte de gordura saturada e de colesterol foram calculados utilizandose dados de experimentos bromatológicos desenvolvidos no laboratório de bromatologia da Faculdade de Saúde Pública (FSP) da Universidade de São Paulo (USP), compilados por TORRES (2000). Os demais, que não constaram dessa listagem, foram calculados de forma indireta por meio de tabelas de composição 
de alimentos: Tabela brasileira de composição de alimentos (LAJOLO e col. 2002), Tabela de composição de alimentos: suporte para decisão nutricional (PHILIPPI 2001) e The composition of foods (MCCANCE e WINDDOWSON 1991); ou por informaçōes do próprio fabricante.

\subsubsection{Como contar os pontos}

$O$ instrumento vem acompanhado de material explicativo, pelo qual, o individuo recebe as instruções detalhadas para determinar a pontuação alvo de CSI diário. Porém, optou-se por denominar o CSI de ICS (Índice de colesterol e gordura saturada) no sistema de pontos, para evitar palavras em outro idioma e melhorar a compreensão.

Para a contagem dos pontos utilizaram-se, exclusivamente, operações matemáticas de somar e multiplicar, por estarem presentes, com maior freqüência, na rotina das pessoas, considerando-as de menor dificuldade.

Para a elaboração da mensagem de como contar os pontos utilizou-se uma linguagem de fácil compreensão, evitando-se palavras de sentido ambiguo, para não comprometer o entendimento.

Foi desenvolvido, ainda, um formulário para anotar os pontos de cada alimento consumido, no qual também se procede à somatória da pontuação total do dia. 


\subsubsection{Alimentação balanceada}

Por se tratar de uma dieta dos pontos para controle do colesterol sérico, na qual não há proibições de alimentos e a escolha é feita diretamente pelo portador da dislipidemia, de acordo com suas preferências e hábitos alimentares, considerou-se oportuno o estabelecimento de um icone para representar uma alimentação balanceada, podendo influenciar na escolha de alimentos (MITCHELL 1996).

Para tanto, utilizou-se como representação gráfica o Guia Alimentar da Pirâmide Saudável, adaptado de WILLETT (2001). Foi apresentado em formato de coração, abordando variedade, proporção e moderação, sem indicar quantidades e porções, que devem ser decididas pela pontuação dos alimentos.

Foram criadas mensagens claras e objetivas em relação à necessidade de manter o peso saudável, o qual pode ser obtido em tabela simplificada e de fácil utilização, tomando-se como base o IMC - Índice de Massa Corporal normal (WHO 1998), além dos passos a serem seguidos para uma alimentação saudável.

A necessidade individual de gorduras e colesterol, para o cálculo do CSI máximo a ser ingerido pelos individuos, foi calculada utilizando-se as recomendaçōes sugeridas pela AHA (2000), para hipercolesterolemia, apresentadas no Quadro 1.

No Quadro 2, pode-se conferir o valor energético total (VET) utilizado para o cálculo percentual de gordura saturada, que foi derivado, teoricamente, da necessidade energética média de um indivíduo adulto até 55 anos ou acima e do 
sexo masculino ou feminino, segundo dados da SBAN - Sociedade Brasileira de Alimentação e Nutrição (VANNUCCHI e col. 1990). Considerou-se atividade leve, pois o perfil de individuos hiperlipidêmicos é de pessoas com pouca atividade física (WILCOX e col. 2000).

Quadro 2: Dados estimados da populacão a utilizar o sistema de pontos e necessidades energéticas.

\begin{tabular}{l|cc}
\hline Característica & Sexo Masculino & Sexo Feminino \\
\hline Peso médio & $65 \mathrm{~kg}$ & $63 \mathrm{~kg}$ \\
Estatura média & $1,70 \mathrm{~m}$ & $1,63 \mathrm{~m}$ \\
Atividade fisica & Leve & Leve \\
$\begin{array}{l}\text { Necessidade energética } \\
\text { (até 55 anos) } \\
\begin{array}{l}\text { Necessidade energética } \\
\text { (acima de 55 anos) }\end{array}\end{array}$ & $2286 \mathrm{kcal}$ & $1855 \mathrm{kcal}$ \\
\hline
\end{tabular}

\subsubsection{Correções e ajustes no sistema de pontos}

Para correções e ajustes no instrumento foram utilizados os dados provenientes de dissertação de mestrado desenvolvida no mesmo projeto (NACIF 2003), que teve por objetivo avaliar a compreensão dos individuos em relação ao instrumento e seguiu a metodologia adaptada de MITCHELL e col. (1996).

Foram aplicadas unidades didáticas do guia alimentar, contendo os conceitos básicos, conteúdo educativo e o material de apoio para 153 individuos, 
de ambos os sexos, maiores de 20 anos, recrutados em um Hospital e em um Centro de Saúde do município de Ourinhos, no Estado de São Paulo, sendo:

- 52 pacientes hipercolesterolêmicos;

- 50 pacientes não hipercolesterolêmicos;

- 51 profissionais da área da saúde (médicos, enfermeiros, auxiliares e técnicos de enfermagem).

Segundo FERREIRA (1986), avaliar significa medir, comparar e concluir. Dentro desse contexto, o processo de avaliação não se limita à coleta de dados, devendo envolver uma comparação entre a situação encontrada e outra que se caracteriza como padrão, para permitir conclusões. Para esse processo, foram necessários instrumentos e critérios previamente estabelecidos.

Os instrumentos são recursos utilizados para a coleta e registro dos dados a serem avaliados. Nesse caso, foram utilizados questionários, que foram preenchidos pela própria pesquisadora, em entrevista com os participantes do estudo.

Os critérios são normas que permitem concluir se os resultados obtidos foram satisfatórios.

No caso do estudo proposto na dissertação de mestrado (NACIF 2003), a verificação da concordância do sistema de pontos do guia foi realizada por obtenção preliminar do consumo alimentar dos entrevistados pelo método recordatório de 24-horas - R24h (SERRA-MAJEM e BARBA 1995). Após a aplicação do método e registro dos alimentos envolvidos, foi solicitado aos participantes do estudo que calculassem individualmente o valor de CSI (nesse 
caso denominado ICS) de sua dieta, consultando a unidade didática intitulada Guia Alimentar para Controle de Colesterol e Gordura no Sangue. A média e o limite de tempo para estimar as pontuações tambèm foram calculados.

A pesquisadora procedeu, então, à análise dessas dietas e determinou as pontuações de referência para CSI, que representaram o gabarito (padrão ouro).

Em seguida, os resultados de cada participante foram corrigidos e comparados ao gabarito. A concordância foi estimada comparando-se os dados obtidos pelos entrevistados e o padrão ouro.

As estimativas dos participantes e as pontuações do gabarito sofreram análise por meio de métodos estatísticos, para que se pudesse verificar o entendimento e a facilidade de manejo desse novo instrumento, e, assim, constatar se ele é realmente auto-explicativo como se propõe.

Esta etapa forneceu subsídios ao aperfeiçoamento do instrumento, por meio de ajustes e correções de eventuais problemas de redação e de apresentação da unidade didática (SHAMAH e col. 1997).

\subsection{Estudo piloto}

\subsubsection{População e local de estudo}

A população de estudo foi constituída por 62 (sessenta e dois) pacientes dislipidêmicos, adultos, não institucionalizados, de ambos os sexos, voluntários, 
agendados para consulta médica no ambulatório de endocrinologia de um HospitalEscola da Faculdade de Medicina da Fundação do ABC (FM-FuABC), no municipio de Santo André, que compõe a região metropolitana de São Paulo. Está localizado a sudeste da Capital do Estado de São Paulo, com extensão de $181 \mathrm{~km}^{2}$ e com população de 649.331 habitantes, segundo o último censo. Sua base econômica é caracterizada pelo pólo industrial e petroquímico e pelo setor de serviços (FUNDAÇÃO IBGE 2000).

\subsubsection{Amostragem}

Por se tratar de um estudo de intervenção, para definir o tamanho da amostra, levou-se em consideração o número minimo de indivíduos que pudesse receber um tratamento estatístico significativo (60 individuos), atendendo às recomendações do Comitê de Ética da Faculdade de Saúde Pública da Universidade de São Paulo, por se tratar de um estudo experimental.

Inicialmente, foram convidados a participar do estudo, 90 (noventa) pacientes, dos quais, 62 (sessenta e dois) retornaram e puderam ser acompanhados até a obtenção dos resultados. Essa amostra reserva de 30 (trinta) indivíduos foi estipulada já se esperando a desistência de uma parte da amostra.

\subsubsection{Critérios de seleção e exclusão}

Foram convidados a participar do estudo todos os pacientes portadores de dislipidemias, comprovadas por exames laboratoriais e que não apresentavam nenhum quesito relativo aos critérios de exclusão. 


\section{Consideraram-se como fatores de exclusão:}

- analfabetos ou indivíduos que não conseguissem escrever - pela necessidade do guia ser lido e entendido, além disso, eles teriam de anotar os alimentos consumidos e sua pontuação;

- pessoas incapazes de fazer contas - por ter de realizar as operações de soma e multiplicação, para proceder à pontuação de CSI;

- pacientes que necessitassem de intervenção medicamentosa (hipolipemiantes), para eliminarmos uma provável variável de confusão;

- portadores de doenças hepática ou renal - por interferirem no metabolismo lipidico;

- pacientes em uso de medicação que interferisse nos lipideos do plasma, como os anticoncepcionais;

- portadores de hipotiroidismo não compensado, com TSH (Hormônio Estimulante da Tireóide) superior a 7 (sete) $\mu \mathrm{Ul} / \mathrm{ml}$.

\subsubsection{Coleta de dados}

A coleta de dados do estudo piloto foi realizada de Maio a Dezembro de 2002, sempre às quartas-feiras, no horário de atendimento do ambulatório de endocrinologia da FM-FuABC, das $8 \mathrm{~h}$ às 12 horas.

\subsubsection{Variáveis de estudo}

Para descrever as caracteristicas da população e proceder ao levantamento de dados relativos à pesquisa foram eleitas as variáveis, que podem ser conferidas mais detalhadamente, no instrumento de coleta de dados da pesquisa (Anexo 2): 
- variáveis sócio-demográficas: sexo, idade (calculada em anos, pela diferença entre a data da primeira orientação e a data de nascimento), escolaridade (obtida em anos de estudo), raça descrita pelo médico no prontuário (branco, preto, pardo e amarelo), estado civil e ocupação (auto-referida). Essas variáveis foram eleitas como subsidio para caracterizar os grupos controle e estudo de maneira similar;

- variáveis diagnósticas: peso, altura, IMC, perimetro da cintura, colesterol total e suas frações, prática de atividade física após a recomendação, comorbidades e uso de medicação.

\subsubsection{Desenho do estudo piloto}

Foi desenvolvido um estudo, de desenho experimental, randomizado (ROUQUAYRIOL 1986), no qual foram acompanhados dois grupos de pacientes:

- um grupo que seguiu uma dieta tradicional para hipercolesterolemia (Anexo 1) - grupo controle;

- outro grupo que foi orientado a utilizar a dieta proposta nesse trabalho (sistema de pontos) - grupo estudo.

Inicialmente, foram destinados 45 (quarenta e cinco) pacientes para cada grupo de forma aleatória, todos portadores de dislipidemias, distribuidos nos dois grupos ao acaso, por sorteio.

Ao final do estudo, o grupo controle foi constituido por 32 (trinta e dois) pacientes e o grupo estudo por 30 (trinta) pacientes. 


\subsubsection{Procedimentos Metodológicos}

\section{Atendimento ambulatorial e perfil de morbidade}

Para admissão no ambulatório de endocrinologia do Hospital-Escola da FMFuABC, os individuos teriam de ser submetidos a uma triagem médica ou vir encaminhados de outra especialidade do Hospital-Escola.

Na primeira consulta no ambulatório de endocrinologia, os pacientes foram atendidos por médico, que relatou todas as informações da anamnese clinica e exame físico no prontuário médico. Nessa mesma oportunidade, receberam os pedidos de exame e um pedido de retorno com exames. No retorno, foram atendidos pelo médico, que registrou no prontuário os valores dos exames laboratoriais, bem como as enfermidades diagnosticadas.

Quanto ao diagnóstico clínico, o médico descreveu todas as doenças diagnosticadas por ele, que se adicionaram a outras já diagnosticadas e tratadas por outras especialidades. As enfermidades foram descritas de acordo com o Código Internacional de Doença - CID (CBCD 1993).

Para a classificação do diabetes e seus estágios pré-clínicos, utilizou-se os procedimentos diagnósticos preconizados pela Sociedade Brasileira de Diabetes (SBD 2002).

Os pacientes com diagnóstico de colesterol limitrofe ou alto, sem prescrição de medicação hipolipêmica, foram encaminhados à nutricionista, autora desse estudo, que realizou as medidas antropométricas, registrou todos os dados 
pertencentes ao protocolo da pesquisa (Anexo 2), extraídos do prontuário médico, e, orientou a dieta, que foi seguida por três meses (DIXON e col. 2000, DITSCHUNEIT e FLECHTNER-MORS 2001), de acordo com o grupo (controle ou estudo) a que o individuo acessasse, desde que o paciente não apresentasse nenhum quesito de exclusão. Porém, nenhum indivíduo ficou sem orientação dietética, mesmo não fazendo parte do protocolo de pesquisa.

O paciente, após orientação nutricional, recebia novos pedidos de exame, a serem realizados ao final de três meses, e, um pedido de retorno com exames, para agendar nova consulta.

Quanto à prática de atividade física, não foi analisado qualitativa ou quantitativamente o nivel, foi somente realizada a pergunta: "Pratica atividade física? sim ou não e averiguado no retorno. Todos os pacientes relataram não praticar, mas foram orientados pelo médico e nutricionista a fazer caminhada diariamente.

No retorno, após o seguimento da dieta por três meses e realização de novos exames bioquímicos, os procedimentos médicos e da nutricionista eram repetidos e registrados.

Cabe salientar que todos os indivíduos participantes da pesquisa, seja no grupo estudo ou controle, receberam a mesma dedicação de tempo, orientações prestadas e foram atendidos pelas mesmas pessoas, diferenciando somente a dieta a ser seguida.

A seguir, o Esquema 1 apresenta o fluxo do protocolo de pesquisa. 


\section{ESQUEMA 1}

PROTOCOLO EXPERIMENTAL

90 pacientes hiperlipidêmicos

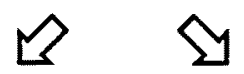

45 pacientes-Grupo Controle<smiles>[Tl]</smiles>

Coleta de sangue (jejum)<smiles>[Tl]</smiles>

Atendimento médico e nutricional<smiles>[Tl]</smiles>

3 meses de dieta tradicional para hiperlipidemias<smiles>[Te]</smiles>

32 pacientes-Grupo Controle<smiles>[Tl]</smiles>

Coleta de sangue (jejum)<smiles>[Te]</smiles>

Retorno médico e nutricional
45 pacientes-Grupo Estudo<smiles>[Tl]</smiles>

Coleta de sangue (jejum)

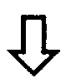

Atendimento médico e nutricional<smiles>[Tl]</smiles>

3 meses de dieta do sistema de pontos<smiles>[Te]</smiles>

30 pacientes-Grupo Estudo

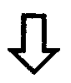

Coleta de sangue (jejum)

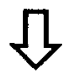

Retorno médico e nutricional

\section{Avaliação bioquimica}

No momento inicial, foram colhidos os índices séricos de colesterol e suas frações de cada participante dos dois grupos. Após 3 meses de seguimento das 
dietas, de acordo com cada grupo, os exames laboratoriais foram repetidos, para ver se houve maior adesão no grupo estudo, com melhores respostas ao tratamento. A coleta de sangue teve de fazer parte da rotina do controle médico dos pacientes envolvidos, e, não, exclusivamente, para dar suporte à pesquisa.

As amostras de sangue foram colhidas sobre EDTA (etilenodiaminotetracético) para análise de lipídeos plasmáticos, após 12 horas de jejum. As concentrações de colesterol total e triglicérides foram determinadas por métodos enzimáticos, a de HDL-colesterol, por precipitação com cloreto de magnésio e dextran sulfato. As concentrações de LDL-colesterol e VLDL-colesterol, foram determinadas por diferença -equação de Fridewald (BACHORIK e ALBERS 1986).

Os exames foram realizados pelo laboratório de análises clínicas da Faculdade de Medicina da Fundação do ABC.

O Quadro 3 apresenta os valores de referência para lipidemias (indivíduos com idade $\geq 20$ anos). 
Quadro 3: Valores de referência dos lípides séricos para indivíduos com 20 anos de idade ou mais.

\begin{tabular}{l|lc}
\hline Lípides & Valores & Categoria \\
\hline Colesterol total $(\mathrm{mg} / \mathrm{dl})$ & $<200$ & Ótimo \\
& $200-239$ & Limitrofe \\
& $\geq 240$ & Alto \\
\hline LDL-colesterol $(\mathrm{mg} / \mathrm{dl})$ & $<100$ & Ótimo \\
& $100-129$ & Desejável \\
& $130-159$ & Limitrofe \\
& $160-189$ & Alto \\
& $\geq 190$ & Muito alto \\
\hline HDL-Colesterol $(\mathrm{mg} / \mathrm{dl})$ & $<40$ & Baixo \\
& $>60$ & Alto \\
\hline Triglicérides $(\mathrm{mg} / \mathrm{dl})$ & $<150$ & Ótimo \\
& $150-200$ & Limitrofe \\
& $201-499$ & Alto \\
& $\geq 500$ & Muito alto \\
\hline
\end{tabular}

Fonte: NCEP (2001) e SBC (2001)

Como já foi citado anteriormente, os dois grupos foram formados por pacientes que não necessitavam de intervenção medicamentosa (hipolipemiantes), para eliminarmos uma provável variável de confusão.

\section{Variáveis antropométricas}

Foram analisados altura e peso pelo índice de Quetelet ou Índice de Massa Corporal (IMC) dado pela relação (WHO 1998):

$$
\text { IMC = peso } \left.(\mathrm{kg}) / \text { altura² }^{2} \mathrm{~m}\right)
$$

O Quadro 4 mostra os parâmetros de classificação para indivíduos adultos. Dessa forma, pode-se verificar se o guia alimentar auxiliou na redução ou 
manutenção do peso ideal, além de servir de subsidio para a formação dos grupos estudo e controle de forma similar.

Quadro 4: Classificação para IMC.

\begin{tabular}{l|c}
\hline Valor do IMC & Classificação \\
\hline$<18,5$ & Baixo peso \\
$18,5 \mid-25,0$ & Eutrofia \\
$25,0 \mid-30,0$ & Pré-obesidade \\
$30,01-35,0$ & Obesidade Grau I \\
$35,0 \mid-40,0$ & Obesidade Grau II \\
$\geq 40$ & Obesidade Grau III \\
\hline
\end{tabular}

Fonte: Adaptado de WHO (1998)

peso foi medido em quilogramas, utilizando-se uma balança Filizola®, pertencente ao Hospital-Escola, em questão, com capacidade para $150 \mathrm{~kg} \mathrm{e}$ sensibilidade de $100 \mathrm{~g}$. Os pacientes foram pesados com vestimentas leves (sem casacos ou paletós) e sem sapatos.

A altura foi medida em metros, utilizando-se o antropômetro em forma de haste, acoplado à mesma balança Filizola®, pertencente ao Hospital-Escola, com capacidade de $1,98 \mathrm{~m}$ e sensibilidade de $0,5 \mathrm{~cm}$. Os pacientes foram medidos descalços, em posição ortostática, olhando para frente, de forma a manter o plano Frankfort (FRISANCHO 1999).

O presente estudo analisou a circunferência abdominal que foi medida com uma fita métrica de fibra de vidro, inelástica, nos indivíduos com o mínimo de vestimentas. 
A circunferência da cintura foi medida em centimetros $(\mathrm{cm})$ no ponto médio entre a extremidade inferior da costela e a crista iliaca, ao final de uma expiração suave, com o individuo em pé, em posição ereta, com o abdome. relaxado, braços ao lado do corpo e pés juntos. Na impossibilidade de encontrar o ponto médio, a medida era feita no nivel do umbigo. Essa medida foi realizada perpendicularmente à linha axial do tronco (GROOT e STAVEREN 1980).

Para avaliação do perimetro abdominal foram adotados os valores de referência (TFR 1998). Segundo Task Force Report o perímetro da cintura igual ou superior a $98 \mathrm{~cm}$ para o sexo masculino ou maior ou igual a $89 \mathrm{~cm}$ para o sexo feminino, está relacionado com aumento de risco de morbidade, com maior impacto aos fatores de risco de DAC para ambos os sexos.

\subsection{Aspectos éticos}

De acordo com a Resolução $n^{\circ} 196$ de 1996, do Conselho Nacional de Saúde, por se tratar de pesquisa envolvendo seres humanos, é preciso a aprovação do Comitê de Ética da Faculdade de Saúde Pública da USP ou da entidade onde será realizada a pesquisa.

A pesquisa foi autorizada pelo Comitê de Ética da Faculdade de Saúde Pública da USP, por meio do documento Of. COEP/067/01 (Anexo 3).

Dessa forma, foi elaborado o termo de consentimento livre e esclarecido, que encontra-se em anexo (Anexo 4), que foi assinado pelos participantes dos grupos experimentais (grupo estudo e grupo controle). 
Os pacientes agendados para consulta médica de rotina no ambulatório de endocrinologia do Hospital-Escola situado na Grande São Paulo, eram argüidos sobre o seu interesse e disponibilidade em participar da pesquisa, após serem entrevistados e informados do objetivo do estudo e dos procedimentos a serem adotados (sorteio dos grupos), além do anonimato, da privacidade $e$ confidencialidade dos dados, bem como da possibilidade de sair do estudo a qualquer momento, sem apresentar motivos ou sofrer qualquer constrangimento. Eram, ainda, informados que teriam plena liberdade de aceitar ou não, ficando cientes de que a negativa de adesão não Ihes traria prejuizo algum à continuidade da assistência.

Os pacientes que aceitaram participar da pesquisa assinaram o termo de consentimento livre e esclarecido, mediante o compromisso de que os resultados Ihes seriam transmitidos oportunamente, em futuras consultas de rotina, uma vez que seriam registrados no prontuário. Como exposto anteriormente, nenhum paciente pertencente ao estudo ficou sem tratamento dietoterápico para dislipidemias, seja ele do grupo estudo ou grupo controle, seguindo o tratamento proposto pelo guia ou o tratamento tradicional, respectivamente.

\subsection{Análise estatística dos dados}

Os dados foram analisados de forma descritiva e por meio da estatística analitica utilizando-se o Advanced do Software para Análise Estatistica SPSS for Windows 10.0 (SPSS 1999). 


\subsubsection{Análise descritiva}

O primeiro passo para a análise dos dados foi o cálculo de algumas medidas-resumo (BUSSAB e col. 1987) que permitiram obter indicações dos resultados que foram confirmados pela aplicação de técnicas estatísticas, bem como avaliação da viabilidade delas.

De acordo com a natureza das variáveis estudadas, foram calculadas algumas medidas-resumo ( $\mathrm{N}$ - número de indivíduos, média, desvio padrão, valores mínimos e máximos encontrados e porcentagens) e construídas tabelas de contingência que trazem a distribuição conjunta das grandezas estudadas considerando o grupo dos indivíduos.

Optou-se por descrever a população como um todo, por haver semelhança entre os grupos.

\subsubsection{Análise inferencial}

Passada a fase descritiva, de análise preliminar, procedeu-se à análise inferencial, em que foram aplicadas técnicas estatísticas adequadas à situação apresentada para a tomada de decisões dentro de um controle do erro amostral.

Inicialmente, foi avaliado se os individuos de ambos os grupos apresentavam o mesmo perfil em relação às grandezas observadas. Com relação 
as variáveis de natureza categórica, foram aplicados os testes de Qui-quadrado, o teste Exato de Fisher ou sua Extensão (AGRESTI 1990), quando necessário.

As variáveis categóricas analisadas por meio dos testes mencionados acima, nos individuos em ambos os grupos foram as seguintes, e o teste utilizado para cada uma delas estão apresentados no Quadro 5:

- Escolaridade

- Sexo

- Ocupação

- Estado civil

- Raça

- Hipertensão arterial

- Diabetes Mellitus

- Resistência à insulina

- Outras comorbidades

- Uso de medicamentos para hipertensão

- Uso de Metiformina

- Uso de Glibenclamida

- Uso de outros medicamentos

- Adesão à atividade física 


\section{Quadro 5: Testes utilizados para comparacōes dos Grupos e demais variáveis.}

\begin{tabular}{ll}
\hline Variáveis comparadas & Teste utilizado \\
\hline Escolaridade e Grupo & Extensão do teste exato de Fisher \\
Sexo e Grupo & Qui-quadrado de Pearson \\
Ocupação e Grupo & Qui-quadrado de Pearson \\
Estado civil e Grupo & Extensão do teste exato de Fisher \\
Raça e Grupo & Extensão do teste exato de Fisher \\
Hipertensão arterial e Grupo & Qui-quadrado de Pearson \\
Diabetes Mellitus e Grupo & Teste exato de Fisher \\
Resisténcia à insulina e Grupo & Teste exato de Fisher \\
Outras comorbidades e Grupo & Extensão do teste exato de Fisher \\
Medicamentos anti-hipertensivo e Grupo & Qui-quadrado de Pearson \\
Uso de Metiformina e Grupo & Teste exato de Fisher \\
Uso de Glibenclamida e Grupo & Teste exato de Fisher \\
Uso de outros medicamentos e Grupo & Extensão do teste exato de Fisher \\
Atividade fisica e Grupo & Qui-quadrado de Pearson \\
\hline
\end{tabular}

Para as variáveis de natureza numérica foi adotado o teste de Análise de variância (NETER e col. 1996). Assim, foi realizado o estudo do perfil dos individuos segundo Grupo e Idade, Altura, Peso, IMC, Circunferência abdominal, Colesterol total, HDL, LDL, VLDL e Triglicérides. Para as variáveis que apresentaram medidas com diferença estatisticamente significantes entre os dois grupos no início da pesquisa, indicavam que a maneira mais adequada para avaliar o desempenho dos indivíduos em ambos os grupos, era a quantificação da redução das medidas observadas.

A redução das medidas observadas dos individuos no decorrer da pesquisa foi avaliada utilizando-se a seguinte fórmula: 


Redução $=\frac{(\text { Medida inicial }- \text { Medida final })}{\text { Medida inicial }} \cdot 100$

A Redução foi expressa em porcentagem para que se tenha uma idéia real da diferença entre os grupos avaliados, podendo, então, ser comparados.

O nivel de significância estatistica considerado foi $p<0,05$.

Em seguida foram apresentadas algumas medidas-resumo, já ajustadas, das Reduções do Peso, IMC, Circunferência abdominal, Colesterol total, Triglicérides, HDL, LDL e VLDL, observadas nos indivíduos em cada grupo.

Por fim, foi realizada uma análise estatística para estudar a relação entre a redução do colesterol e as variáveis Idade, Sexo, Grupo, Raça, Redução do IMC e Redução da Circunferência abdominal, para tanto se utilizou a análise de regressão linear múltipla (NETER e col. 1996). 


\section{RESULTADOS}

Esse estudo foi realizado em duas etapas e para facilitar a compreensão dos resultados, também serão apresentados em: Elaboração do Sistema de Pontos e Estudo Piloto.

\subsection{Elaboração do sistema de pontos}

Trata-se de uma dieta dos pontos para colesterol, intitulada "Sistema de Pontos para Colesterol e Gordura no Sangue" com as seguintes características:

a) formato de uma cartilha, contendo 22 (vinte e duas) páginas, acompanhada de material explicativo, pelo qual, o individuo recebe instruções detalhadas para escolher os alimentos e determinar a pontuação alvo de CSI (denominado ICS no instrumento) diário, por meio de tabelas simplificadas e de fácil utilização, sem proibição de nenhum alimento;

b) utilizou-se como representação gráfica a Pirâmide Alimentar Saudável, adaptado de WILLETT (2001), pois reflete rapidamente conceitos alimentares importantes e já com algumas modificações em relação à Pirâmide Alimentar Americana (USDA, 1995), mais adequada à redução das lipidemias (BEYRUTI 2002). Optou-se por apresentá-la em formato de coração, como uma alusão à prevenção de doenças cardiovasculares, abordando variedade, proporção e moderação, sem indicar quantidades e porções, que devem ser decididas pela pontuação dos alimentos. Há, ainda, mensagens claras e objetivas em relação à necessidade de se manter o peso saudável, o qual pode ser obtido em 
tabela simplificada e de fácil utilização, tomando-se como base o IMC Índice de Massa Corporal normal (WHO 1998), além dos passos a serem seguidos para uma alimentação saudável;

c) sistema de pontos constituído por uma listagem de alimentos freqüentemente consumidos pela população, baseada em uma lista de alimentos que comparou o padrão alimentar e os lipideos séricos da população de um município da região metropolitana de São Paulo. (FORNÉS 1998), com o cálculo de CSI (ICS) em medidas caseiras, de acordo com dados da Agência Nacional de Vigilância Sanitária (ANVISA 2001) e da Pirâmide alimentar: guia para escolha dos alimentos (USP 1999);

d) modelo para o individuo anotar os alimentos consumidos e proceder à soma das pontuações diariamente.

Foram inicialmente identificados 240 alimentos para compor a listagem do sistema de pontos. De acordo com a metodologia citada anteriormente, no item 3.2.3 (CONNOR e col. 1986) a pontuação de CSI foi calculada para cada alimento, em medidas caseiras. Esses alimentos foram dispostos em uma única lista, em ordem alfabética e após a formatação do instrumento, ele foi submetido a um teste que verificou a concordância do sistema de pontos realizado por NACIF (2003), para avaliar a compreensão das pessoas em relação à sua utilização. Essa pesquisa foi realizada com 153 individuos, como detalhado no item 3.2.6.

Esse estudo forneceu os resultados esperados (acima de $94 \%$ dos entrevistados utilizaram o guia adequadamente), no entanto, sugestões pertinentes ao aperfeiçoamento do instrumento, bem como necessidade de ajustes e correções sentidas pela pesquisadora foram acatadas e implementadas. Dessa forma, 
eventuais problemas de redação e de apresentação do instrumento foram ajustados, para a produção da versão final, apresentada nesse trabalho, para que uma nova aplicação do programa fosse realizada no estudo piloto, entre eles:

- apresentação da pontuação em ordem crescente de valor de CSI, por ser considerado, pelos entrevistados, como algo que facilita na escolha dos alimentos;

- tabela contendo o peso saudável (teórico), que foi uma dificuldade que as pessoas demonstraram em identificar;

- chamar a atenção para alguns alimentos com CSI baixo, porém com alto valor energético ou que alteram o metabolismo das gorduras, como por exemplo o álcool que diminui a oxidação de ácido graxo, podendo levar ao acúmulo de triglicérides (MOREIRA e col. 1996).

O Sistema de Pontos se mostrou adequado quanto à clareza e compreensão dos entrevistados, em relação à sua utilização, sendo manipulado e calculado com facilidade pelos participantes da pesquisa. $O$ tempo médio de resposta para o cálculo do recordatório de 24-horas - R24h foi inferior a 6 minutos.

O Coeficiente de correlação entre os cálculos realizados pelos entrevistados e o padrão ouro é apresentado na Tabela 1. 
Tabela 1: Coeficiente de correlacão dos cálculos de CSI em relacão à escolaridade dos participantes da pesquisa. Ourinhos, 2002.

\begin{tabular}{l|c}
\hline $\begin{array}{c}\text { Escolaridade } \\
\text { (anos de estudo) }\end{array}$ & Coeficiente de Correlação \\
\hline $1-4$ & 0,9502 \\
$5-8$ & 0,9440 \\
$9-11$ & 0,9972 \\
12 ou + & 0,9960 \\
\hline
\end{tabular}

Fonte: Adaptado de NACIF (2003)

\subsubsection{Sistema de pontos para colesterol e gordura no sangue}

Todas as alterações pertinentes foram incluidas e implementadas e são apresentadas a seguir, na versão final desse instrumento. 


\section{Sistema de Pontos para Controle de Colesterol e Gordura no Sangue}

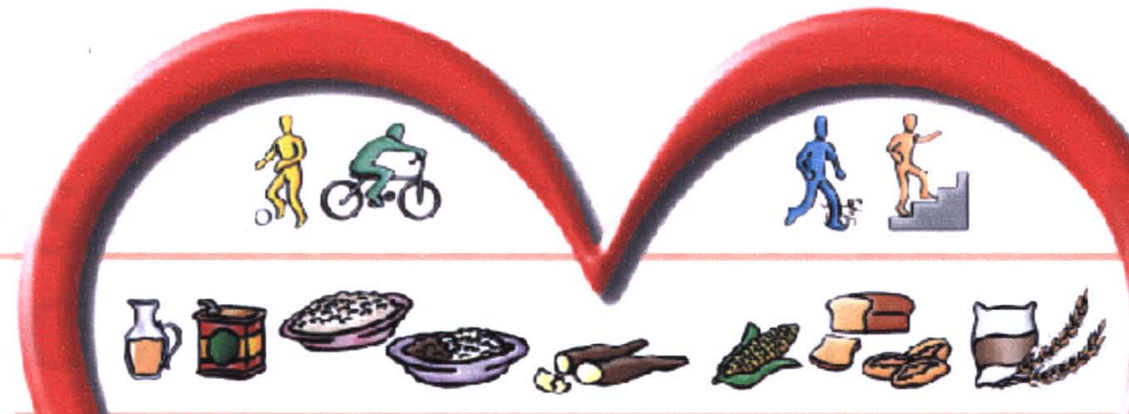

-

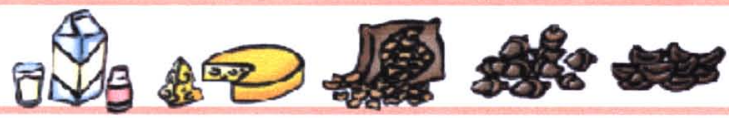
ac 00

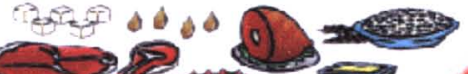
की axing

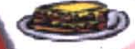

Ajude o sen Conafĩa a viver Mais Melhor 


\section{SISTEMA DE PONTOS PARA CONTROLE DE COLESTEROL E GORDURA NO SANGUE}

Edeli Simioni de Abreu Márcia A. L. Nacif Elizabeth A. F. S. Torres 


\section{Índice}

Índice

Apresentação

01

Representação Gráfica da

Alimentação Saudável.

Passos para uma

Alimentação Saudável

Como Contar os Pontos ........... 04

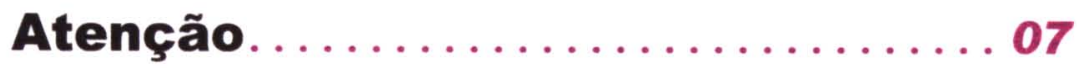

Lista de Pontos

dos Alimentos ................. 08

Modelo ......................... 21

Referências Bibliograficas....... 22 


\section{Apresentação}

A alimentação saudável tem papel fundamental na prevenção de doenças e na redução e manutenção dos níveis de colesterol no sangue. Sabe-se que uma dieta com elevados indices de colesterol e gordura saturada agrava esses riscos. Assim, fica fácil deduzir que o consumo de alimentos com reduzido teor de gordura saturada e pobres em colesterol é importante na redução dos níveis de colesterol sangüíneos.

O que fica difícil medir é o potencial de aumentar o colesterol que cada alimento possui. Para facilitar esse entendimento foi desenvolvido um Índice de colesterol/gordura saturada - ICS, que pode ser utilizado para comparar diferentes alimentos e preparações, por meio de pontuações.

Controlar o peso é outro fator que diminui os riscos para o aumento de colesterol $\mathrm{e}$, conseqüentemente, previne o aparecimento de doenças do coração, diabetes, hipertensão arterial, entre outras. Porém, isso não é tarefa fácil, mas com um pouco de boa vontade, é possível atingir o objetivo, sem fazer grandes sacrifícios. O que é necessário é aprender a escolher os alimentos certos.

Para começar, devemos banir a idéia de "fazer regime", que está associada a fazer sacrifício durante um tempo e depois abandonar, voltando, muitas vezes, à estaca zero. O correto é adotar um plano dietético, ou seja, uma forma de se alimentar hoje, nos próximos dias e sempre.

Para auxiliar na promoção de um melhor estado nutricional e no estabelecimento de hábitos alimentares adequados, foi desenvolvido o presente Sistema de Pontos, de fácil compreensão e manejo, que pode ser calculado pelo próprio indivíduo que aprenderá a elaborar sua dieta através de pontuações de ICS, além de uma representação gráfica da alimentação saudável. 


\section{Representação Gráfica da Alimentação Saudável}

\section{Uma ferramenta para controle e prevenção de colesterol elevado e gordura no sangue.}

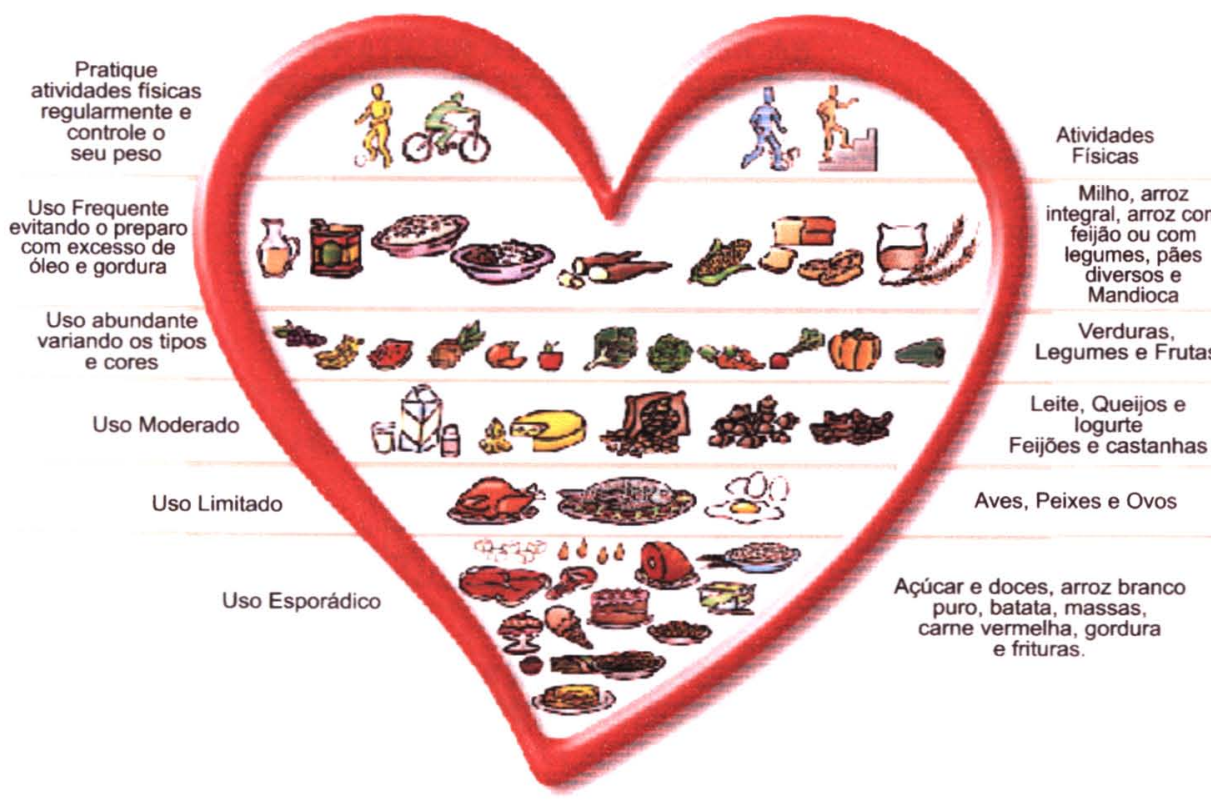

ESCOLHA UMA ALIMENTAÇÃO SAUDÁVEL 


\section{Passos para uma Alimentação Saudável}

1 - CONSUMIR UMA ALIMENTAÇÃO VARIADA

2 - BASEAR A ALIMENTAÇÃO NO CONSUMO DE ALIMENTOS DERIVADOS DE GRÃOS E RAÍZES, LEGUMES, VERDURAS E FRUTAS

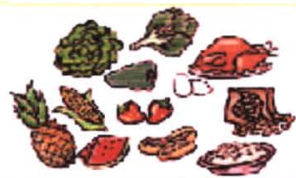

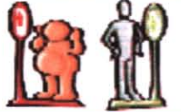

4 - PRATICAR ATIVIDADES FÍSICAS REGULARMENTE E COM ORIENTAÇÃO
3 - EVITAR A OBESIDADE, MANTENDO O PESO CORPORAL DESEJÁVEL

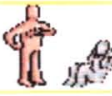

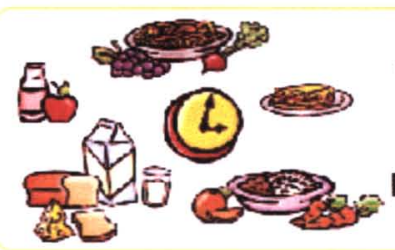

5 - SELECIONAR UMA DIETA COM BAIXA QUANTIDADE DE GORDURA, COLESTEROL

E GORDURA SATURADA

6 - FRACIONAR A DIETA, FAZENDO TRÊS REFEIÇÕES E DOIS LANCHES ENTRE ELAS ESCOLHENDO ALIMENTOS SAUDÁVEIS

7 - EVITAR O CONSUMO DE FRITURAS

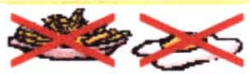

स्ञा

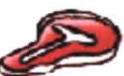

8 - CONSUMIR PRODUTOS DE ORIGEM ANIMAL MODERADAMENTE

9 - PREFERIR AS CARNES MAGRAS E RETIRAR GORDURAS VISÍVEIS

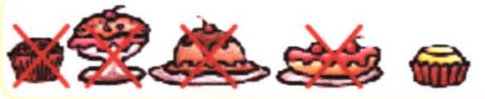

10 - CONSUMIR AÇÚCAR E DOCES COM MODERAÇÃO

11 - REDUZIR O CONSUMO DE SAL

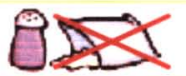

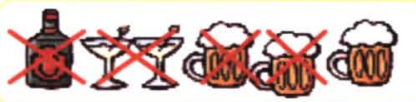

12 - LIMITAR O CONSUMO DE ÁLCOOL, SE INGERIR, FAÇA-O COM MODERAÇÃO

13 - NÃO ESQUECER DE CONSUMIR ÁGUA, POIS É ESSENCIAL À SAÚDE

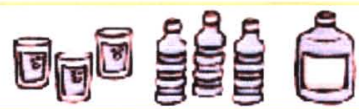




\section{Como Contar os Pontos}

Esse é o seu guia de alimentos. Utilize-o para fazer escolhas convenientes onde quer que você estiver.

\section{No que se baseia esse sistema de pontos?}

Não há proibição de nenhum alimento: uma pessoa com excesso de colesterol não tem que se isolar do mundo ou comer pratos especiais.

Propicia uma variedade de alimentos para escolher:

uma dieta com alimentos permitidos e proibidos é monótona. Esse sistema permite que cada um module sua alimentação sem eliminar os alimentos preferidos.

Permite que se tenha uma vida alimentar normal: dá para comer bem.

Em pouco tempo:

aprende-se a conhecer o valor e a equivalência dos alimentos, não sendo mais necessário anotá-los, e, isso vale para o resto da vida.

Quantos pontos de ICS (Índice de Colesterol e Gordura Saturada) que se pode consumir por dia para baixar o colesterol?

É só procurar na próxima tabela (tabela 1) os pontos de ICS que estão liberados para a sua dieta de acordo com sexo e idade.

Tabela 1: Quantidade máxima de ICS, segundo sexo.

ICS por dia

Sexo

Masculino

Feminino
Até 55 anos

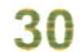

25
Acima de 55 anos 


\title{
Como Contar os Pontos
}

\author{
E é necessário anotar os \\ pontos de tudo que se come?
}

Anotar os pontos leva a melhores resultados. Após algum tempo, é possível deixar de anotar porque o método e os princípios já foram assimilados. Mas até isso acontecer, anote os seus pontos, consultando as listas de pontos (a partir da página 08), em ordem crescente de ICS, de acordo com as porções que você ingerir. Exemplo : se você consumir 4 colheres de sopa de arroz, salada de alface temperada com azeite e 1 bife, anote e conte os pontos da seguinte forma:

$\begin{array}{lccc}\text { Alimento } & \begin{array}{c}\text { Quantidade } \\ \text { de Porçóes }\end{array} & \begin{array}{c}\text { Pontuaçäo de } \\ \text { ICs por Porçăo }\end{array} & \begin{array}{c}\text { Pontuacâa } \\ \text { total de ICS }\end{array} \\ \text { Arroz } & 2 & 1 & \mathbf{2} \\ \text { Alface } & 1 & 0 & \mathbf{0} \\ \text { Azeite } & 1 & 1 & \mathbf{1} \\ \text { Bife } & 1 & 12 & \mathbf{1 2} \\ \text { Total } & & & \mathbf{1 5}\end{array}$

Tente e você vai ver que não é difícil ter uma alimentação saudável sem banir os alimentos preferidos.

\section{Onde anotar os pontos?}

Na página 21 você vai encontrar um modelo que pode ser copiado em um caderno ou outro tipo de papel em que você deve anotar os pontos e guardar para mostrar ao seu médico.

\section{Procure manter o seu peso ideal:}

De acordo com a sua altura, pode-se verificar o seu peso ideal mínimo e máximo, apresentados na Tabela 2. 


\section{Como Contar os Pontos}

Tabela 2: Peso saudável segundo altura

\begin{tabular}{ccc} 
& \multicolumn{2}{c}{$\begin{array}{c}\text { Peso ideal } \\
\text { corporal em Kg }\end{array}$} \\
Altura $(\mathrm{cm})$ & Mínimo & Máximo \\
$\mathbf{1 4 0}$ & 39,2 & 40,0 \\
$\mathbf{1 4 2}$ & 40,3 & 50,4 \\
$\mathbf{1 4 4}$ & 41,5 & 51,8 \\
$\mathbf{1 4 6}$ & 42,6 & 53,3 \\
$\mathbf{1 4 8}$ & 43,5 & 54,8 \\
$\mathbf{1 5 0}$ & 45,0 & 56,3 \\
$\mathbf{1 5 2}$ & 46,2 & 57,8 \\
$\mathbf{1 5 4}$ & 47,4 & 59,3 \\
$\mathbf{1 5 6}$ & 48,7 & 60,8 \\
$\mathbf{1 5 8}$ & 49,9 & 62,4 \\
$\mathbf{1 6 0}$ & 51,2 & 64,0 \\
$\mathbf{1 6 2}$ & 52,5 & 65,6 \\
$\mathbf{1 6 4}$ & 53,8 & 67,2 \\
$\mathbf{1 6 6}$ & 55,1 & 68,9 \\
$\mathbf{1 6 8}$ & 56,4 & 70,6 \\
$\mathbf{1 7 0}$ & 57,8 & 72,3 \\
$\mathbf{1 7 2}$ & 59,2 & 74,0 \\
$\mathbf{1 7 4}$ & 60,6 & 75,7 \\
$\mathbf{1 7 6}$ & 62,0 & 77,4 \\
$\mathbf{1 7 8}$ & 63,4 & 79,2 \\
$\mathbf{1 8 0}$ & 64,8 & 81,0 \\
$\mathbf{1 8 2}$ & 66,2 & 82,8 \\
$\mathbf{1 8 4}$ & 67,7 & 84,6 \\
$\mathbf{1 8 6}$ & 69,2 & 86,5 \\
$\mathbf{1 8 8}$ & 70,7 & 88,4 \\
$\mathbf{1 9 0}$ & 72,2 & 90,3 \\
$\mathbf{1 9 2}$ & 73,7 & 92,2 \\
$\mathbf{1 9 4}$ & 75,3 & 94,1 \\
$\mathbf{1 9 6}$ & 76,8 & 96,0 \\
$\mathbf{1 9 8}$ & 78,4 & 98,0 \\
$\mathbf{2 0 0}$ & 80,0 & 100,0 \\
& & \\
\hline
\end{tabular}

EXPERIMENTE! VALE A PENA TER UMA ALIMENTAÇÃO SAUdÁVEL COMENDO DE TUDO!! 


\section{Atenção}
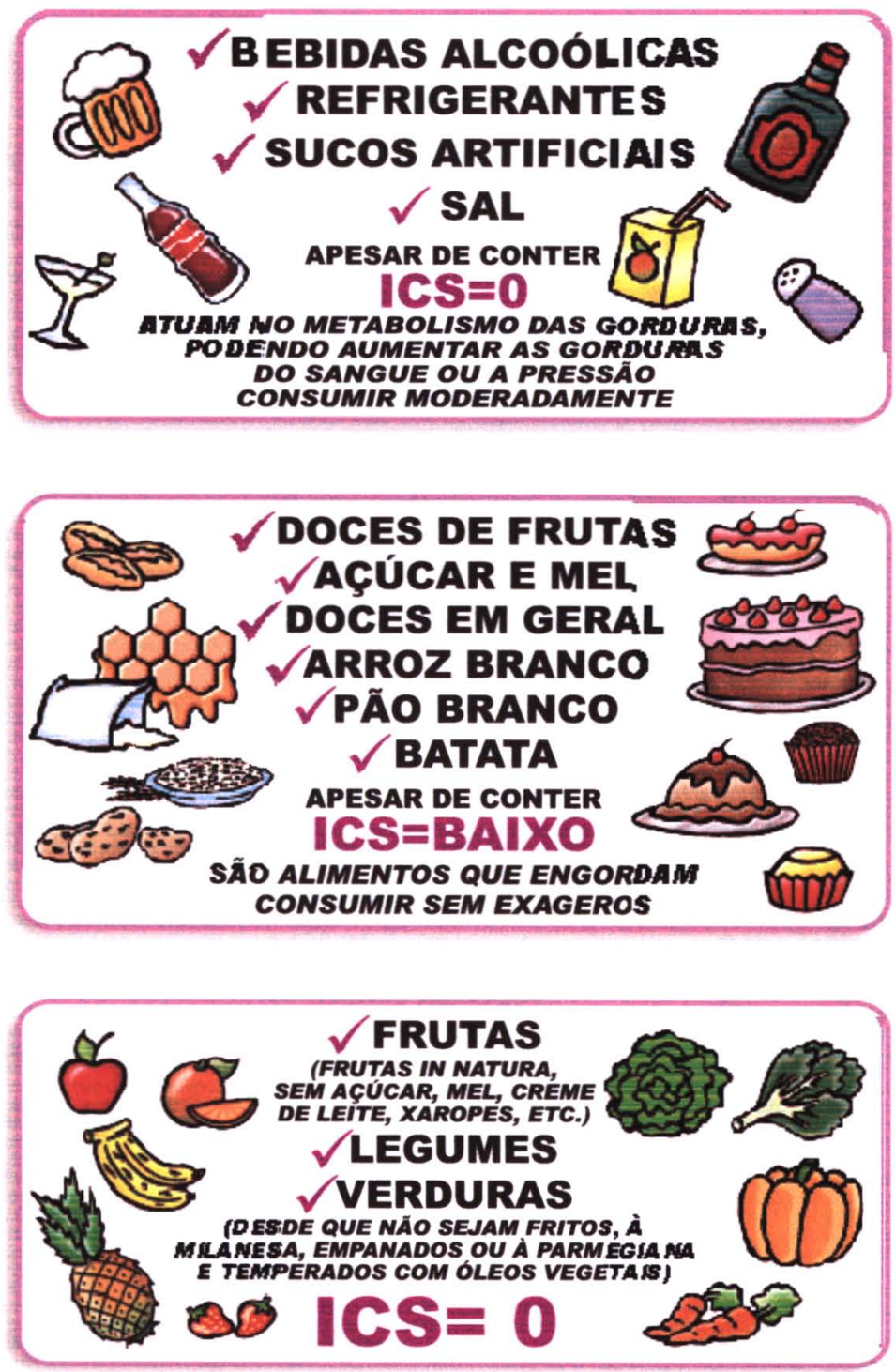


\section{Lista de Pontos dos Alimentos}

\section{0 pontos}

\begin{tabular}{|l|l|l|}
\hline \multicolumn{2}{|c|}{ Alimento } & \multicolumn{1}{|c|}{$\begin{array}{l}\text { ICs } \\
\text { por Porção }\end{array}$} \\
\hline Açúcar mascavo/refinado & 01 colher de sopa & 0 \\
\hline Água de coco & 01 colher de chá & 0 \\
\hline Aveia & 01 copo de requeijão & 0 \\
\hline Azeitona & 01 colher de sopa & 0 \\
\hline Balas /balas diet & 01 unidade & 0 \\
\hline Café com açúcar/ sem açúcar & 01 unidade & 01 xícara de café \\
\hline Caldo de cana & 01 copo de requeijão & 0 \\
\hline Catchup & 01 colher de sopa & 0 \\
\hline Cereal matinal & 01 xícara de chá & 0 \\
\hline Chá com açúcarl sem açúcar & 01 colher de sopa & 0 \\
\hline Chiclete /diet & 01 copo de requeijão & 0 \\
\hline Doces de frutas & 01 unidade & 0 \\
\hline Farelo de trigo & 01 colher de sopa & 0 \\
\hline Farinha de mandioca & 01 colher de sopa & 0 \\
\hline Farinha de milho & 01 colher de sopa & 0 \\
\hline Frutas em calda & 01 colher de sopa & 0 \\
\hline Fubá & 01 unidade & 0 \\
\hline Gatorade & 01 colher de sopa & 0 \\
\hline Gelatina/gelatina diet & 01 copo de requeijäo & 0 \\
\hline Geléia/geléia diet & 01 pote & 0 \\
\hline & 01 colher de sopa & 0 \\
\hline
\end{tabular}




\section{Lista de Pontos dos Alimentos}

\section{0 pontos}

\begin{tabular}{|l|l|l|}
\hline \multicolumn{1}{|c|}{ Alimento } & \multicolumn{1}{|c|}{$\begin{array}{l}\text { ICS } \\
\text { por Porção }\end{array}$} \\
\hline Goiabada & 01 fatia fina & 0 \\
\hline Grão de bico cozido & 01 colher de servir & 0 \\
\hline Groselha com água/diet & 01 copo de requeijão & 0 \\
\hline logurte desnatado & 01 pote & 0 \\
\hline logurte diet ou light & 01 pote & 0 \\
\hline Kani Kama & 05 unidades & 0 \\
\hline Leite de soja & 01 copo de requeijão & 0 \\
\hline Leite desnatado & 01 copo de requeijão & 0 \\
\hline Leite em pó desnatado & 02 colheres de sopa & 0 \\
\hline Leite fermentado - Yakult & 01 pote & 0 \\
\hline Mel & 01 colher de sopa & 0 \\
\hline Mostarda & 01 colher de sopa & 0 \\
\hline Ovo cozido (clara) & 01 unidade & 0 \\
\hline Queijo de soja & 01 fatia & 0 \\
\hline Refrigerante/ diet ou light & 01 copo & 0 \\
\hline Salada de frutas & 01 xícara de chá & 0 \\
\hline Soja cozida & 01 colher de servir & 0 \\
\hline Sucos de frutas & 01 copo de requeijão & 0 \\
\hline Sushi & 01 unidade & 0 \\
\hline Suspiro & 01 unidade & 0 \\
\hline Trigo & 01 colher de sopa & 0 \\
\hline Vinagre & 01 colher de sopa & 0 \\
\hline & & \\
\hline
\end{tabular}




\section{Lista de Pontos dos Alimentos}

\section{1 ponto}

\begin{tabular}{|l|l|l|}
\hline \multicolumn{2}{|c|}{ Alimento } & \multicolumn{2}{|c|}{$\begin{array}{c}\text { ICs } \\
\text { por Porção }\end{array}$} \\
\hline Apresuntado & 01 fatia & 1 \\
\hline Arroz à grega & 01 colher de servir /escumadeira & 1 \\
\hline Arroz integral cozido & 02 colheres de sopa & 1 \\
\hline Arroz branco cozido & 01 colher de servir lescumadeira & 1 \\
\hline Azeite de oliva & 02 colheres de sopa & 1 \\
\hline Atum em lata & 01 colher de servirlescumadeira & 1 \\
\hline Barra de cereais & 02 colheres de sopa & 1 \\
\hline Batata cozida & 01 colher de sopa & 1 \\
\hline Batata doce cozida & 01 colher de sopa & 1 \\
\hline & 01 unidade & 1 \\
\hline Batata doce frita & 01 colher de servir & 1 \\
\hline Batata frita & 01 unidade & 1 \\
\hline Batata frita ("chips") & 01 colher de servir & 1 \\
\hline Batata frita (palha) & 01 unidade & 1 \\
\hline Berinjela à milanesa & 01 colher de servir & 1 \\
\hline Bis & 01 colher de servir/escumadeira & 1 \\
\hline Biscoito de maisena & 01 colher de servir & 1 \\
\hline Biscoito de polvilho & 01 colher de servir & 1 \\
\hline Blanquet de peru & 01 fatia & 1 \\
\hline & 01 unidade & 1 \\
\hline 04 unidades & 1 \\
\hline 05 unidades & 1 \\
\hline 02 fatias & 1 \\
\hline
\end{tabular}




\section{Lista de Pontos dos Alimentos}

\section{1 ponto}

\begin{tabular}{|c|c|c|}
\hline Alimento & Porção & $\begin{array}{l}\text { ICS } \\
\text { por Porção }\end{array}$ \\
\hline Bolacha água e sal/cream craker & 04 unidades & 1 \\
\hline Bolacha doce & 02 unidades & 1 \\
\hline Bolacha recheada & 01 unidade & 1 \\
\hline Brigadeiro & 01 unidade & 1 \\
\hline Cappuccino diet pronto & 01 xícara de café & 1 \\
\hline Cappuccino & 01 xícara de café & 1 \\
\hline Coração de frango & 01 unidade & 1 \\
\hline Creme de milho & 01 colher de servir/concha & 1 \\
\hline Doce de leite & 01 colher de sopa & 1 \\
\hline Farofa & 01 colher de sopa & 1 \\
\hline Feijão branco cozido & 01 colher de servir & 1 \\
\hline Feijão cozido & $\begin{array}{l}01 \text { concha } \\
02 \text { colheres de sopa }\end{array}$ & $\begin{array}{l}1 \\
1\end{array}$ \\
\hline Leite condensado & 01 colher de sopa & 1 \\
\hline Lentilha refogada & 2 colheres de sopa & 1 \\
\hline Lombo defumado & 01 fatia fina & 1 \\
\hline Macarrão alho e óleo & 01 colher de servir /pegador & 1 \\
\hline Maionese light & 01 colher de sopa & 1 \\
\hline Mandioca frita & 01 colher de servir & 1 \\
\hline Margarina light & $\begin{array}{l}1 / 2 \text { colher de sopa } \\
1 \text { ponta de faca }\end{array}$ & $\begin{array}{l}1 \\
1\end{array}$ \\
\hline Margarina & $\begin{array}{l}1 / 2 \text { colher de sopa } \\
1 \text { ponta de faca }\end{array}$ & $\begin{array}{l}1 \\
1\end{array}$ \\
\hline
\end{tabular}




\section{Lista de Pontos dos Alimentos}

\section{1 ponto}

\begin{tabular}{|l|l|l|}
\hline \multicolumn{1}{|c|}{ Alimento } & \multicolumn{1}{|c|}{$\begin{array}{c}\text { ICs } \\
\text { por Porção }\end{array}$} \\
\hline Nugget de frango & 02 unidades & 1 \\
\hline Óleos canola/ girassol/ milhol soja & 01 colher de sopa & 1 \\
\hline Paçoca & 01 unidade & 1 \\
\hline Pão de forma (todos os tipos) & 02 fatias & 1 \\
\hline Pão francês & 01 unidade & 1 \\
\hline Pão de hambúrguer/hot dog & 01 unidade & 1 \\
\hline Pão tipo bisnaguinha & 02 unidades & 1 \\
\hline Pé de frango & 01 unidade & 1 \\
\hline Peito de peru defumado & 02 fatias finas & 1 \\
\hline Polenta com molho & 01 colher de servir & 1 \\
\hline Polenta frita & 01 fatia & 1 \\
\hline Presunto & 01 fatia fina & 1 \\
\hline Purê de batata & 01 colher de servir & 1 \\
\hline Queijo petit suisse-danoninho & 01 pote & 1 \\
\hline Quiabo frito & 04 colheres de sopa & 1 \\
\hline Rosbife & 01 fatia fina & 1 \\
\hline Salada de maionese & 01 colher de servir & 1 \\
\hline Salame & 01 fatia fina & 1 \\
\hline Sopa de feijão com macarrão & 01 concha & 1 \\
\hline Sopa de legumes/ legumes c/macarrão & 01 concha & 1 \\
\hline Sorvete diet ou light & 01 bola & 1 \\
\hline Torradas (pão francês) & 05 fatias/unidades & 1 \\
\hline & & 1 \\
\hline
\end{tabular}




\section{Lista de Pontos dos Alimentos}

\begin{tabular}{|l|l|l|}
\hline \multicolumn{2}{|c|}{2} & pontos \\
\hline Alimento & \multicolumn{2}{|c|}{ Porção } \\
\hline Banana frita & 01 unidade \\
\hline Bombom & 01 unidade & 2 \\
\hline Abacate & 1 fatia média & 2 \\
\hline Açaí & 01 copo & 2 \\
\hline Amendoim torrado & 01 colher de sopa & 2 \\
\hline Arroz doce & 01 pote & 2 \\
\hline Caldo verde & 01 concha & 2 \\
\hline Canja & 01 concha & 2 \\
\hline Castanhas & 01 colher de sopa & 2 \\
\hline Creme de leite light & 01 colher de sopa & 2 \\
\hline Flan & 01 pote & 2 \\
\hline logurte de frutas & 01 pote & 2 \\
\hline logurte de frutas para beber & 01 pote & 2 \\
\hline Leite integral semi desnatado & 01 copo de requeijão & 2 \\
\hline Leite tipo C & 01 copo de requeijão & 2 \\
\hline Macarrão cl molho de carne & 01 colher de servir/pegador & 2 \\
\hline Maionese & 01 colher de sopa & 2 \\
\hline Marisco cozido com casca & 01 pires & 2 \\
\hline McFritas & 01 unidade pequena & 2 \\
\hline Mortadela & 01 fatia fina & 2 \\
\hline Nozes & 01 colher de sopa & 2 \\
\hline Pão caseiro & 01 fatia & 2 \\
\hline & & 2 \\
\hline
\end{tabular}




\section{Lista de Pontos dos Alimentos}

\section{2 pontos}

\begin{tabular}{|l|l|l|}
\hline \multicolumn{1}{|c|}{ Alimento } & \multicolumn{1}{|c|}{ Porção } & \multicolumn{1}{|l|}{$\begin{array}{l}\text { ICS } \\
\text { porção }\end{array}$} \\
\hline Pipoca & 01 xícara de chá & 2 \\
\hline Queijo fresco light & 01 fatia grande & 2 \\
\hline Queijo parmesão & 01 colher de sopa & 2 \\
\hline Salgados fritos & 01 unidade média & 2 \\
\hline Salsichão & 01 fatia fina & 2 \\
\hline Sopas tipo creme & 01 concha & 2 \\
\hline Tomate seco & 01 colher de sopa & 2 \\
\hline
\end{tabular}

3 pontos

\begin{tabular}{|l|l|l|}
\hline \multicolumn{1}{|c|}{ Alimento } & \multicolumn{1}{|c|}{$\begin{array}{c}\text { ICS } \\
\text { por Porção }\end{array}$} \\
\hline Almônón & 3 \\
\hline Bacalhau ao forno & 01 unidade & 3 \\
\hline Carne moída refogada & 01 pires & 3 \\
\hline Esfiha de carne & 01 colher de sopa & 3 \\
\hline Ovo de codorna & 01 unidade & 3 \\
\hline Queijo mussarela & 01 unidade & 3 \\
\hline Requeijão light & 01 fatia pequena & 3 \\
\hline Sardinha & 01 colher de sopa & 3 \\
\hline Sopa de legumes c/ carne & 01 unidade & 3 \\
\hline Sashimi & 01 concha & 3 \\
\hline Sorvete com leite & 01 porção & 3 \\
\hline Vitamina de leite com frutas & 01 bola & 3 \\
\hline
\end{tabular}




\section{Lista de Pontos dos Alimentos}

4 pontos

\begin{tabular}{|l|l|l|}
\hline \multicolumn{2}{|c|}{ Alimento } & \multicolumn{1}{|c|}{$\begin{array}{l}\text { ICS } \\
\text { por Porção }\end{array}$} \\
\hline Bolo comum & 01 fatia & 4 \\
\hline Bolo diet & 01 fatia & 4 \\
\hline Carne seca & 01 colher de sopa & 4 \\
\hline Cream cheese light & 01 colher de sopa & 4 \\
\hline Frango refogado & 01 pedaço & 4 \\
\hline logurte com mel & 01 pote & 4 \\
\hline Manteiga & $1 / 2$ colher de sopa & 4 \\
\hline & 1 ponta de faca & 4 \\
\hline McFritas & 01 unidade média & 4 \\
\hline Nhoque c/molho & 01 colher de servir & 4 \\
\hline Pão de queijo & 01 unidade & 4 \\
\hline Queijo de minas & 01 fatia grande & 4 \\
\hline Queijo prato & 01 fatia pequena & 4 \\
\hline Queijo provolone & 01 fatia pequena & 4 \\
\hline Ricota & 01 fatia grande & 4 \\
\hline Salgados assados & 01 unidade média & 4 \\
\hline Torta de maçã ou banana & 01 unidade & 4 \\
\hline Yakisoba & 01 porção & 4 \\
\hline
\end{tabular}




\section{Lista de Pontos dos Alimentos}

5 pontos

\begin{tabular}{|c|c|c|}
\hline Alimento & Porção & por Porçấo \\
\hline Bucho & 1 porção & 5 \\
\hline Chantilly & 01 colher de sopa & 5 \\
\hline Carne assada/ de panela/cozida & 01 pedaço & 5 \\
\hline Creme de leite & 01 colher de sopa & 5 \\
\hline Esfiha de queijo & 01 unidade & 5 \\
\hline Frango (carne branca) grelh. & 01 filé pequeno & 5 \\
\hline Gordura vegetal hidrogenada & 01 colher de sopa & 5 \\
\hline McFritas & 01 unidade grande & 5 \\
\hline Moela & 01 pedaço & 5 \\
\hline Panqueca & 01 unidade & 5 \\
\hline Patê & 01 colher de sopa & 5 \\
\hline Peixe assado/cozido/grelhado & 01 filé pequeno & 5 \\
\hline Polenguinho & 01 unidade & 5 \\
\hline Porco (pernil) assado & 01 fatia & 5 \\
\hline Requeijão & 01 colher de sopa & 5 \\
\hline Salsicha cozida & 01 unidade & 5 \\
\hline Torta salgada & 01 fatia & 5 \\
\hline \multicolumn{3}{|c|}{6 pontos } \\
\hline Alimento & Porção & $\begin{array}{l}\text { ICS } \\
\text { por Porção }\end{array}$ \\
\hline Bolo de aniversário & 01 fatia & 6 \\
\hline Canelone & 01 unidade & 6 \\
\hline Catupiry & 01 colher de sopa & 6 \\
\hline Chocolate & 01 unidade pequena & 6 \\
\hline
\end{tabular}




\section{Lista de Pontos dos Alimentos}

6 pontos

\begin{tabular}{|l|l|l|}
\hline \multicolumn{1}{|c|}{ Alimento } & \multicolumn{1}{|c|}{$\begin{array}{c}\text { ICS } \\
\text { por Porção }\end{array}$} \\
\hline Chocolate diet & 01 unidade pequena & 6 \\
\hline Coalhada & 01 copo & 6 \\
\hline Hambúrguer & 01 unidade & 6 \\
\hline logurte natural & 01 pote & 6 \\
\hline Leite em pó integral & 02 colheres de sopa & 6 \\
\hline Leite tipo B & 01 copo de requeijão & 6 \\
\hline Milk shake & 01 unidade pequena & 6 \\
\hline Pastel & 01 unidade & 6 \\
\hline Pizza & 01 pedaço & 6 \\
\hline Porco (lombo) assado & 01 fatia & 6 \\
\hline Quibe frito & 01 unidade & 6 \\
\hline Quindim & 01 unidade & 6 \\
\hline Sonho & 01 unidade & 6 \\
\hline
\end{tabular}

7 pontos

\begin{tabular}{|lll} 
Alimento & ICS \\
por Porção
\end{tabular}

\begin{tabular}{|l|l|l|}
\hline Bacon & 01 fatia fina & 7 \\
\hline Banha de porco & 01 colher de sopa & 7 \\
\hline Cocada & 01 unidade & 7 \\
\hline Cream cheese & 01 colher de sopa & 7 \\
\hline Feijoada & 01 concha & 7 \\
\hline Lingüiça & 01 gomo & 7 \\
\hline Panetone & 01 fatia & 7 \\
\hline Peixe frito & 01 filé pequeno & 7 \\
\hline
\end{tabular}




\section{Lista de Pontos dos Alimentos}

8 pontos

\begin{tabular}{|l|l|c|}
\hline \multicolumn{1}{|c|}{ Alimento } & \multicolumn{1}{c|}{$\begin{array}{c}\text { PCs } \\
\text { porção }\end{array}$} \\
\hline Chouriçóo & 01 porção \\
\hline Capelete & 01 colher de servir & 8 \\
\hline Frango frito & 01 pedaço & 8 \\
\hline McChicken & 01 unidade & 8 \\
\hline Ravióli & 01 colher de servir & 8 \\
\hline Rondelli & 01 pedaço & 8 \\
\hline Strogonoff & 1 concha & 8 \\
\hline Suflês & 01 fatia & 8 \\
\hline
\end{tabular}

9 pontos

\begin{tabular}{|l|l|l|}
\hline \multicolumn{1}{|c|}{ Alimento } & \multicolumn{1}{|c|}{$\begin{array}{c}\text { ICs } \\
\text { por }\end{array}$ Porçãóa } \\
\hline Carne de vaca (magra) grelh. & 01 bife pequeno & 9 \\
\hline Frango à milanesa & 01 filé & 9 \\
\hline Músculo & 01 porção & 9 \\
\hline Salgadinhos chips & 01 pacote & 9 \\
\hline Torresmo & 01 unidade & 9 \\
\hline Tortas doces & 01 fatia & 9 \\
\hline Toucinho defumado & 01 fatia fina & 9 \\
\hline
\end{tabular}




\section{Lista de Pontos dos Alimentos}

11 pontos

\begin{tabular}{|l|l|l|}
\hline \multicolumn{1}{|c|}{ Alimento } & \multicolumn{1}{|c|}{ Porção } \\
\cline { 1 - 2 } & $\begin{array}{l}\text { ICS } \\
\text { por }\end{array}$ Porção \\
\hline Camarão refogado & 01 pires & 11 \\
\hline Lasanha & 01 pedaço & 11 \\
\hline Ovo cozido (gema) & 01 unidade & 11 \\
\hline Ovo cozido (inteiro) & 01 unidade & 11 \\
\hline Peru & 01 porção & 11 \\
\hline Pudim & 01 fatia & 11 \\
\hline
\end{tabular}

12 pontos

\begin{tabular}{|l|l|c|}
\hline \multicolumn{1}{|c|}{ Alimento } & \multicolumn{1}{|c|}{ Porção } \\
\cline { 1 - 2 } & $\begin{array}{l}\text { ICs } \\
\text { por Porção }\end{array}$ \\
\hline Bife & 01 bife & 12 \\
\hline Bisteca de porco & 01 bife & 12 \\
\hline Camarão frito & 10 unidades grandes & 12 \\
\hline Lagosta cozida & 01 unidade & 12 \\
\hline Lula frita & 01 pires & 12 \\
\hline Ovo frito & 01 unidade & 12 \\
\hline Peixe empanado & 01 filé pequeno & 12 \\
\hline
\end{tabular}

14 pontos

\begin{tabular}{|l|l|c|}
\hline \multicolumn{1}{|c|}{ Alimento } & \multicolumn{1}{|c|}{$\begin{array}{c}\text { PCorção } \\
\text { por Porção }\end{array}$} \\
\hline Carne de vaca (gorda) grelh. & 01 bife & 14 \\
\hline Pavê & 01 pedaço & 14 \\
\hline
\end{tabular}




\section{Lista de Pontos dos Alimentos}

15 pontos

\begin{tabular}{|l|l|c|}
\hline \multicolumn{1}{|c|}{ Alimento } & \multicolumn{1}{|c|}{$\begin{array}{c}\text { ICS } \\
\text { por Porção }\end{array}$} \\
\hline BigMac & 01 unidade & 15 \\
\hline Omelete simples & 01 un. - 1 ovo & 15 \\
\hline
\end{tabular}

18 pontos

\begin{tabular}{|l|l|c|}
\hline \multicolumn{1}{|c|}{ Alimento } & \multicolumn{1}{|c|}{$\begin{array}{c}\text { ICS } \\
\text { por Porçãăo }\end{array}$} \\
\hline Bife à milanesa & 01 bife & 18 \\
\hline Omelete com queijo & 01 un. - 1 ovo & 18 \\
\hline
\end{tabular}

20 pontos ou mais

\begin{tabular}{|l|l|c|}
\hline \multicolumn{1}{|c|}{ Alimento } & \multicolumn{1}{|c|}{$\begin{array}{c}\text { Porção } \\
\text { por }\end{array}$ Porção } \\
\hline Rim & 01 porção & 21 \\
\hline Vísceras & 01 porção & 21 \\
\hline Bife à parmegiana & 01 bife & 22 \\
\hline Fígado (bovino) grelh. & 01 bife pequeno & 26 \\
\hline
\end{tabular}




\section{Modelo}

\section{ANOTE SEUS PONTOS}

PERÍODO: 01 DIA

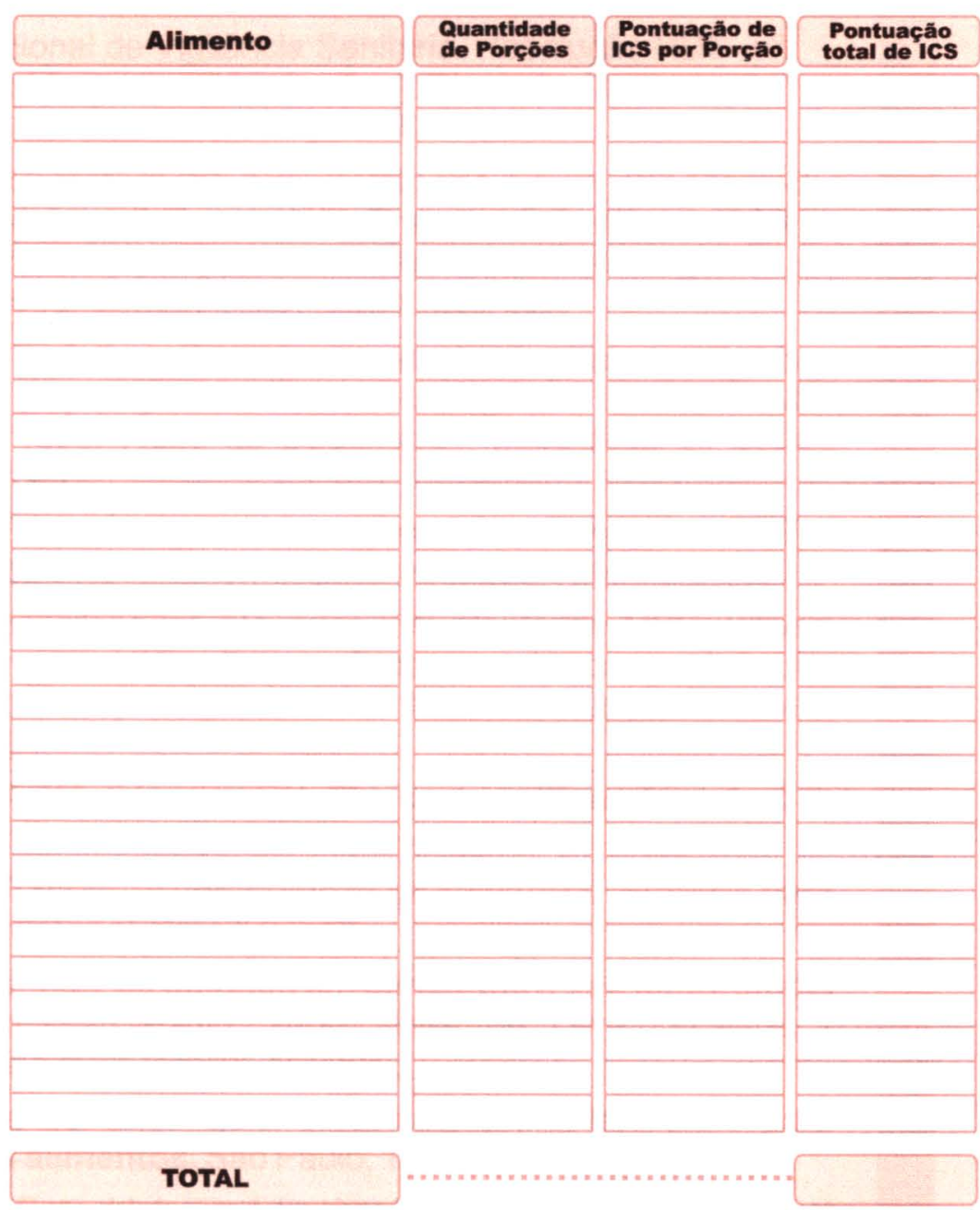

Não esqueça que não se deve ultrapassar os valores de ICS encontrados na tabela 1. Boa sorte!!!!! 


\section{Referências Bibliográficas}

American Heart Association, 2000 [on line]. Available from http://www.americanheartassociation.com [2002 jun 08].

Agência Nacional de Vigilância Sanitária. Resolução RDC- $n^{\circ}$ 39, de 21 de Março de 2001 [on line]. Disponível em http://www.anvisa.gov.br [2002 jun 10].

Connor SL, Gustafson JR, Artaud-Wild SM, Favell, DP, ClassickKohn CJ, Hatcher LF, Connor WE. The cholesterol/satured-fat index: an indication of hipercolesterolaemic and atherogenic potential of food. Lancet 1986; (May):1229-32.

Fornés, NS. Padrões alimentares e suas relações com lipídios séricos em população da área metrolopitana de São Paulo. São Paulo; 1998. [Tese de Doutorado - Faculdade de Saúde Pública da USP].

Fundação IBGE. Pesquisa de orçamentos familiares 1987 e 1996. [on line]. Disponível em http://www.ibge.gov.br/sidra. [2001]

Lajolo FM, coordenador, Menezes EW, Penteado MVC, Filisetti TMCC, Marquez UML. Tabela Brasileira de composição de alimentos [on line]. Disponível em http://www.usp.br/fcf/tabela [2002 jun 20].

McCance RA, Winddowson EM. The composition of foods. 5 th ed. Portland: Book News; 1991.

Philippi, ST. Tabela de composição de alimentos Suporte para decisão nutricional. Brasília; 2001.

Torres EAFS. Teor de lipídeos em alimentos e sua importância na nutrição. São Paulo; 2000. [Tese de Livre Docência Faculdade de Saúde Pública da USP].

Universidade de São Paulo. Pirâmide alimentar: Guia para escolha dos alimentos. São Paulo; 1999.

Willett WC. Eat, drink, and be healthy. The Harvard Medical School Guide to Healthy Eating. New York; 2001

World Health Organization. Obesity: preventing and managing the global epidemic. Report. Geneva; 1998. 


\title{
HÁBITOS ALIMENTARES MAIS SAUDÁVEIS VÃO TRAZER GRANDES \\ BENEFÍcIOS PARA A SUA SAÚdE
}

\author{
Elaboração: \\ Edeli Simioni de Abreu \\ Márcia A. L. Nacif \\ Profa. Assoc. Elizabeth A. F. S. Torres \\ Diagramação: \\ Osvaldo Salmazo Jr.
}

\begin{abstract}
Apoio:
CAPES

CNPq

FAPESP
\end{abstract}

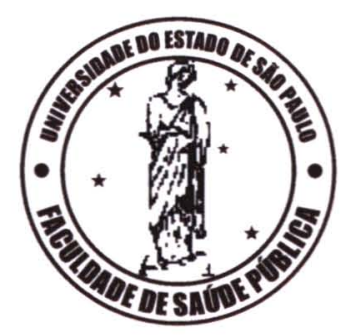

Universidade de São Paulo

Faculdade de Saúde Pública

Departamento de Nutrição 


\subsection{Estudo piloto}

Dos 90 pacientes recrutados a participar do estudo, 62 puderam ser acompanhados até a obtenção dos resultados, no período de Maio a Dezembro de 2002. Os 28 pacientes que foram perdidos da amostra inicial durante esse período, não fizeram parte do protocolo de pesquisa por não terem conseguido agendar o retorno no tempo estipulado de três meses, pelo volume de atendimentos no ambulatório de endocrinologia da FM-FuABC, ou por abandonar do tratamento.

Quanto aos 62 pacientes que fizeram parte desse estudo de desenho experimental, 32 constituiram o Grupo Controle e 30 compuseram o Grupo Estudo.

\subsubsection{Caracterização da população e dos Grupos Controle e Estudo}

De acordo com as variáveis sócio-demográficas, a população de estudo apresentou predominância de individuos do sexo feminino $(66,1 \%)$, com idade média de 53,77 anos (DP $=10,69$ anos), sendo a maioria da raça branca $(54,8 \%)$, casada $(56,5 \%)$, aposentados ou pensionistas $(32,3 \%)$ e com nivel de escolaridade de até 4 anos de estudo (64,5\%). Esses dados são demonstrados a seguir, de acordo com o grupo de intervenção - Grupo Controle e Grupo Estudo, nos quais a mesma tendência se manteve.

A caracterização dos individuos nos Grupos, segundo as variáveis sóciodemográficas investigadas foram descritas por meio de tabela de contingência e 
sua distribuição estudada em relação ao Grupo de origem, na Tabela 2. A idade está descrita por meio de algumas medidas-resumo na Tabela 3, como se segue:

Tabela 2: Características sócio-demográficas dos individuos hiperlipidêmicos, segundo Grupo. Ambulatório de endocrinologia da FM-FuABC, Santo André, 2002.

\begin{tabular}{|c|c|c|c|c|c|c|c|}
\hline \multirow[t]{3}{*}{ Variáveis } & \multicolumn{4}{|c|}{ Grupo } & \multirow{2}{*}{\multicolumn{2}{|c|}{$\begin{array}{c}\text { Total }^{\star *} \\
\left(N^{\star}=62\right)\end{array}$}} & \multirow{3}{*}{$\begin{array}{c}\text { Nivel } \\
\text { descritivo } \\
\text { (p) }\end{array}$} \\
\hline & \multicolumn{2}{|c|}{$\begin{array}{c}\text { Controle } \\
\left(N^{*}=32\right)\end{array}$} & \multicolumn{2}{|c|}{$\begin{array}{l}\text { Estudo } \\
\left(N^{*}=30\right)\end{array}$} & & & \\
\hline & $\mathbf{N}^{*}$ & $\%$ & $\mathbf{N}^{*}$ & $\%$ & $\mathbf{N}^{*}$ & $\%$ & \\
\hline Sexo & & & & & & & 0,931 \\
\hline Masculino & 11 & 34,4 & 10 & 33,3 & 21 & 33,9 & \\
\hline Feminino & 21 & 65,6 & 20 & 66,7 & 41 & 66,1 & \\
\hline Raça & & & & & & & 0,799 \\
\hline Branca & 16 & 50,0 & 18 & 60,0 & 34 & 54,8 & \\
\hline Não Branca & 15 & 50,0 & 12 & 40,0 & 28 & 45,2 & \\
\hline Estado civil & & & & & & & 0,559 \\
\hline Casado & 19 & 59,4 & 16 & 53,3 & 35 & 56,5 & \\
\hline Solteiro & 1 & 3,1 & 4 & 13,3 & 5 & 8,1 & \\
\hline Viúvo & 7 & 21,9 & 7 & 23,3 & 14 & 22,6 & \\
\hline Separado & 5 & 16,6 & 3 & 10,0 & 8 & 12,9 & \\
\hline Ocupação & & & & & & & 0,402 \\
\hline Aposentado/Pensionista & 12 & 37,5 & 8 & 26,7 & 20 & 32,3 & \\
\hline Pedreiro/Pintor/Encanador & 3 & 9,4 & 7 & 23,3 & 10 & 16,1 & \\
\hline Prendas Domésticas & 10 & 31,3 & 7 & 23,3 & 17 & 27,4 & \\
\hline Outros & 7 & 21,9 & 8 & 26,7 & 15 & 24,2 & \\
\hline $\begin{array}{l}\text { Escolaridade (anos de } \\
\text { estudo) }\end{array}$ & & & & & & & 0,061 \\
\hline $1-4$ & 24 & 75,0 & 16 & 53,3 & 40 & 64,5 & \\
\hline $5-8$ & 8 & 25,0 & 10 & 33,3 & 18 & 29,0 & \\
\hline $9-11$ & - & - & 4 & 13,3 & 4 & 6,5 & \\
\hline
\end{tabular}

*Número de indivíduos

*Todos os grupos 
Tabela 3: Distribuicão da média e desvio-padrão dos individuos hiperlipidêmicos, segundo Idade e Grupo. Ambulatório de endocrinologia da FM-FuABC, Santo André, 2002.

\begin{tabular}{|c|c|c|c|c|}
\hline \multirow[t]{2}{*}{ Variável } & \multicolumn{2}{|c|}{ Grupo } & \multirow{2}{*}{$\begin{array}{l}\text { Total }^{* *} \\
\left(N^{*}=62\right)\end{array}$} & \multirow{2}{*}{$\begin{array}{c}\text { Nivel } \\
\text { descritivo } \\
\text { (p) }\end{array}$} \\
\hline & $\begin{array}{c}\text { Controle } \\
\left(N^{*}=32\right)\end{array}$ & $\begin{array}{l}\text { Estudo } \\
\left(\mathbf{N}^{*}=30\right)\end{array}$ & & \\
\hline Idade (anos) & & & & 0,086 \\
\hline Média & 56,03 & 51,37 & 53,77 & \\
\hline Desvio-padrão & 10,58 & 10,45 & 10,69 & \\
\hline Mínimo & 36,00 & 23,00 & 23,00 & \\
\hline Máximo & 76,00 & 72,00 & 76,00 & \\
\hline
\end{tabular}

*Número de indivíduos

**Todos os grupos

Com referência às variáveis diagnósticas, no início da pesquisa, antes das medidas de intervenção dietética, a média de peso foi de $75,57 \mathrm{~kg}(\mathrm{DP}=12,27 \mathrm{~kg})$, de altura foi de $160,67 \mathrm{~cm}(D P=8,31 \mathrm{~cm}), I M C$ de $29,22 \mathrm{~kg} / \mathrm{m}^{2}\left(D P=4,01 \mathrm{~kg} / \mathrm{m}^{2}\right)$, circunferência abdominal de $96,10 \mathrm{~cm}(D P=9,17 \mathrm{~cm}), C T$ de $274,75 \mathrm{mg} / \mathrm{dl}$ (DP = $54,84 \mathrm{mg} / \mathrm{dl}), \mathrm{HDL}$ de $50,02 \mathrm{mg} / \mathrm{dl}(\mathrm{DP}=13,73 \mathrm{mg} / \mathrm{dl}), \mathrm{LDL}$ de $183,61 \mathrm{mg} / \mathrm{dl}(\mathrm{DP}=$ $52,45 \mathrm{mg} / \mathrm{dl}), \mathrm{VLDL}$ de $41,06 \mathrm{mg} / \mathrm{dl}(\mathrm{DP}=20,43 \mathrm{mg} / \mathrm{dl})$, triglicérides de 203,07 $\mathrm{mg} / \mathrm{dl}$ $(D P=101,86 \mathrm{mg} / \mathrm{dl})$. Nenhum dos participantes da pesquisa referiu praticar atividade fisica, a comorbidade mais comum foi a hipertensão arterial (apresentada por $40,3 \%$ da população) e os medicamentos mais utilizados foram os antihipertensivos (37,1\% da população estudada fazia uso desse tipo de medicação).

A caracterização dos individuos nos Grupos, segundo altura, está descrita por meio de algumas medidas-resumo na Tabela 4, como se segue: 
Tabela 4: Distribuição da média e desvio-padrão dos indivíduos hiperlipidêmicos, segundo Altura e Grupo. Ambulatório de endocrinologia da FM-FuABC, Santo André, 2002.

\begin{tabular}{|c|c|c|c|c|}
\hline \multirow[t]{2}{*}{ Variável } & \multicolumn{2}{|c|}{ Grupo } & \multirow{2}{*}{$\begin{array}{c}\text { Total }^{* *} \\
\left(N^{*}=62\right)\end{array}$} & \multirow{2}{*}{$\begin{array}{c}\text { Nível } \\
\text { descritivo } \\
\text { (p) }\end{array}$} \\
\hline & $\begin{array}{c}\text { Controle } \\
\left(N^{*}=32\right)\end{array}$ & $\begin{array}{l}\text { Estudo } \\
\left(N^{*}=30\right) \\
\end{array}$ & & \\
\hline Altura (cm) & & & & 0,326 \\
\hline Média & 159,66 & 161,75 & 160,67 & \\
\hline Desvio-padrão & 7,76 & 8,88 & 8,31 & \\
\hline Mínimo & 141,00 & 145,00 & 141,00 & \\
\hline Máximo & 174,00 & 178,00 & 178,00 & \\
\hline
\end{tabular}

*Número de indivíduos

*Todos os grupos

As medidas antropométricas e as avaliações bioquímicas dos individuos nos Grupos, observadas no início e ao término da pesquisa, após o estudo de intervenção, estão descritas pelo método de medidas-resumo a seguir, na Tabela 5 , na qual são mostrados esses resultados, referentes ao peso, IMC, circunferência abdominal, CT, HDL, LDL, VLDL e triglicérides. 
Tabela 5: Distribuicão da média e desvio-padrão dos indivíduos hiperlipidêmicos, segundo as variáveis diagnósticas e Grupo. Ambulatório de endocrinologia da FM-FuABC, Santo André, 2002.

\begin{tabular}{|c|c|c|c|c|c|c|c|}
\hline \multirow[t]{3}{*}{ Variáveis } & \multicolumn{4}{|c|}{ Grupo } & \multirow{2}{*}{\multicolumn{2}{|c|}{$\begin{array}{l}\text { Total } \\
\left(N^{\star}=62\right)\end{array}$}} & \multirow{3}{*}{$\begin{array}{c}\text { Nivel } \\
\text { descritivo } \\
\text { (p) }\end{array}$} \\
\hline & \multicolumn{2}{|c|}{$\begin{array}{c}\text { Controle } \\
\left(N^{*}=32\right)\end{array}$} & \multicolumn{2}{|c|}{$\begin{array}{l}\text { Estudo } \\
\left(N^{*}=30\right)\end{array}$} & & & \\
\hline & Inicial & Final & Inicial & Final & Inicial & Final & \\
\hline Peso (kg) & & & & & & & 0,047 \\
\hline Média & 72,59 & 70,46 & 78,76 & 75,32 & 75,57 & 72,81 & \\
\hline Desvio-padrão & 11,76 & 11,59 & 12,18 & 11,80 & 12,27 & 11,85 & \\
\hline Mínimo & 46,40 & 43,20 & 46,40 & 46,00 & 46,40 & 43,20 & \\
\hline Máximo & 95,00 & 93,00 & 99,80 & 96,70 & 99,80 & 96,70 & \\
\hline IMC & & & & & & & 0,121 \\
\hline Média & 28,46 & 27,64 & 30,04 & 28,71 & 29,22 & 28,16 & \\
\hline Desvio-padrão & 4,38 & 4,30 & 3,46 & 3,26 & 4,01 & 3,84 & \\
\hline Mínimo & 20,90 & 19,46 & 20,90 & 20,72 & 20,90 & 19,46 & \\
\hline Máximo & 42,79 & 41,89 & 35,12 & 32,98 & 42,79 & 41,89 & \\
\hline Circunferência abdominal & & & & & & & 0,007 \\
\hline Média & 93,12 & 92,05 & 99,29 & 96,99 & 96,10 & 94,44 & \\
\hline Desvio-padrão & 8,80 & 8,50 & 8,59 & 8,19 & 9,17 & 8,65 & \\
\hline Mínimo & 71,80 & 71,30 & 78,30 & 78,10 & 71,80 & 71,30 & \\
\hline Máximo & 110,40 & 108,20 & 115,30 & 110,40 & 115,30 & 110,40 & \\
\hline Colesterol Total (mg/dL) & & & & & & & 0,873 \\
\hline Média & 273,65 & 243,72 & 275,91 & 223,73 & 274,75 & 234,05 & \\
\hline Desvio-padrão & 45,50 & 45,05 & 64,11 & 52,69 & 54,84 & 49,52 & \\
\hline Minimo & 202,00 & 151,00 & 210,00 & 157,80 & 202,00 & 151,00 & \\
\hline Máximo & 397,00 & 348,00 & 531,00 & 445,20 & 531,00 & 445,20 & \\
\hline HDL (mg/dL) & & & & & & & 0,735 \\
\hline Média & 49,44 & 49,22 & 50,63 & 48,01 & 50,02 & 48,63 & \\
\hline Desvio-padrão & 13,32 & 13,52 & 14,36 & 13,16 & 13,73 & 13,25 & \\
\hline Mínimo & 24,00 & 25,00 & 30,00 & 25,00 & 24,00 & 25,00 & \\
\hline Máximo & 78,00 & 75,00 & 78,00 & 79,00 & 78,00 & 79,00 & \\
\hline LDL (mg/dL) & & & & & & & 0,478 \\
\hline Média & 178,99 & 154,43 & 188,54 & 145,27 & 183,61 & 150,00 & \\
\hline Desvio-padrão & 40,08 & 38,33 & 63,41 & 49,82 & 52,45 & 44,14 & \\
\hline Mínimo & 87,00 & 68,00 & 126,80 & 100,00 & 87,00 & 68,00 & \\
\hline Máximo & 295,20 & 250,00 & 457,00 & 363,80 & 457,00 & 363,80 & \\
\hline VLDL (mg/dL) & & & & & & & 0,093 \\
\hline Média & 45,28 & 41,63 & 36,56 & 30,51 & 41,06 & 36,25 & \\
\hline Desvio-padrão & 20,16 & 19,73 & 20,06 & 12,68 & 20,43 & 17,48 & \\
\hline Mínimo & 18,40 & 16,80 & 14,00 & 13,40 & 14,00 & 13,40 & \\
\hline Máximo & 98,80 & 98,00 & 104,60 & 74,60 & 104,60 & 98,00 & \\
\hline Triglicérides (mg/dL) & & & & & & & 0,064 \\
\hline Média & 226,20 & 205,10 & 178,40 & 152,53 & 203,07 & 179,66 & \\
\hline Desvio-padrāo & 100,83 & 97,34 & 98,67 & 63,17 & 101,86 & 86.11 & \\
\hline Mínimo & 97,00 & 84,00 & 72,00 & 67,00 & 72,00 & 67,00 & \\
\hline Máximo & 494,00 & 490,00 & 523,00 & 373,00 & 523,00 & 490,00 & \\
\hline
\end{tabular}

*Número de indivíduos

**Todos os grupos 
Os individuos foram ainda investigados a respeito de outras informações descritas nas tabelas de contingência, que pode ser a seguir. Em cada uma dessas variáveis, foi estudada a sua distribuição em relação ao Grupo de origem.

A Tabelas 6 demonstra os resultados dos dados referentes a comorbidades apresentadas pelos pacientes de ambos os Grupos de intervenção.

Tabela 6: Distribuição dos individuos hiperlipidêmicos, segundo a presença comorbidades e Grupo. Ambulatório de endocrinologia da FMFuABC, Santo André, 2002.

\begin{tabular}{|c|c|c|c|c|c|c|c|}
\hline \multirow[t]{3}{*}{ Variáveis } & \multicolumn{4}{|c|}{ Grupo } & \multirow{2}{*}{\multicolumn{2}{|c|}{$\begin{array}{l}\text { Total }{ }^{* *} \\
\left(N^{*}=62\right)\end{array}$}} & \multirow{3}{*}{$\begin{array}{c}\text { Nivel } \\
\text { descritivo } \\
\text { (p) }\end{array}$} \\
\hline & \multicolumn{2}{|c|}{$\begin{array}{c}\text { Controle } \\
\left(N^{*}=32\right)\end{array}$} & \multicolumn{2}{|c|}{$\begin{array}{l}\text { Estudo } \\
\left(N^{*}=30\right)\end{array}$} & & & \\
\hline & $\mathbf{N}^{*}$ & $\%$ & $\mathbf{N}^{*}$ & $\%$ & $\mathbf{N}^{*}$ & $\%$ & \\
\hline Hipertensão arterial & & & & & & & 0,570 \\
\hline Não & 18 & 56,3 & 19 & 63,3 & 37 & 59,7 & \\
\hline Sim & 14 & 43,8 & 11 & 36,7 & 25 & 40,3 & \\
\hline Diabetes mellitus tipo 2 & & & & & & & 0,728 \\
\hline Não & 28 & 87,5 & 25 & 83,3 & 53 & 85,5 & \\
\hline Sim & 4 & 12,5 & 5 & 16,7 & 9 & 14,5 & \\
\hline Resistência à insulina & & & & & & & 0,258 \\
\hline Não & 26 & 81,3 & 28 & 93,3 & 54 & 87,1 & \\
\hline Sim & 6 & 18,8 & 2 & 6,7 & 8 & 12,9 & \\
\hline Outras comorbidades & & & & & & & 0,101 \\
\hline Não & 27 & 84,4 & 20 & 66,7 & 47 & 75,8 & \\
\hline Sim & 5 & 15,6 & 10 & 33,3 & 15 & 24,2 & \\
\hline
\end{tabular}

Número de indivíduos

**Todos os grupos

$\mathrm{Na}$ Tabela 7 são indicados os resultados dos dados referentes ao uso de medicação pelos pacientes dos Grupos Controle e Estudo. 
Tabela 7: Distribuicão dos individuos hiperlipidêmicos, segundo o uso de medicamentos e Grupo. Ambulatório de endocrinologia da FMFuABC, Santo André, 2002.

\begin{tabular}{|c|c|c|c|c|c|c|c|}
\hline \multirow[t]{3}{*}{ Variáveis } & \multicolumn{4}{|c|}{ Grupo } & \multirow{2}{*}{\multicolumn{2}{|c|}{$\begin{array}{l}\text { Total }{ }^{* *} \\
\left(N^{*}=62\right)\end{array}$}} & \multirow{3}{*}{$\begin{array}{c}\text { Nivel } \\
\text { descritivo } \\
\text { (p) }\end{array}$} \\
\hline & \multicolumn{2}{|c|}{$\begin{array}{l}\text { Controle } \\
\left(N^{*}=32\right)\end{array}$} & \multicolumn{2}{|c|}{$\begin{array}{l}\text { Estudo } \\
\left(N^{*}=30\right)\end{array}$} & & & \\
\hline & $\mathbf{N}^{*}$ & $\%$ & $\mathbf{N}^{*}$ & $\%$ & $\mathbf{N}^{\star}$ & $\%$ & \\
\hline $\begin{array}{l}\text { Uso de medicamentos } \\
\text { anti-hipertensivos }\end{array}$ & & & & & & & 0,946 \\
\hline Não & 20 & 62,5 & 19 & 63,3 & 39 & 62,9 & \\
\hline Sim & 12 & 37,5 & 11 & 36,7 & 23 & 37,1 & \\
\hline Uso de Metiformina & & & & & & & 0,230 \\
\hline Não & 32 & 100,0 & 28 & 93,3 & 60 & 96,8 & \\
\hline Sim & - & - & 2 & 6,7 & 2 & 3,2 & \\
\hline Uso de Glibenclamida & & & & & & & 0,999 \\
\hline Não & 30 & 93,8 & 29 & 96,7 & 59 & 95,2 & \\
\hline Sim & 2 & 6,3 & 1 & 3,3 & 3 & 4,8 & \\
\hline $\begin{array}{l}\text { Uso de outros } \\
\text { medicamentos }\end{array}$ & & & & & & & 0,173 \\
\hline Não & 27 & 84,4 & 24 & 80,0 & 51 & 82,3 & \\
\hline Sim & 5 & 15,6 & 6 & 20,0 & 11 & 17,7 & \\
\hline
\end{tabular}

"Número de individuos

"Todos os grupos

Como já foi citado anteriormente, nenhum dos participantes da pesquisa referiu, na primeira consulta, praticar atividade física. Após a orientação realizada no início do tratamento, no Grupo Estudo, 24 indivíduos $(80,0 \%)$ referiram adesão à atividade física, o que foi referido por 18 pacientes $(56,3 \%)$, no Grupo Controle $(p=0,046)$.

\subsubsection{Análise do perfil dos individuos dos Grupos Controle e Estudo}

Em decorrência à fase descritiva preliminar, procedeu-se à avaliação do perfil dos indivíduos de ambos os Grupos em relação às grandezas observadas, 
para se verificar se a distribuição desses indivíduos apresentava diferença estatisticamente significante nos Grupo Controle e Estudo.

Com relação às variáveis de natureza categórica, após a aplicação dos respectivos testes estatísticos, encontraram-se os resultados que vêm demonstrados na Tabela 8, a seguir:

Tabela 8: Resultados inferenciais dos testes entre as comparacōes dos Grupos e demais variáveis. Ambulatório de endocrinologia da FM-FuABC, Santo André, 2002.

\begin{tabular}{lclc}
\hline \multicolumn{1}{c}{ Variáveis comparadas } & $\begin{array}{c}\text { Nivel } \\
\text { descritivo } \\
(\mathbf{p})\end{array}$ & \multicolumn{1}{c}{ Teste utilizado } & $\begin{array}{c}\text { Poder } \\
\text { do } \\
\text { Teste }\end{array}$ \\
\hline Escolaridade e Grupo & 0,061 & Extensão do teste exato de Fisher & 0,551 \\
Sexo e Grupo & 0,931 & Qui-quadrado de Pearson & 0,050 \\
Ocupação e Grupo & 0,402 & Qui-quadrado de Pearson & 0,275 \\
Estado civil e Grupo & 0,559 & Extensão do teste exato de Fisher & 0,231 \\
Raça e Grupo & 0,799 & Extensão do teste exato de Fisher & 0,159 \\
Hipertensão arterial e Grupo & 0,570 & Qui-quadrado de Pearson & 0,085 \\
$\begin{array}{l}\text { Diabetes mellitus e Grupo } \\
\text { Resistência à insulina e }\end{array}$ & 0,728 & Teste exato de Fisher & 0,075 \\
Grupo & 0,258 & Teste exato de Fisher & 0,294 \\
$\begin{array}{l}\text { Outras comorbidades e Grupo } \\
\text { Medicamentos anti- }\end{array}$ & 0,101 & Extensão do teste exato de Fisher & 0,551 \\
hipertensivos e Grupo & 0,946 & Qui-quadrado de Pearson & 0,50 \\
$\begin{array}{l}\text { Uso de Metiformina e Grupo } \\
\text { Uso de Glibenclamida e }\end{array}$ & 0,230 & Teste exato de Fisher & 0,322 \\
Grupo & $>0,999$ & Teste exato de Fisher & 0,083 \\
$\begin{array}{l}\text { Uso de outros medicamentos } \\
\text { e Grupo }\end{array}$ & 0,173 & Extensão do teste exato de Fisher & 0,449 \\
\hline
\end{tabular}

Quanto às variáveis acima mencionadas, não foram detectadas diferenças estatisticamente significantes entre os Grupos, conforme pode-se notar resumidamente nos resultados apresentados na Tabela 8. 
Para as variáveis de natureza numérica, após a aplicação do teste de Análise de variância, chegou-se aos resultados que podem ser observados na Tabela 9.

Tabela 9: Resultados inferenciais dos testes entre os Grupos, segundo as medidas observadas no início da pesquisa. Ambulatório de endocrinologia da FM-FUABC, 2002.

\begin{tabular}{ccc}
\hline Variável & Nivel descritivo & Conclusão \\
\hline Idade & 0,086 & Grupo Controle $=$ Grupo Estudo \\
Peso & 0,047 & Grupo Controle $<$ Grupo Estudo \\
IMC & 0,121 & Grupo Controle $=$ Grupo Estudo \\
Circunferência abdominal & 0,007 & Grupo Controle $<$ Grupo Estudo \\
Colesterol total & 0,873 & Grupo Controle $=$ Grupo Estudo \\
HDL & 0,735 & Grupo Controle $=$ Grupo Estudo \\
LDL & 0,478 & Grupo Controle $=$ Grupo Estudo \\
VLDL & 0,093 & Grupo Controle $=$ Grupo Estudo \\
Triglicérides & 0,064 & Grupo Controle $=$ Grupo Estudo \\
\hline
\end{tabular}

O estudo do perfil dos individuos segundo Grupo e Idade, Altura, Peso, IMC, Circunferência abdominal, Colesterol total, HDL, LDL, VLDL e Triglicérides, feito por meio da Análise de variância, revelou que os individuos do Grupo Controle apresentaram medidas de Peso e de Circunferência abdominal superiores aos indivíduos do Grupo Estudo. Com relação às demais variáveis, não foram encontradas medidas com diferença estatisticamente significante entre os Grupos, conforme pode-se observar de maneira resumida na Tabela 9.

Com o objetivo de ajustar a diferença estatisticamente significante encontrada nos resultados das análises preliminares que revelaram valor médio de Peso e Circunferência abdominal diferentes entre os Grupos no inicio da pesquisa, 
optou-se, em avaliar o desempenho dos indivíduos em ambos os Grupos, pela quantificação da redução das medidas observadas, cuja fórmula foi apresentada no item 3.6, no capítulo de método.

\subsubsection{Análise do desempenho dos Grupos mediante a intervenção}

São apresentadas a seguir algumas medidas-resumo das Reduções do Peso, IMC, Circunferência abdominal, Colesterol total, HDL, LDL, VLDL e Triglicérides, observados dos indivíduos em cada Grupo, após o estudo de intervenção a que foram expostos.

A Tabela 10 mostra esses resultados. 
Tabela 10: Redução percentual das variáveis diagnósticas dos individuos hiperlipidêmicos, segundo Grupo. Ambulatório de endocrinologia da FM-FuABC, Santo André, 2002.

\begin{tabular}{|c|c|c|c|c|c|}
\hline \multirow[t]{2}{*}{ Variáveis } & \multicolumn{2}{|c|}{ Grupo } & \multirow[b]{2}{*}{$\begin{array}{c}\text { Total }^{* *} \\
\left(N^{*}=62\right) \\
\text { Reduçāo } \\
(\%)\end{array}$} & \multirow[b]{2}{*}{$\begin{array}{c}\text { Nivel } \\
\text { descritivo } \\
\text { (p) }\end{array}$} & \multirow{2}{*}{$\begin{array}{c}\text { Relação } \\
\text { percentual } \\
\text { da } \\
\text { variação } \\
\text { de } \\
\text { reducão } \\
\end{array}$} \\
\hline & $\begin{array}{c}\text { Controle } \\
\left(N^{*}=32\right) \\
\text { Redução } \\
(\%)\end{array}$ & $\begin{array}{c}\text { Estudo } \\
\left(\mathrm{N}^{*}=30\right) \\
\text { Redução } \\
(\%)\end{array}$ & & & \\
\hline Peso (kg) & & & & 0,048 & \\
\hline Média & 2,94 & 4,33 & 3,61 & & $47,3 \%$ \\
\hline Minimo & $-4,94$ & 0,86 & $-4,94$ & & $>$ para 0 \\
\hline Máximo & 7,59 & 8,73 & 8,73 & & Grupo Estudo \\
\hline IMC & & & & 0,026 & \\
\hline Média & 2,86 & 4,37 & 3,59 & & $52,8 \%$ \\
\hline Mínimo & $-3,90$ & 0,86 & $-3,90$ & & $>$ para o \\
\hline Máximo & 6,89 & 9,68 & 9,68 & & Grupo Estudo \\
\hline Circunferência abdominal & & & & $<0,001$ & \\
\hline Média & 1,12 & 2,29 & 1,68 & & $104,5 \%$ \\
\hline Mínimo & $-1,06$ & 0,26 & $-1,06$ & & $>$ para 0 \\
\hline Máximo & 3,26 & 4,72 & 4,72 & & Grupo Estudo \\
\hline Colesterol Total (mg/dL) & & & & 0,002 & \\
\hline Média & 10,60 & 18,51 & 14,43 & & $74,6 \%$ \\
\hline Minimo & $-11,97$ & 2,19 & $-11,97$ & & $>$ para o \\
\hline Máximo & 30,39 & 38,84 & 38,84 & & Grupo Estudo \\
\hline HDL (mg/dL) & & & & 0,807 & \\
\hline Média & 0,44 & 5,17 & 1,39 & & $>1000$ \\
\hline Mínimo & $-66,67$ & $-84,38$ & $-84,38$ & & $>$ para o \\
\hline Máximo & 38,36 & 56,34 & 56,34 & & Grupo Estudo \\
\hline LDL (mg/dL) & & & & 0,016 & \\
\hline Média & 12,90 & 21,93 & 17,27 & & $70,0 \%$ \\
\hline Minimo & $-23,46$ & $-4,37$ & $-23,46$ & & $>$ para o \\
\hline Máximo & 38,33 & 48,84 & 48,84 & & Grupo Estudo \\
\hline VLDL (mg/dL) & & & & 0,920 & \\
\hline Média & 8,06 & 16,54 & 11,71 & & $105,2 \%$ \\
\hline Minimo & $-88,39$ & $-157,14$ & $-157,14$ & & $>$ para o \\
\hline Máximo & 56,41 & 75,72 & 75,72 & & Grupo Estudo \\
\hline Triglicérides (mg/dL) & & & & 0,782 & \\
\hline Média & 9,30 & 14,5 & 11,52 & & $55,9 \%$ \\
\hline Minimo & $-89,51$ & $-150,00$ & $-150,00$ & & $>$ para 0 \\
\hline Máximo & 56,41 & 75,72 & 75,72 & & Grupo Estudo \\
\hline
\end{tabular}


A comparação da Redução das medidas antropométricas e bioquímicas entre os Grupos foi também realizada por meio de Análise de variância. Os resultados dessa análise, exibidos na Tabela 11, mostram que o Grupo Estudo apresentou uma redução média maior que o Grupo Controle com relação ao Peso, IMC, Circunferência abdominal, Colesterol total e LDL, com maior adesão à atividade física. Houve diferença estatisticamente significante para essas variáveis.

Os Grupos apresentaram a mesma redução média com relação às medidas do HDL, VLDL e Triglicérides.

Tabela 11: Resultados inferenciais dos testes entre os Grupos, segundo a Redução das medidas observadas. Ambulatório de endocrinologia da FM-FuABC, 2002.

\begin{tabular}{cccc}
\hline Variável & $\begin{array}{c}\text { Nivel } \\
\text { descritivo } \\
\text { (p) }\end{array}$ & Conclusão & $\begin{array}{c}\text { Poder } \\
\text { do teste }\end{array}$ \\
\hline Peso & 0,048 & Grupo Controle < Grupo Estudo & 0,511 \\
IMC & 0,026 & Grupo Controle $<$ Grupo Estudo & 0,615 \\
Circunferência abdominal & $<0,001$ & Grupo Controle $<$ Grupo Estudo & 0,979 \\
Colesterol total & 0,002 & Grupo Controle $<$ Grupo Estudo & 0,877 \\
HDL & 0,807 & Grupo Controle $=$ Grupo Estudo & 0,057 \\
LDL & 0,016 & Grupo Controle $<$ Grupo Estudo & 0,677 \\
VLDL & 0,920 & Grupo Controle $=$ Grupo Estudo & 0,051 \\
Triglicérides & 0,782 & Grupo Controle $=$ Grupo Estudo & 0,059 \\
\hline
\end{tabular}

A seguir, são apresentados os resultados da análise de regressão linear múltipla realizada para estudar a relação entre a redução do colesterol e as variáveis Idade, Sexo, Grupo, Raça, Redução do IMC e Redução da Circunferência abdominal. 
Os resultados dessa análise revelaram a existência do efeito de interação entre Grupo e Raça e entre Grupo e IMC. Desta forma, utilizou-se modelo final ajustado para cada categoria das variáveis consideradas. As equações apresentadas a seguir demonstram os resultados da análise.

Resultados inferenciais da análise de regressão

\section{Equação para o grupo controle e raça branca:}

Redução de colesterol $=0,5526+2,5480^{*}$ (Redução de IMC)

\section{Equação para o grupo controle e raça não branca:}

Redução de colesterol $=6,0935+2,5480^{*}$ (Redução de IMC)

\section{Equação para o grupo estudo e raça branca:}

Redução de colesterol $=16,8456+0,9065^{\star}($ Redução de IMC)

\section{Equação para o grupo estudo e raça não branca:}

Redução de colesterol $=11,1021+0,9065^{\star}($ Redução de IMC)

A análise dos resíduos demonstra o ajuste do modelo, o que pode ser conferido no Anexo 5.

A distribuição da redução do colesterol e das variáveis Idade, Sexo, Grupo, Raça, Redução do IMC e Redução da Circunferência abdominal, foi feita graficamente por meio do diagrama de dispersão para as variáveis numéricas, como serão mostradas nos Gráficos de 1 a 3 e os modelos para as variáveis categóricas serão apresentados nos Gráficos 4 e 5. 
Gráfico 1: Distribuição da Idade e da Redução percentual de CT, segundo Grupos. Ambulatório de endocrinologia da FM-FuABC, 2002.

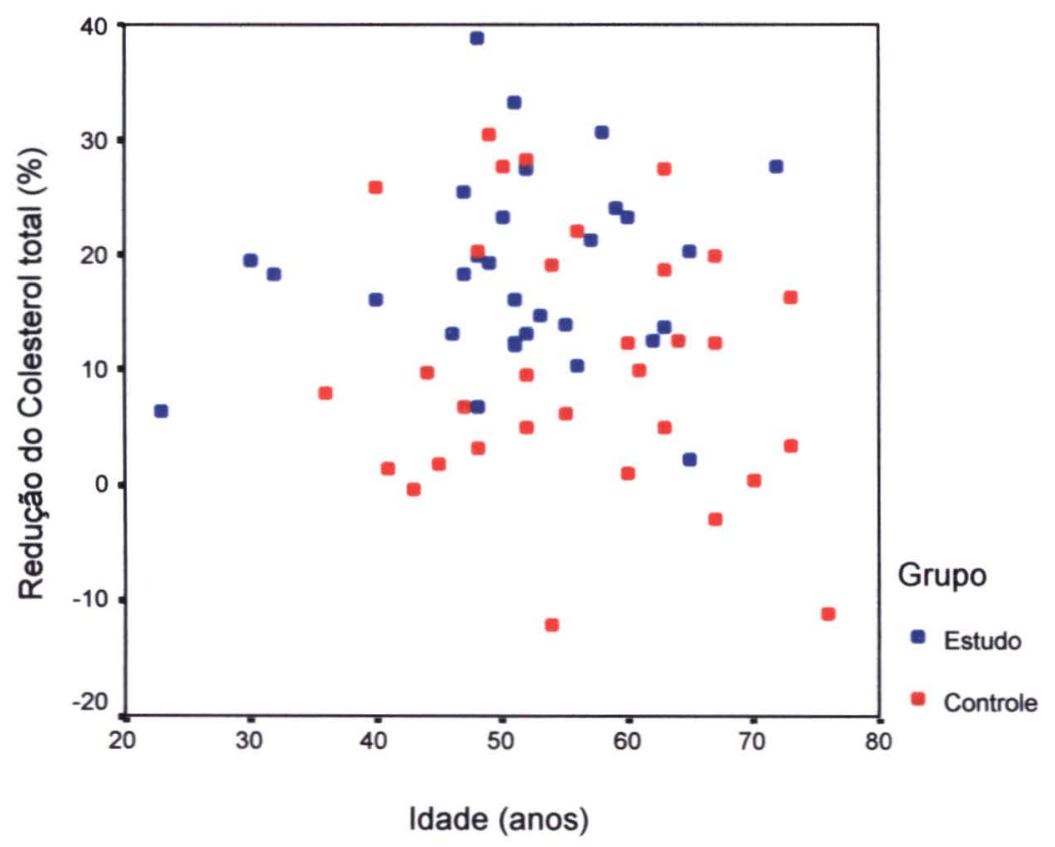

Gráfico 2: Distribuição da Reducão percentual de IMC e da Redução percentual de CT, segundo Grupos. Ambulatório de endocrinologia da FM-FuABC, 2002.

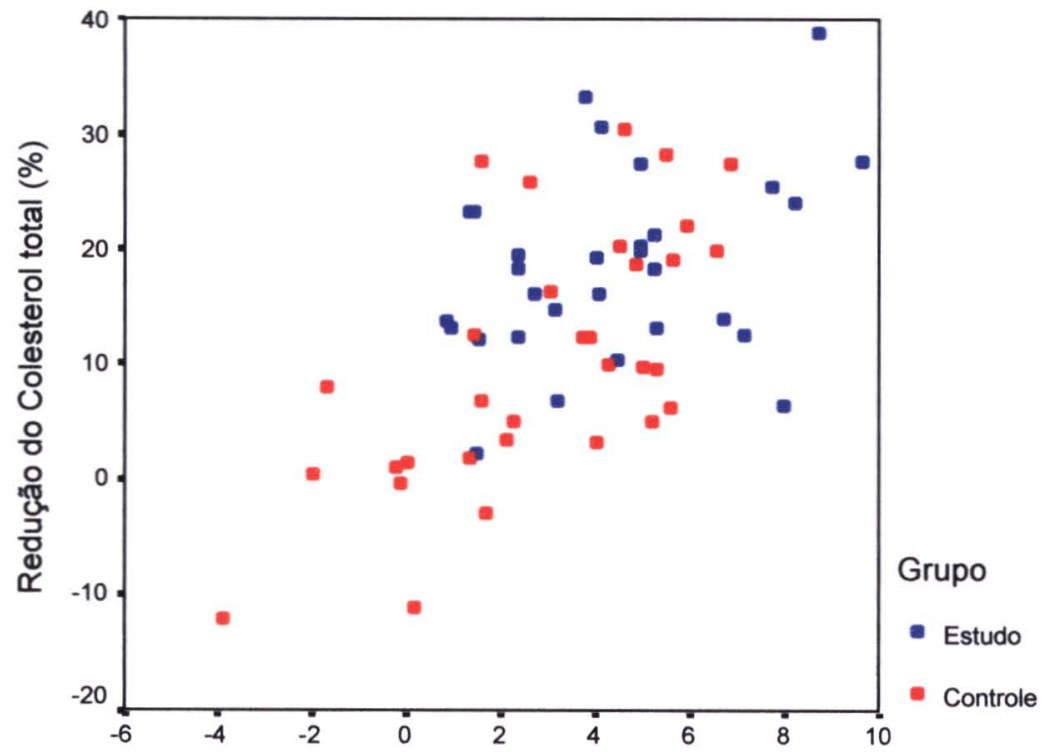

Redução do IMC (\%) 
Gráfico 3: Distribuição da Circunferência abdominal e da Redução percentual de CT, segundo Grupos. Ambulatório de endocrinologia da FM-FuABC, 2002.

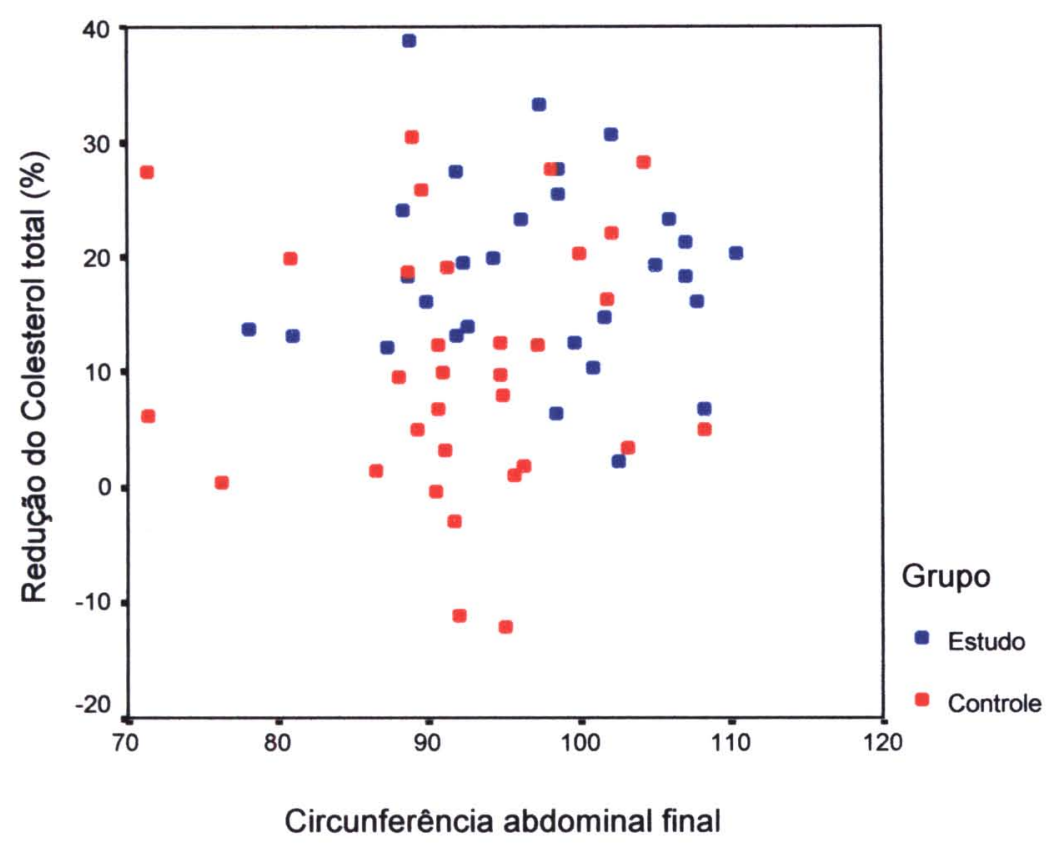

Gráfico 4: Distribuição Sexo e da Redução percentual de CT, segundo Grupos. Ambulatório de endocrinologia da FM-FuABC, 2002.

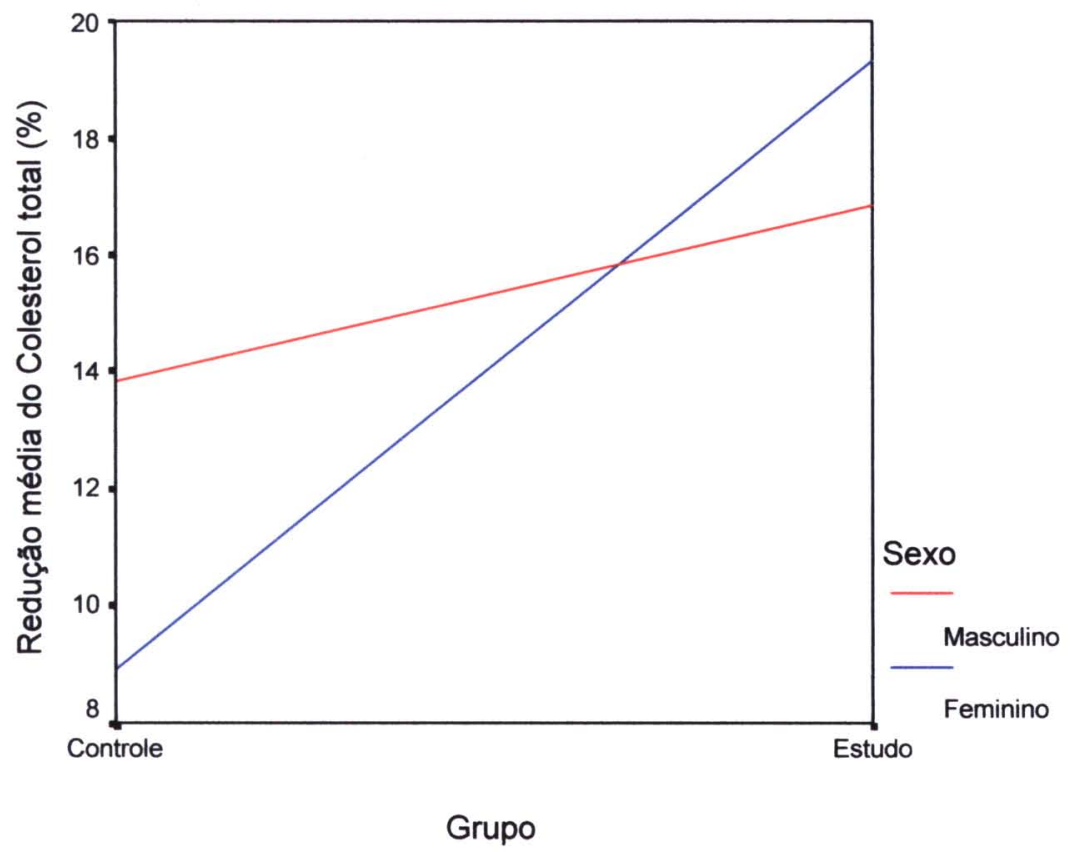


Gráfico 5: Distribuicão Raça e da Reducão percentual de CT, segundo Grupos. Ambulatório de endocrinologia da FM-FuABC, 2002.

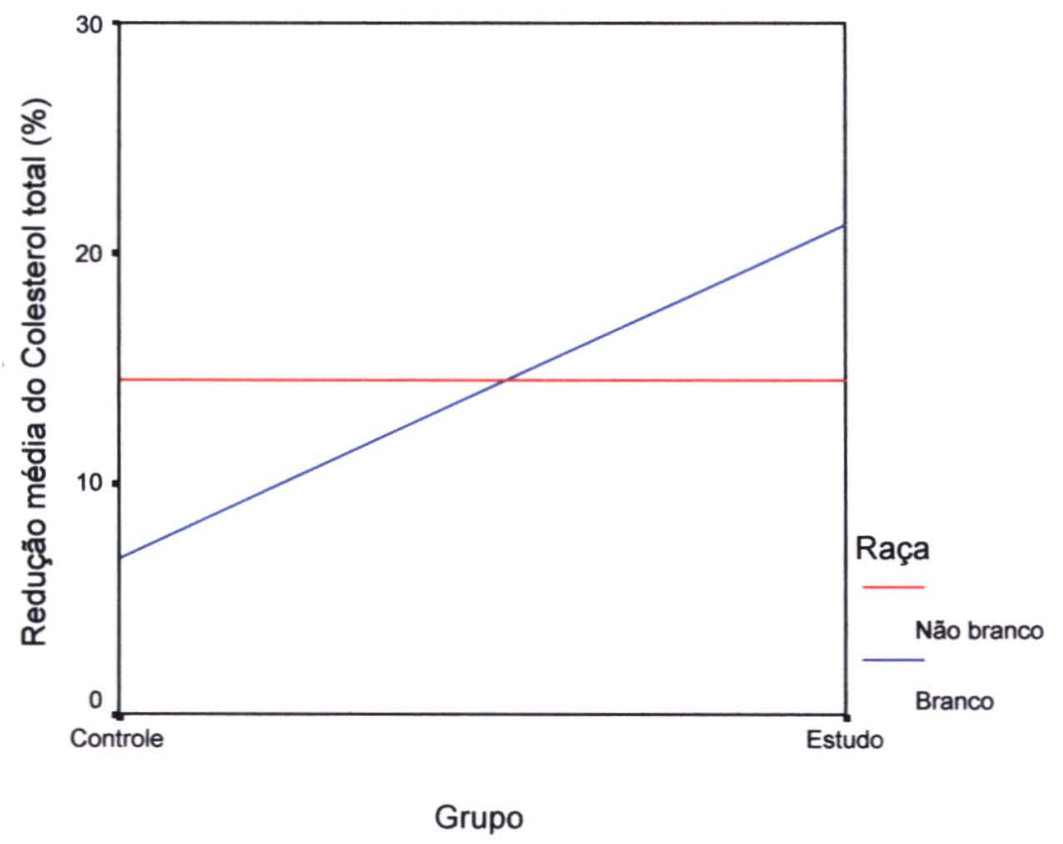




\section{DISCUSSÃO}

São muitos os estudos epidemiológicos que vêm sendo realizados, nas últimas décadas, na tentativa de elucidar os fatores envolvidos na gênese das enfermidades crônicas não transmissiveis (ECNT). A Organização Mundial da Saúde (WHO 2000) reconhece que certas exposições na vida adulta como obesidade associada à dieta inadequada, tabagismo, sedentarismo, hipertensão arterial, hipercolesterolemia e consumo de álcool aumentam o risco de ECNT.

A dieta é considerada, entre os fatores de risco, como uma das variáveis mais importantes, a julgar que possui alguns fatores associados à prevenção e controle, enquanto outros potencializam os riscos a ECNT.

Dessa forma, o desenvolvimento de ferramentas adequadas, para orientação à correta escolha dos alimentos, é de extrema importância para a saúde pública. Para atender ao objetivo principal desse trabalho, foi elaborado e avaliado um instrumento de orientação alimentar para controle de lipidemias. Porém, o objetivo maior é que esse instrumento possa ser um facilitador para a adoção de práticas dietéticas saudáveis à população brasileira, portadora de hiperlipidemias.

Em decorrência da forma em que foram demonstrados os resultados, a discussão também se apresenta subdividida nos mesmos tópicos. 


\subsection{Elaboração do sistema de pontos}

Vários estudos são realizados junto à população adulta com o objetivo de diminuir o consumo de gorduras (BUZZARD e col. 1990, LÓPEZ e col. 1997, CERVATO 1999). Essas pesquisas se destinam a medir o desempenho da educação alimentar, no entanto não se tem encontrado na literatura o desenvolvimento de guias alimentares para o controle das lipidemias, principalmente utilizando-se o CSI dos alimentos. Com exceção feita ao estudo de MITCHELL e col. (1996), que desenvolveu e validou um sistema de cartões que orientava como monitorar o CSI contido nos alimentos.

O instrumento de orientação alimentar desenvolvido nesse estudo se propôs, além de divulgar o conhecimento científico existente na área de alimentação e nutrição em relação às gorduras, a ser uma alternativa para os indivíduos que necessitam controlar a dieta para manter os niveis lipidêmicos dentro da normalidade e que não possuem acompanhamento nutricional.

Quanto à facilidade de utilização e manejo do instrumento elaborado nesse trabalho, a partir do estudo realizado por NACIF (2003), à observação de seus resultados, ficou demonstrado que os dados de concordância foram suficientemente favoráveis. O sistema de pontos pôde ser decodificado e compreendido pelos destinatários. O tempo médio despendido no cálculo também foi apropriado (NACIF 2003). Os dados dessa pesquisa sugerem que o instrumento em discussão é ágil e fácil de ser compreendido pela população. 
Dessa forma, tentou-se sair do plano intelectual, e, entrar no terreno da comunicação para testar o impacto do instrumento, o que demonstrou êxito no determinado grupo em que ocorreu a avaliação.

Poucos são os estudos que consideram o CSI como uma ferramenta para se atribuir aterogenicidade aos alimentos. Porém, a maioria dos estudos epidemiológicos e experimentais alega que o teor de gordura saturada e colesterol contidos nos alimentos apresentam correlação positiva com os indices de colesterol sérico (CONNOR 1999, TOELLER 1999).

Além do estudo realizado por MITCHELL e col. (1996), TIMLIN e col. (2002) utilizaram o sistema de CSI para avaliar a mudança de comportamento de pacientes cardiacos em um programa de reabilitação que concluiu que a escolha dietética aumentou a adesão a dietas hipogordurosas.

O presente instrumento de orientação alimentar utilizou como representação gráfica o Guia da Pirâmide de Alimentação Saudável, adaptado de WILLETT (2001), pois a pirâmide de alimentos tradicional - Pirâmide Alimentar Americana (USDA 1995), que está em vigor há uma década e que combateu o colesterol na época de sua implantação, pela apologia feita contra esse componente, atualmente, não consegue controlar nem o aumento da prevalência de obesidade - grau III nos Estados Unidos que passou de 4,9\% em 1990 a 7,5\% em 2000 (BERTOLAMI 2002). 
Os avanços relacionados à ciência da nutrição têm dado respaldo a questionamentos quanto à efetividade da tradicional pirâmide de alimentos que sugere um alto consumo de massas, pães e arroz refinados, de rápida absorção (WILLETT 2002).

Estudos referentes à nutrição e qualidade de vida demonstram que a prática de atividade física associada a uma alimentação equilibrada pode atender às necessidades fisiológicas do organismo (JAMES 2001). A nova pirâmide alimentar proposta por um grupo de cientistas da Faculdade de Saúde Pública da Universidade de Harvard (WILLETT 2001), adaptada e utilizada nesse estudo, preenche essa lacuna, pois recomenda a prática de atividade física diária e a manutenção do peso saudável em sua base, além da diminuição do consumo de carboidratos de alto indice glicêmico (FORBS 1999).

Outra recomendação equivocada da Pirâmide Alimentar Americana está no estimulo ao consumo de carnes vermelhas ricas em gorduras saturadas ao mesmo tempo em que faz severas restrições a todos os tipos de óleos, inclusive aos comprovadamente benéficos à saúde como as gorduras monoinsaturadas e as ricas em ácidos graxos ômega 3 e 6, podendo ocasionar comprometimento cardiovascular (WILLETT 2002). No caso da Pirâmide da Alimentação Saudável (WILLETT 2001) adotada nesse trabalho, sugere-se a diminuição do consumo de carnes vermelhas, ricas em gorduras saturadas, bem como o aumento do consumo de cereais integrais (LIU e col. 1999), vegetais, leguminosas (HADDAD e col. 1999) e oleaginosas, aumentando a oferta de vitaminas e minerais, além do estímulo ao consumo de óleos vegetais como azeite e canola (HELSING 1995). 
As mudanças sugeridas pela nova pirâmide de alimentos contribuem para uma vida saudável, pois evita desencadear doenças crônicas derivadas do consumo alimentar inadequado, como é o caso das doenças relacionadas às dislipidemias (PESSA 1998, DUTRA de OLIVEIRA e col. 2000), cujo controle é objeto de estudo do sistema de pontos desenvolvido nesse trabalho, que pretende se tornar uma alternativa nutricional para a população hiperlipidêmica.

Optou-se por apresentar a pirâmide em formato de coração, como uma alusão à prevenção de doenças cardiovasculares, abordando variedade, proporção e moderação, sem indicar quantidades e porções, que devem ser decididas por meio da pontuação dos alimentos. O coração foi escolhido, ainda, por apresentar formato semelhante ao da pirâmide, porém, invertida.

Em um estudo realizado por SPINELLI e col. (2000) que avaliou a pirâmide alimentar, como um instrumento de educação nutricional, foi encontrado em seus resultados, que $62 \%$ dos entrevistados não apresentaram uma compreensão correta do conceito da pirâmide, indicando a dificuldade de entendimento do instrumento. As maiores dificuldades encontradas foram o periodo a que se refere o número de porções, a quantidade de alimentos por porção e que os alimentos que estão no topo da pirâmide seriam os mais importantes, por estarem acima dos demais. Os autores concluiram que para o entendimento ser satisfatório é necessário o acompanhamento de um técnico, não tornando a pirâmide um instrumento auto-explicativo como se propõe. 
Assim, partindo-se de um contexto mais amplo, no qual a pirâmide em sua forma tradicional teve sua função questionada como representação gráfica na orientação alimentar de populações, considerou-se a possibilidade de desenvolver outro icone para exercer essa função, nesse caso, o coração. Porém, há a necessidade de ser validado (MOLINA e col. 1995, CASTILLO e col. 1997, Molina 2002).

O instrumento de orientação alimentar desenvolvido nesse trabalho apresenta, ainda, mensagens claras e objetivas em relação à necessidade de se manter o peso ideal, o qual pode ser obtido em tabela simplificada e de fácil utilização, tomando-se como base o IMC - Índice de Massa Corporal normal WHO 1998), além dos passos a serem seguidos para uma alimentação saudável. Essa etapa do instrumento não sofreu qualquer tipo de validação, houve somente a concordância do sistema de pontos e um estudo piloto que analisou o poder de adesão do paciente à dieta. Porém, o que se pode concluir é que essa etapa, no mínimo, não atrapalhou na utilização do sistema de pontos, induzindo a se pensar que as pessoas tenham entendido as mensagens nele contidas. No entanto, recomenda-se que seja realizada uma validação em estudo qualitativo, utilizandose grupos focais, por ser uma metodologia direta e objetiva para expor os valores sociais de segmentos específicos da população (CRUZ e col. 1999).

Vale salientar, que as mensagens contidas nos guias alimentares, mesmo sendo tecnicamente corretas, se não forem compreendidas pela população a que se destinam, terão perdido o seu propósito (PEÑA e MOLINA 1998). 
A literatura descreve diferentes metodologias para a criação de listagens de alimentos freqüentemente consumidos por uma determinada população. No caso do sistema de pontos desenvolvido nesse trabalho, optou-se por obter esses alimentos em uma lista de um estudo que comparou o padrão alimentar e os lipídeos séricos da população, desenvolvida por FORNÉS (1998), na tentativa de diminuir o risco de exclusão de alimentos representativos do consumo alimentar da população estudada. Outros alimentos disponiveis no mercado e a linha oferecida em fast-foods, foram adicionados a essa lista, pois são alimentos e preparações que podem ser consumidos com menor freqüência, mas que, atualmente, já fazem parte da dieta de muitos individuos (MITCHELL 1996). Desse modo, tentou-se cobrir a maioria dos alimentos que eventualmente possam integrar a dieta cotidiana e esporádica da população em estudo.

O cálculo de CSI foi descrito em medidas caseiras, utilizando-se as recomendações da Agência Nacional de Vigilância Sanitária (ANVISA 2001), para rotulagem de alimentos, por serem exigidas pela legislação e estarem em maior contato com o consumidor (GRACIANO e col. 2000), além da facilidade de compreensão e de cálculo pela população a que se destina.

Foi criado, ainda, um modelo para proceder à anotação dos pontos diários consumidos. Essa ferramenta foi desenvolvida para facilitar o controle individual da pontuação e permitir melhores resultados. No entanto, segundo o relato de alguns pacientes e a experiência individual do Dr. Alfredo Halpern (HALPERN 2000) que desenvolveu um sistema semelhante para a contagem de calorias e de Linda Huett - presidente mundial dos Vigilantes do Peso (LOBATO e LEMOS 2002) que possui um sistema de "PontosAtivos", com o passar do tempo é possivel deixar de anotar os pontos, quando o método e os princípios forem assimilados. 
Os altos coeficientes de correlação encontrados por NACIF (2003) em estudo de concordância do sistema de pontos, deram pouca margem a ajustes e correções no instrumento. É possivel considerar que essa etapa forneceu resultados satisfatórios (acima de 0,94 para intervalo com $95 \%$ de confiança), em que apenas $3,9 \%$ dos entrevistados apresentaram sugestões para 0 aperfeiçoamento do instrumento (NACIF 2003). Mas, como pôde ser observado no item 4.2 em resultados, sugestões pertinentes foram acatadas e implementadas para a confecção da versão final do sistema de pontos, seguindo-se os passos para a elaboração de guias alimentares propostos por PEÑA e MOLINA (1998).

Dentre os ajustes e correções implementados no sistema de pontos, destaca-se a apresentação da pontuação em ordem crescente de CSI, o que, segundo depoimento de alguns pacientes pertencentes a esse estudo, induz o usuário a escolher os alimentos com menor pontuação, modificando hábitos alimentares e consolidando a escolha por alimentos mais saudáveis. $E$, em contrapartida, alimentos com pontuação muito alta intimidam o indivíduo que tende a bani-los de sua dieta, por sua própria vontade.

$\mathrm{Na}$ pesquisa de concordância do sistema de pontos, somente $3,0 \%$ dos entrevistados relataram que o instrumento em questão não seria útil para controle e prevenção do aumento de colesterol sérico (NACIF 2003). Esse dado sugere que a proposta abordada pelo sistema de pontos não afronte preconceitos e hábitos da população e, que a sua utilização será bem aceita pela comunidade, pois ela entende a importância de uma alimentação equilibrada (DUTRA de OLIVEIRA e col. 2000). No entanto, há a necessidade de ser validado. 


\subsection{Estudo piloto}

A realização de um estudo piloto teve como objetivo central avaliar a eficácia do sistema de pontos como ferramenta de orientação nutricional auto-monitorada. Por se tratar de um estudo experimental (ROUQUAYRIOL 1986), sua finalidade foi realizar intervenção dietética para indivíduos com hiperlipidemias.

Dos 90 pacientes inicialmente recrutados para participação no estudo, contou-se com uma amostra reserva de 30 individuos que foi estipulada já na expectativa de haver alguma desistência, fato comum em estudos experimentais, em que se seguem os pacientes por um periodo de tempo, que no caso dessa pesquisa foi de três meses (TARASUK e BROOKER 1997). Assim, 62 individuos puderam ser acompanhados até a obtenção dos resultados.

\subsubsection{Caracterização da população}

\section{Variáveis sócio-demográficas}

As variáveis sócio-demográficas analisadas entre os 62 individuos que fizeram parte do estudo permitiram a realização de comentários que poderão ser vistos adiante.

A população foi composta por individuos, que foram recrutados entre os pacientes agendados para consulta no ambulatório de endocrinologia da FMFuABC, onde foi realizado o estudo. Houve predominância de mulheres superior à 
existente na população residente na cidade, que segundo dados do último censo, registrou $52 \%$ de pessoas do sexo feminino (FUNDAÇÃO IBGE 2000).

Apesar de se tratar de uma amostra aleatória, que preferencialmente deveria seguir a mesma tendência demográfica da população, havia a voluntariedade na participação e, aparentemente, nesse ambulatório, as mulheres procuram mais os serviços de saúde do que os homens.

Mas, esse fato não alterou os resultados da pesquisa, que comparou dois grupos, nos quais a tendência se manteve.

A média de idade dos participantes ficou entre 53 e 54 anos. A cidade de Santo André apresenta $5,2 \%$ de sua população em idade entre 50 e 54 anos (FUNDAÇÃO IBGE 2000).

Devido ao tipo de pesquisa realizado, em que os participantes necessariamente deveriam ter alteração do colesterol sérico, era de se esperar uma população com idade mais avançada, uma vez que a hiperlipidemia isolada, raramente apresenta sintomas e quando o indivíduo procura um serviço de saúde e descobre o distúrbio, ele já vem associado a outras comorbidades que levam à consulta médica. Tal fato poderia ser minimizado se houvesse um serviço de saúde preventiva eficiente, no qual as pessoas pudessem descobrir, controlar e prevenir as dislipidemias.

Em relação à distribuição dos indivíduos por raça, a população em estudo seguiu a mesma distribuição descrita pelos dados do último censo (FUNDAÇÃO 
IBGE 2000) com predominância de raça branca, seguida pela parda, negra e amarela.

Dos participantes do estudo, a maioria é casada, estado civil muito comum entre individuos da faixa etária dos participantes da pesquisa. Quanto à ocupação, predominou aposentados ou pensionistas. Na cidade $12 \%$ da população já não se encontra mais em atividade profissional, por tempo de serviço. Porém, dentro da faixa etária da população estudada, essa condição já era esperada.

Na cidade de Santo André, $44 \%$ da população apresenta até quatro anos de estudo (FUNDAÇÃO IBGE 2000). Já na amostra estudada, a escolaridade foi bastante baixa, sendo que a grande maioria não passou da $4^{a}$ série do Ensino Fundamental. Esse fato pode ser devido, novamente, à faixa etária estudada e à baixa condição sócioeconômica que os pacientes do ambulatório do Hospital Escola, de modo geral, apresentam. O acesso do individuo à rede de educação e o conseqüente alcance dos mais elevados niveis de escolaridade são derivados do seu posicionamento na estrutura social (VASCONCELLOS 1995).

\section{Variáveis diagnósticas}

As variáveis diagnósticas discutidas a seguir se reportam ao início da pesquisa, anterior às medidas de intervenção dietética.

A média de peso encontrada na população em estudo foi de $75,57 \mathrm{~kg}$ e de altura foi de $160,67 \mathrm{~cm}$. Porém, o peso ou a altura isoladamente não fornecem nenhum dado que possa ser analisado, sugerindo o estado nutricional dos indivíduos. Para tanto é necessário fazer a relação entre ambos. No caso do estudo 
aqui realizado, optou-se por utilizar o IMC, cuja média foi de $29,22 \mathrm{~kg} / \mathrm{m}^{2}$, que segundo a classificação da OMS (WHO 1998) permaneceu entre pré-obesidade e obesidade grau $\mathrm{I}$.

No sentido mais exato, o termo obesidade refere-se a uma doença crônica, recorrente, que afeta milhões de pessoas no mundo e descreve o excesso de gordura corpórea armazenada, enquanto que sobrepeso ou pré-obesidade é simplesmente o excesso de peso corpóreo em relação à altura. $\mathrm{Na}$ prática, entretanto, essas duas condições são mais freqüentemente tratadas como estágios dentro de uma série contínua de relações entre peso e altura WHO MONICA 1989).

O excesso de gordura corpórea ocorre quando o total de consumo de energia, na forma de alimentos, excede o seu dispêndio, na forma de metabolismo em repouso e atividades físicas adicionais. Tanto a ingestão excessiva como o baixo dispêndio energético podem ser os fatores causadores, em muitos casos, parecendo que ambos atuam conjuntamente (JAMES 2001). Alguns autores consideram que haja também um elemento genético na variação de peso corpóreo (BOUCHARD e col. 1990, CALLAWAY e col. 1992).

Qualquer que seja a natureza da predisposição genética à obesidade, ficaclaro que os niveis relativos de ingestão e dispêndio de energia são cruciais no desenvolvimento do excesso de peso. Da mesma forma, não há evidência de que a taxa de dispêndio de energia durante exercicios de alto rendimento esteja relacionada com a hereditariedade (BOUCHARD e col. 1989). 
Ao mesmo tempo é impossivel que, a genética isoladamente, seja suficientemente capaz de explicar o aumento maciço da obesidade, como tem ocorrido mundialmente nos últimos 20 anos $\mathrm{e}$, inquestionavelmente, o meio ambiente desempenha um papel importante, quando permite a expressão da predisposição genética (BOUCHARD e PÉRUSSE 1993).

No Brasil esse panorama não é diferente, vários estudos têm apontado para o crescente aumento da prevalência de obesidade em diversas regiões do País (SICHIERI 1998, CONDE e col. 2002). Estima-se que acima de $40 \%$ dos adultos apresentam excesso de peso, isto é, IMC $\geq 25 \mathrm{~kg} / \mathrm{m}^{2}$ (SICHIERI 1998).

$\mathrm{Na}$ população estudada a grande maioria dos individuos apresentou excesso de peso (IMC $\geq 25 \mathrm{~kg} / \mathrm{m}^{2}$ ). Esse pode ser um dos fatores que contribuiu para o aparecimento de dislipidemias nesses pacientes, como acontece na Sindrome Plurimetabólica (REPETTO, 1998). Pois, em longo prazo, a obesidade impõe uma série de perigos médicos, entre os quais a resistência à insulina e o desenvolvimento do diabetes mellitus tipo 2; diminuição da tolerância à glicose; hiperinsulinemia; hiperlipidemias, em geral, elevados niveis de triglicérides e de colesterol, em especial da fração LDL; e, hirpertensão arterial (PI-SUNYER 1993).

São vários os estudos que ressaltam a importância não só da prevalência de obesidade, mas também da distribuição da gordura corporal, principalmente da obesidade abdominal, também como fator de risco para distúrbios da saúde como doenças cardiovasculares, hipertensão, hiperlipidemia e diabetes mellitus tipo 2 (NAVARRO e col. 2001, RAMOS DE MARINS e col. 2001, SMITH e col. 2001, VIGGIANO 2001, LERÁRIO e col. 2002). 
Segundo os valores de referência da Task Force Report (TFR 1998) a circunferência da cintura igual ou superior a $98 \mathrm{~cm}$ para o sexo masculino e maior ou igual a $89 \mathrm{~cm}$ para o sexo feminino, estão relacionados com aumento de risco de morbidade, com maior impacto aos fatores de risco de DAC para ambos os sexos.

No presente trabalho, a circunferência abdominal média ultrapassou, em maioria, os valores de referência adotados. Em um estudo sobre a prevalência da Sindrome Plurimetabólica, associou-se a adiposidade abdominal à elevação das lipidemias em indivíduos com mais de 30 anos (VIGGIANO 2001), que é o caso do estudo em questão, podendo, a circunferência abdominal, despontar como outro fator que pode ter contribuido ao aparecimento de dislipidemias nesses pacientes.

São múltiplas as evidências que associam a alta prevalência de doenças crônico-degenerativas ao aumento da obesidade (NAVARRO e col. 2001, LERÁRIO e col. 2002).

O nivel de colesterol sérico e suas frações, quando adicionados a todos os fatores discutidos anteriormente, tendem a aumentar o risco do aparecimento dessas doenças.

A presente pesquisa apresentou, CT, LDL, VLDL e triglicérides médios elevados e HDL médio adequado. É obvio que esses dados eram si ne qua non para a consecução desse trabalho, que recrutou apenas individuos hiperlipidêmicos, mas, não se pode deixar de comentar que o perfil lipidico desses pacientes, associado ao perfil antropométrico encontrado, só podem contribuir com o risco de aparecimento de ECNT (ALFARO 1996, CERVATO e col. 1997, RABELO e MARTINEZ 1998, RABELO 2000). 
Muitos estudos sugerem que o nivel de CT está associado à taxa de mortalidade por DAC, porém dados conferidos, em um estudo de 25 anos, com 12.457 homens de cinco paises europeus, Estados Unidos e Japão, confirmaram que as concentrações de CT estão relacionadas linearmente com a mortalidade por DAC (VERSCHUREN e col. 1995). Os resultados de estudos clínicos sobre redução de colesterol sérico a curto e longo prazo, confirmam essa relação (LEVINE e col. 1995). E, demonstram, ainda, que os eventos isquêmicos podem ser prevenidos e a mortalidade reduzida com a efetiva redução dos níveis de LDL, reconhecido como aterogênico.

Os resultados encontrados, em estudos que avaliaram o perfil lipidico e a prática de atividade física, em idosos e adultos com mais de 30 anos, demonstraram que o sedentarismo é uma característica de indivíduos hiperlipidêmicos (TADDEI e col. 1997, WILCOX e col. 2000). Esses dados foram confirmados nesse trabalho, em que nenhum dos participantes da pesquisa referiu praticar atividade física na consulta inicial.

Atualmente, ocorre um grande aumento no consumo de gorduras, acompanhado do sedentarismo na vida da maioria das pessoas. Essas tendências foram percebidas primeiramente nos Estados Unidos e se espalharam desde então para outros paises (ROBERT e FRENCH 1998). Nesse contexto, a mudança ambiental mais importante dos últimos tempos pode ser a bem documentada alteração no padrão típico da dieta, e, atividades físicas que têm ocorrido nos países industrializados.

Mesmo nos paises com dietas tradicionalmente mais saudáveis, como no sul da Europa, as pessoas, atualmente, comem mais gordura do que no passado 
(BLUNDELL 1995). Parte do problema pode ser explicada por uma preferência inata por alimentação gordurosa, sendo a gordura responsável pelo sabor e prazer de comer. Acredita-se que a gordura envie apenas sinais fracos de saciedade do trato grastrintestinal para os centros controladores do apetite no cérebro. Essa situação se contrasta intensamente com a de outros macronutrientes. Há um consenso geral que a proteina tem um efeito poderoso de saciedade e há evidências de que os carboidratos produzem uma eficaz inibição do apetite em curto prazo (BLUNDELL 1995). Em outras palavras, uma refeição rica em proteinas e carboidratos gera sinais que são enviados para o cérebro e freiam o apetite, enquanto que a gordura, o macronutriente que menos gera saciedade, faz com que o indivíduo continue comendo por mais tempo e, conseqüentemente, coma mais.

Tais alteraçōes de comportamento das pessoas, que levam à obesidade e hiperlipidemias predispõem os individuos a uma série de comorbidades, como já foi citado anteriormente: resistência à insulina, diabetes mellitus tipo 2; diminuição da tolerância à glicose; hiperinsulinemia; hiperlipidemias, e hirpertensão arterial (PISUNYER 1993, VIGGIANO 2001).

A comorbidade mais comum encontrada entre os pacientes estudados foi a hipertensão arterial, seguida pelo diabetes mellitus tipo 2 e resistência à insulina.

TADDEl e col. (1997) em um estudo multicêntrico com idosos em ambulatórios constataram que o principal motivo que levou os pacientes à primeira consulta foi a pressão arterial (48\%), já o diabetes mellitus foi o motivo de $13 \%$ dos pacientes. 
No entanto, a pretensão desse trabalho não foi controlar essas doenças. Esses dados foram levantados apenas com o objetivo de traçar o perfil dos pacientes pertencentes aos Grupos Estudo e Controle e de verificar se não apresentavam alguma comorbidade que representasse um fator de exclusão do participante da pesquisa.

Os medicamentos mais utilizados foram os anti-hipertensivos, até pela alta prevalência do distúrbio na população estudada, seguidos pelo uso de hipoglicemiantes orais (glibenclamida e metiformina).

Em um estudo realizado no México, com 2036 hipertensos idosos, constatou-se que $96 \%$ dessa população fazia uso de medicamentos para o controle da pressão arterial e, que os demais que não utilizavam farmacoterapia, não apresentaram um adequado controle (GARCIA PEÑA e col. 2001).

UEHARA (1999) realizou um estudo randomizado, com 26 individuos portadores de diabetes mellitus tipo 2 e de hipertensão arterial, que foram tratados com placebo durante 4 semanas e, posteriormente, com metiformina, por 12 semanas. Os resultados apontaram que somente a intervenção com metiformina diminuiu a glicemia de jejum e a pressão arterial. No entanto, seu possivel efeito anti-hipertensivo não está completamente esclarecido.

\subsubsection{Análise do perfil dos individuos dos Grupos Controle e Estudo}

Após a fase descritiva preliminar que caracterizou a população estudada e o perfil dos Grupos Controle e Estudo, procedeu-se à análise dos dados, segundo 
testes estatísticos adequados, com nivel de significância de $p<0,05$, cujos resultados foram apresentados nas Tabelas 8 e 9 .

Com relação às variáveis de natureza categórica, no inicio da pesquisa, não foi possivel detectar diferença estatisticamente significante na distribuição dos individuos no Grupo Controle e Estudo. Quanto às variáveis numéricas, pôde-se observar essa diferença quanto ao peso e à circunferência abdominal.

Mas foi possivel notar que a distribuição para IMC foi semelhante nos Grupos Controle e Estudo. Sendo o IMC a relação entre o peso e a altura, é um dado mais importante do que o peso isoladamente, que por si só não pode ser analisado do ponto de vista antropométrico.

Para evitar que os dois grupos não apresentassem o mesmo perfil, no início da pesquisa, e os resultados, ao final do tratamento, pudessem ser comparados, realizou-se o ajuste das variáveis peso e circunferência abdominal, por meio da quantificação da redução das medidas observadas (NETER e col. 1996), detalhada no capítulo de método.

Dessa forma, tentou-se ajustar os Grupos Controle e Estudo e, assim, proceder à análise do desempenho perante as duas intervenções dietèticas.

\subsubsection{Análise do desempenho dos grupos mediante a intervenção}

Os resultados da análise, do desempenho dos grupos mediante a intervenção mostram que o Grupo Estudo sofreu reduções significativamente 
maiores que o grupo controle referente ao peso, IMC, circunferência abdominal, colesterol total, LDL e prática de atividade física.

Os grupos apresentaram respostas semelhantes em relação às medidas de HDL, VLDL e Triglicérides.

A redução do peso, no grupo estudo, em média, foi de $4,33 \%$. A literatura admite que uma redução de $5 \%$ do peso em pacientes com comorbidades crônicas, que caracterizam a síndrome plurimetabólica (REPETTO 1998) em maior ou menor grau - hiperinsulinemia, resistência à insulina, adiposidade abdominal, hipertensão arterial, dislipidemias, intolerância á glicose, diabetes mellitus tipo 2 e cardiopatia isquêmica - auxilia na redução da glicemia, trigliceridemia e colesterolemia (PYÖRALLA e col. 1985).

Dessa forma, foi possivel considerar que a dieta proposta pelo sistema de pontos mostrou-se eficiente para a redução do peso corporal dos indivíduos estudados.

A redução do $I M C$, que está diretamente associada à redução do peso corporal, também foi maior no grupo estudo, $4,37 \%$ em média, passando de 30,04 $\mathrm{kg} / \mathrm{m}^{2}$ para $28,71 \mathrm{~kg} / \mathrm{m}^{2}$. A AHA (2000) recomenda que os individuos mantenham o IMC abaixo de $25 \mathrm{~kg} / \mathrm{m}^{2}$, para diminuir o risco de doenças cardiovasculares.

A dieta proposta pelo sistema de pontos foi avaliada durante três meses, assim, nem todos os individuos conseguiram atingir o peso desejável, porém, eles foram encorajados a continuar com o tratamento dietético, para que esse objetivo fosse alcançado. 
O sistema de pontos não foi criado para servir como dieta por um periodo de tempo pré-determinado, como foi o caso desse estudo piloto, por razões de metodologia, mas sim para servir como plano alimentar para que os indivíduos que o utilizam possam fazer uma reeducação alimentar. Dessa forma, o objetivo é alcançar o IMC adequado e mantê-lo.

A circunferência abdominal teve uma redução média de $2,29 \%$ no Grupo Estudo, passando de $99,29 \mathrm{~cm}$ para $96,99 \mathrm{~cm}$. É uma média ainda elevada para um grupo com $66,7 \%$ de individuos do sexo feminino.

REAVEN (1992), há mais de dez anos descreveu que a gordura abdominal, mesmo em individuos não obesos, associava-se a doenças crônicas, que segundo suas observações costumavam ocorrer na meia-idade. Tratava-se das comorbidades que compõem a síndrome plurimetabólica, denominada inicialmente de "sindrome $X$ ".

A maior prevalência de adiposidade centralizada, denominada obesidade andróide, segundo a literatura, encontra-se em individuos mais idosos, principalmente em mulheres após o climatério (SINGH e col. 1999), que é o caso de grande parte dos individuos pertencentes a esse estudo.

Mais uma vez o sistema de pontos apresentou maior eficiência em relação à dieta tradicional adotada para o grupo controle. Mesmo que a circunferência abdominal não tenha atingido os valores de referência, para todos os participantes da pesquisa, no periodo de segmento. 
Quanto ao colesterol total e LDL a redução média foi de $18,51 \%$ e $21,93 \%$ respectivamente. O CT médio foi reduzido para $223,73 \mathrm{mg} / \mathrm{dl}$ e o LDL para 145,27 $\mathrm{mg} / \mathrm{dl}$. Mesmo essas médias não tendo chegado aos niveis desejáveis para a prevenção de doenças cardiovasculares (CT < 200mg/dl e LDL < 130mg/dl), encontram-se nos niveis limítrofes, não sendo consideradas aumentadas.

Segundo dados da literatura, o tratamento dietoterápico hipocolesterolêmico possui um desempenho de 10 a $15 \%$ na redução dos niveis de colesterol plasmáticos (POSNER e col. 1986, CONNOR e col.1989, CERVATO e col. 1997). Dessa forma, pode-se considerar que o sistema de pontos não só se apresentou mais eficiente que a dieta tradicional adotada nesse estudo, mas também em relação ao tratamento dietético para controle de colesterol, em geral, que considera modificações no consumo de colesterol e gordura saturada.

As concentrações plasmáticas de HDL não se modificaram em ambos os grupos. Sabe-se, por descrição em vários estudos na literatura, que aumentar as concentrações plasmáticas de HDL é um grande desafio da medicina, mesmo quando se utiliza a farmacoterapia (ASSMANN e col. 1996).

Porém, as concentrações médias de HDL em ambos os grupos, já se encontravam dentro dos niveis desejáveis, $\geq 40 \mathrm{mg} / \mathrm{dl}$, sendo que a dieta proposta pelo sistema de pontos, manteve esses limites.

Em relação às concentrações séricas de triglicérides e VLDL, derivada da concentração plasmática de triglicérides, a redução média não variou entre os grupos, possivelmente em razão da alta variação apresentada dentro dessa amostra. Mas, pode-se considerar que mesmo o sistema de pontos, não tendo se 
mostrado mais eficiente, que a dieta tradicional, não teve efeito desfavorável em relação a esses componentes, pois apresentou redução de $14,5 \%$ na trigliceridemia e $16,54 \%$ nos niveis de VLDL. Esses resultados podem ser atribuídos à perda de peso ocorrida durante o seguimento (GUEDES e GUEDES 1998), pois mesmo no início da pesquisa, a média de triglicérides e VLDL plasmáticos já se encontravam dentro dos limites desejáveis.

A prática regular de atividade física exerce efeitos benéficos à saúde, entre os quais destaca-se a perda e manutenção do peso corporal, controle da glicemia e das lipidemias, bem como da pressão arterial (GUEDES e GUEDES 2001). Todos esses fatores associados minimizam os riscos de doenças cardiovasculares (AHA 2000).

Apesar da forma subjetiva pela qual se mensurou a prática de atividade fisica nesse estudo, partiu-se da consulta inicial, na qual todos os participantes referiram não praticar nenhum tipo de atividade. Após os três meses de intervenção, no Grupo Estudo, a maioria referiu ter aderido à prática de atividade física, principalmente as caminhadas, enquanto no Grupo Controle a aderência foi menor.

A pirâmide alimentar desenvolvida por WILLETT (2001), adaptada no instrumento, sugere a prática de atividade física regularmente. Uma vez que, todos os participantes da pesquisa, de ambos os grupos foram orientados, na primeira consulta, a realizar algum tipo de atividade física, o resultado obtido sinaliza que o sistema de pontos pode ter sido mais eficiente para a alteração desse comportamento dos individuos. Porém, outros estudos precisam ser realizados para confirmar essa hipótese. 
Os resultados da análise de regressão linear, desenvolvida nessa pesquisa, revelaram a existência do efeito de interação entre Grupo e Raça e entre Grupo e IMC. Há estudos que relacionam a etnicidade aos riscos de doenças cardiovasculares (SUNDQUIST e col. 2001, LERÁRIO e col. 2002), mas, a forma como essa variável foi tratada nesse estudo, não nos fornece um resultado conclusivo, somente direciona para que outras pesquisas bem controladas sejam desenvolvidas, até pela complexidade envolvida nessa variável, tais como a dificuldade de mensuração da raça em nosso meio e os fatores acerca desse tema que ainda continuam muito polêmicos.

Quanto à relação com o IMC, já era um resultado bastante esperado, pois na literatura a relação da hiperlipidemia com a massa e gordura corporal tem sido bastante explorada (RAMOS DE MARINS e col. 2001). Principalmente, a redução do IMC e da gordura abdominal que apontam para uma melhora no perfil lipídico sérico (PYÖRALLA e col. 1985, REPETTO 1998).

Em resumo, esse estudo piloto pôde constatar a eficácia do sistema de pontos como ferramenta para intervenções dietéticas, para individuos com hipercolesrolemias, ressaltando a satisfação dos usuários em relação aos resultados obtidos, à facilidade de utilização e por se aproximar ao máximo à dieta habitual dos indivíduos.

Cabe salientar que a população em estudo não apresentou alto nivel sóciocultural, com escolaridade predominante de até 4 anos de estudo, o que leva a considerar que pode ser recomendado para a população brasileira hiperlipidêmica, excluindo-se somente os analfabetos e pessoas que não sabem somar. 
Essa forma de apresentação do sistema de pontos demonstrou-se útil: como instrumento e como meio de traduzir o científico para o popular e evitar a proibição de alimentos.

É, ainda, uma ferramenta para apoiar a capacitação de profissionais promotores da saúde, orientação de pacientes e da população hiperlipidêmica em geral, podendo ser utilizada na atenção primária à saúde, em ambulatórios e consultórios nos quais não hajam nutricionistas.

No entanto, os estudos relacionados ao instrumento, desenvolvido nesse trabalho não devem ser interrompidos, sendo recomendada a validação do instrumento como um todo, em segmentos representativos da população brasileira. Há que se considerar as limitações desse estudo. 


\section{CONCLUSÃO}

A elaboração e avaliação da eficácia de um instrumento de orientação alimentar para individuos hiperlipidêmicos permitiram as seguintes conclusões.

Foi elaborado, com sucesso, um instrumento de orientação alimentar denominado Sistema de Pontos para Controle de Colesterol e Gordura no Sangue, em formato de cartilha, com 240 alimentos listados e com pontuação de CSI, por meio de tabelas simplificadas e sem proibição de alimentos.

O sistema de pontos mostrou-se adequado em relação aos seus objetivos, pois se apresentou como ferramenta de rápida aplicação e de fácil compreensão, com eficiência superior em relação à dieta tradicional para dislipidemias, por demonstrar reduções significativamente maiores referentes ao peso, IMC, circunferência abdominal, colesterol total, LDL e prática de atividade física. As respostas foram semelhantes em relação às medidas de HDL, VLDL e Triglicérides, porém, apresentaram resultados favoráveis ao controle da lipidemias.

Há que se considerar as limitações dessa pesquisa, por se tratar de um estudo piloto. No entanto seus resultados apontam para a eficácia do sistema de pontos, demonstrando que os estudos não devem ser interrompidos, sendo recomendada a validação do instrumento como um todo, em segmentos representativos da população brasileira hiperlipidêmica. 


\section{REFERÊNCIAS}

Agresti A. Categorical data analysis. New York: Wiley Interscience; 1990.

[AHA] American Heart Association, 2000 [on line]. Available from http://www. americanheartassociation.com [2002 oct 31].

Alfaro Villatoro NC. Fatores de riesgo que condicionan las enfermidades cardiovasculares y una propuesta de intervención. Guatemala: INCAP/SE/005; 1996.

Anderson KM, Castelli WP, Levy D. Cholesterol and mortality 30 year follow up from Framinhan study. JAMA 1987; 257:2176-80.

Anderson TA, Gustafson NJ. Hypocholesterolemic effects of dietary fiber of oat and bean products. Am J Clin Nutr 1988; 48:826-9.

[ANVISA] Agência Nacional de Vigilância Sanitária. Resolução RDC - nº 39, de 21 de Março de 2001 [on line]. Disponivel em http://www.anvisa.gov.br [2002 jun 10].

Arntzenius AC. Kromhout D, Barth JD, Reiber JH, Bruschke AV, Buis B, van Gent CM, Kempen-Voogd N, Strikwerda S, van der Velde EA. Diet, lipoproteins, and the progression of coronary atherosclerosis. The Leiden Intervention Trial. N Eng J Med 1985; 312(13):805-11. 
Artaud-Wild SM, Connor SL, Sexton G, Connor WE. Differences in coronary mortality can be explained by differences in cholesterol and saturated fat intakes 1040 countries but not in France and Finland. A paradox. Circulation 1994; $90(6): 3118-9$.

Aschierio A, Rimm EB, Giovanicchi EL, Spiegelman D, Stampfer M, Willett WC. Dietary fat and risk of oronary heart disease in men: cohort follow up study in the United States. BMJ 1996; 313:84-90.

Assmann G, Schulte $H$, von Eckardstein A. Hypertriglyceridemia and elevated lipoprotein (a) are risk factors for major coronary events in middle-aged men. Am J Cardiol 1996; 77:1179-84.

Bachorik PS, Albers S. Precipitation methods for quantifications of lipoproteins. Methods Enzymol 1986; 129:78-100.

Berquó ES, Leite VM. Algumas considerações sobre a demografia da população idosa no Brasil. Ciên Cult 1988; 40(7):679-88.

Bertolami MC. Síndrome plurimetabólica e DAC. In: I Congresso Paulista de Nutrição Clínica; 2002, out; São Paulo, Brasil.

Beyruti M. Tratamento nutricional da obesidade e comorbidades. In: I Congresso Paulista de Nutrição Clínica; 2002, out; São Paulo, Brasil. 
Bittencourt Jr PIH, Senna SM. Ácidos graxos e aterosclerose. In: Curi R, Pompéia C, Miyasaka CK, Procópio J. Entendendo a gordura. São Paulo: Manole; 2002: p.537-54.

Bjorntorp P. Obesity and the risk of cardiovascular disease. Annal Clinical Research 1995; 17:3-9.

Bleil SI. Mudança de hábitos a partir da industrialização agroalimentar. Rio de Janeiro; 1998. [Dissertação de Mestrado - UFRRJ/CPDA].

Blundell JE. Food intake and appetite control: from energy intake to dietary patterns. [Paper presented at European Congress on Obesity; 1995 May 31 - Jun 3; Copenhagen.]

Boog MCF. Educação nutricional, orientação alimentar e o papel dos nutricionistas na midia. [Conferência magistral de abertura do $15_{-}^{\circ}$ Congresso Brasileiro de Nutrição; 1998 ago; Brasilia, DF.]

Bouchard C, Pérusse L. Genetics of obesity. Annu Rev Nutr 1993; 13: 337-54.

Bouchard C, Tremblay A, Després JP. The response to long-term overfeeding in identical twins. N Engl J Med 1990; 322: 1477-82.

Bouchard C, Tremblay A, Nadeau A. Genetic effect in resting and exercise metabolic rates. Metabolism 1989; 38: 364-70. 
Bussad WO, Morettin PA. Estatística básica. $4^{\mathrm{a}}$ ed. São Paulo; Atual Editora; 1987.

Buzzard M, Asp EH, Chlebowski RT, Boyar AP, Jeffery RW, Nixon DW e col. Diet intervention methods to reduce fat intake: nutrient and food group composition of self-selected low-fat diets. J Am Diet Assoc 1990; 90:42-50.

Camargo ABM, Saad PM. A transição demográfica no Brasil e seu impacto na estrutura etária da população. In: O idoso na Grande São Paulo. São Paulo; Fundação SEADE (Coleção Realidade Paulista), 1990.

Callaway CW, Forey JP, Nuckolls JG, Vanltallie TB. Obesity: a quartet of approches. Patient Care 1992; 15:157-99.

Castillo CL, Atalah ES, Uauy RD. Guias de alimentación para la población chilena. Santiago: Chile; 1997.

[CBCD] Conselho Brasileiro de Classificação de Doenças - CID-10 de 1993 [on line]. Disponivel em http://www.fsp.usp.br/ cbcd/ [2003 fev 10].

Cervato AM. Intervenção nutricional educativa: promovendo a saúde de adultos idosos em universidades abertas à terceira idade. São Paulo; 1999. [Tese de Doutorado - Faculdade de Saúde Pública da USP].

Cervato AM, Mazzilli RN, Martins IS, Marucci MF. Dieta Habitual e fatores de risco para doenças cardiovasculares. Rev. Saúde Pública 1997; 31 (3): 227-35. 
Conde WL, Levy-Costa RL, Monteiro CA. Quantas pessoas têm excesso de peso? Estudos epidemiológicos em obesidade no Brasil. In: Halpern A, Macini MC, organizadores. Manual de obesidade para o clínico. São Paulo: Ed. Roca; 2002.

Connor SL, Gustafson JR, Sexton G, Becker N, Artaud-Wild SM, Connor WE. The diet habit survey: a new method of dietary assessment that relates to plasma cholesterol changes. J Am Diet Assoc 1992; 92:41-7.

Connor SL, Gustafson JR, Artaud-Wild SM, Favell, DP, Classick-Kohn CJ, Hatcher LF, Connor WE. The cholesterol/satured-fat index: an indication of hipercolesterolaemic and atherogenic potential of food. Lancet 1986; (May):1229-32.

Connor SL, Gustafson JR, Artaud-Wild SM, Favell, DP, Classick-Kohn CJ, Hatcher LF, Connor WE. The cholesterol/satured-fat index for coronary prevention: Background, use, and a comprehensive table of foods. J Am Diet Assoc 1989; 89:807-16.

Connor WE, Connor SL. Importance of diet in the treatement of familial hypercholesterolemia. Am J Cardiol 1993; 72(10):42D-53D.

Connor WE. Diet-heart research in the first part of $20^{\text {th }}$ century. Acta Cardiol 1999; 54:135-9; .

Cruz LC. Validação de guias alimentares: sondagem qualitativa. Relatório, maio, 1999. 
Dietschy JM. Theoretical considerations of what regulates low-density-lipoprotein and high-density-lipoprotein cholesterol. Am J Clin Nutr 1997; 65(Suppl):1581-9.

Dioguardi GS, Pimenta J, Knoplich J. Fatores de risco para doenças cardiovasculares em médicos. Dados preliminares do projeto VIDAM da Associação Paulista de M-edicina. Arq Bras Cardiol 1994; 62:383-8.

Ditschuneit $\mathrm{HH}$, Flechtner-Mors $\mathrm{M}$. Value of structured meals for weight management: risk factors and long-term weight maintenance. Obes Res 2001; 9 (Suppl 4):284S-9S.

Dixon LB, Tershakovec AM, McKenzie J, Shannon B. Diet quality of young children who received education promoting lower dietary fat. Public Health Nutr 2000; $3(4): 411-6$.

Dutra de Oliveira JE, Moreira EAM, Berezovsky MW, Portella AO, Cruz LC. Normas e guias da boa alimentação para a população brasileira. Nutr Pauta 2000; 41:6-11.

East C, Bilheimer DW, Grundy SM. Combination drug therapy for familial combined hyperlipidemia. Am Intern Med 1988; 109(1):25-32.

Endo A, Kuroda M, Tsujita Y. ML-236A, ML-236B, and ML-236C, new inhibitors of cholesterogenesis produced by Penicillinum Citrinum. J Antibiot 1976; 29:136-48.

Ferreira $\mathrm{ABH}$. Novo dicionário Aurélio da língua portuguesa. Rio de Janeiro: Editora Nova Fronteira; 1986. 
Fetcher ES, Foster N, Anderson JT, Grande F, Keys A. Quantitative estimation of diets to control serum cholesterol. Am J Clin Nutr 1967; 20(5):475-92.

Fisberg RM, Stella RH, Marimoto JM, Pasquali LS, Philippi ST, Latorre MRDO. Perfil lipidico de estudantes de nutrição e a sua associação com fatores de risco para doenças cardiovasculares. Arq. Bras Cardiol 2001; 76(2):137-42.

Forattini OP. Epidemiologia geral. $2^{a}$ ed. São Paulo: Editora Artes Médicas; 1996.

Forbs GB. The potato's placement in the dietary piramid. Am J Clin Nutr 1999; 69:572-3.

Fornés, NS. Padrões alimentares e suas relações com lipidios séricos em população da área metrolopitana de São Paulo. São Paulo; 1998. [Tese de Doutorado - Faculdade de Saúde Pública da USP].

Fornés, NS, Martins IS, Hernan M, Velásquez-Meléndez G, Ascherio A. Food frequency consumption and lipoproteins serum levels in the population of an urban area, Brazil. Rev Saúde Pública 2000; 34(4):380-7.

Fornés, NS, Martins IS, Hernan M, Velásquez-Meléndez G, Latorre MRDO. Food consumption scores and serum lipids levels in the population of São Paulo, Brazil. Rev Saúde Pública 2002; 36(1):12-8.

Forti N, FukushimaJ, Giannini SD. Perfil lipídico de indivíduos submetidos à cinecoronariografia em diferentes regiōes do Brasil. Arq Bras Cardiol 1997; $68: 333-42$. 
Friedman LA, Kimball AW. Coronary heart disease mortality and alcohol consumption in Framingham. Am J Clin Epid 1986; 124: 481-9.

Frisancho AR. Anthropometric standards for the assessment of growth and nutritional status. Ann Arbor: University of Michigan; 1999.

Fundação IBGE. Anuário estatístico do Brasil, 1996. Rio de Janeiro: IBGE; 1996. v. 56. p.2-124.

Fundação IBGE. 2000 [on line]. Disponivel em http//:www.ibge.gov.br [2001 abr 4].

Garcia Peña C, Thorogood M, Reyes S, Salmerón Castro J, Durán C. The prevalence and treatment of hypertension in the elderly population of the Mexican Institute of Social Security. Salud Publica Méx 2001; 43(5):415-20.

Giannini SD, Gois JM, Dereviacki BE. Prevenção primária em servidores do Hospital das Clinicas de São Paulo. Exposição dos achados em funcionários do Instituto do Coração. Rev Bras Med (Cardiologia) 1988; 3:125-9.

Graciano R A S, Gonzáles E, Jorge L I F, Silva M L P. Avaliação crítica da rotulagem praticada pela indústria alimenticia brasileira. Hig Alimentar 2000; $14(73): 21-7$

Groot L, Staveren WW. Working plan and manual of operation - anthropometry Nutririon and the elderly aconcerted action on nutrition health. In: European Community Euro-nut Netherlands, November, 1980. 
Guedes DP, Guedes JERP. Atividade física, aptidão cardiorrespiratória, composição da dieta e fatores de risco predisponentes às doenças cardiovasculares. Arq Bras Cardiol 2001; 77(3):243-50.

Guedes DP, Guedes ERP. Distribuição de gordura corporal, pressão arterial e niveis de lipidios-lipoproteinas plasmáticas. Arq Bras Cardiol 1998; 93-8.

Gutiérrez Fuentes JA. Que alimentos convêm ao coração? Hig Aliment 1998; 12(53):7-11.

Haddad EH, Sabate J, WhittenCG. Vegetarian food guid pyramid: a conceptual framework. Am J Clin Nutr 1999; 70(Suppl):615-9.

Halpern A. Pontos para o gordo. 6a ed. Rio de Janeiro: Record; 2000.

Hegested DM, McGandy RB, Meyers MI, Stare FJ. Quantitative effects of dietary fat on serum cholesterol in men. Am J Clin Nutr 1965; 17:281-95.

Helsing E. Traditional diets and disease patterns of the mediterraneam, circa 1960. Am J Clin Nutr 1995; 61(Suppl): 1329-37.

Hirata MH, Hirata RDC. Transporte de ácidos graxos no plasma. In: Curi R, Pompéia C, Miyasaka CK, Procópio J. Entendendo a gordura. São Paulo: Manole; 2002: p.59-72.

Hooper L, Summerbell CD, Higgins JP, Thompson RL, Clements G, Capps N, Davey Smith G, Riemersma RA, Ebrahim S. Reduced or modified dietary fat for 
prevention of cardiovascular disease. Cochrane Database Syst Rev 2000; (2):CD002137.

[ITFPCHD] International Task Force for Prevention of Coronary Heart Disease. Guidelines of the European Atherosclerosis Society: a desktop guide to the management of risk factors for coronary heart disease. 1992.

Jacotot B, Sola R, Motta C. Dietary monounsaturated fats and serum HDL. Europ J Clin Nutr 1991; 45(Suppl):66-9.

James WP. European diet and public health: the continuing challenge. Public Health Nutr $2001 ; 4(2 A): 275-92$.

Jenkins DJA, Kendall CWC, Ransom TPP. Dietary fiber, the evolution of the human diet and coronary heart disease. Nutr Research 1998; 18(4):633-52.

Jeppesen J, Hein HO, Suadicani P, Gyntelberg F. Triglyceride concentration and ischemic heart disease - an eight-years follow-up in the Copenhagen male study. Circulation 1998; 97:1029-36.

Johansson L, Drevon CA, Bjorneboe GEAA. The Norwegian diet during the last hundred years in relation to coronary heart disease. Eur J Clin Nutr 1996; 50:27783.

Juárez MB, Iglesias R, Scoppa HG, Agnelli H; Gauna HF. Niveles de colesterolemia y de pression arterial. Su relación com diferentes configuracions de estrés crônico. Rev Fac Cienc Méd 2000; 57(2):227-37. 
Kallithraka S, el-Jazouli A, Zeghichi S. Mediterranean diets in the Maghreb. World Rev Nutr Diet 2000; 87:160-79.

Kato H, Tillotson J, Nichaman MZ, Rhoads GG, Hamilton, HB. Epidemiologic studies of coronary heart disease and stroke in japanese men living in Japan, Hawaii and California. Am J Epid 1973:97:6:372-85.

Keys A. Coronary heart disease in seven countries. Circulation 1970; 41(Suppl 1):1-211.

Keys A, Anderson JT, Grande F. Serum cholesterol response to changes in the diet. IV. Particular saturated fat in the diet. Metabolism 1965:14:776-87.

Koenig J, Elmadfa I. Food-based dietary guidelines - the Austrian perspective. Br J Nutr 1999; 81(Suppl 2):S31-5.

Kris-Etherton PM, Eissenstat B, Jaax S, Srinath U, Scott L, Rader J, Pearson T. Validation for MEDFICTS, a dietary assessment instrument for evaluating adherence to total and saturated fat recommendations of the National Cholesterol Education Program Step 1 and Step 2 diets. J Am Diet Assoc 2001; 101(1):81-6.

Kris-Etherton PM, Yu-Poth S. Individual fatty acid effects on plasma lipids and lipoproteins: human studies. Am J Clin Nutr 1997; 65:1628S-44S.

Kwiterovich Jr PO. The effect of dietary fat, antioxidants, and pro-oxidants on blood lipids, lipoprotein, end atherosclerosis. J Am Diet Assoc 1994; 97(7Suppl):S31-41. 
Ladeia AMT. Prevenção secundária da doença aterosclerótica coronariana na

Bahia: avaliação da atitude dos cardiologistas e do controle dos fatores de risco. Salvador; 1998. [Tese de Doutorado - Faculdade de Medicina da Universidade Federal da Bahia].

Lajolo FM, coordenador, Menezes EW, Penteado MVC, Filisetti TMCC, Marquez UML. Tabela brasileira de composição de alimentos. [on line]. Disponivel em http://uww.usp.br/fcf/tabela [2002 jun 20].

Lane JD, Pieper CF, Barefoot JC, Williams RB, Siegler NC. Caffeine and cholesterol: interactions with hostility. Psychosom Med 1994; 56(3):260-6.

LaRosa JC, Hunninglake D, Bush D. The cholesterol facts: a summary of the evidence relating dietary fats, serum cholesterol, and coronary heart disease. Circulation 1990; 81:1721-33.

Lebrunie MCL, Mattos MSR, Braga JCF, Labrunie A. Controle dietoterápico ambulatorial. Rev Soc Cardiol Estado de São Paulo 1997; 7(4):465-74.

Lefer AM, Scalia R, Lefer DJ. Vascular effects of HMG CoA-reductase inhibitors (statins) unrelated to cholesterol lowering: new concepts for cardiovascular disease. Cardiov Res 2001; 49:281-7.

Lerário DDG, Gimeno SG, Franco LJ, lunes M, Ferreira SRG. Excesso de peso e gordura abdominal para a sindrome metabólica em nipo-brasileiros. Rev Saúde Pública 2002; 36(1):4-11. 
Lessa I, Conceição JL, Mirabeau LS, Oliveira V, Carneiro J, Melo J e col. Prevalência de dislipidemias em adultos da demanda laboratorial de Salvador, Brasil. Arq Bras Cardiol 1997; 69(6):395-400.

Levine GN, Keaney Jf Jr, Vita JÁ. Cholesterol reduction in cardiovascular disease: clinical benefits and possible mechanisms. N Engl J Med 1995; 332:512-21.

Lichtenstein AH, Kennedy E, Phyllis B, Danford D, Ernst DN, Lefeille GA, Horn LV, Williams CL, Booth SL. Dietary fat consumption and health. Nut Rev 1998; 56(5):S3-S28.

Liu S, Stamper MJ, HU FB, Givannucci E, Rimm E, Manson JE, Hennekens CH, Willett WC. Whole-grains and risk of coronary heart disease: results from the Nurses" Health Study. Am J Clin Nutr 1999; 70:412-9.

Lobato E, Lemos V. Aposta nos pontos. Rev IstoÉ 2002 out 30. [on line]. Disponivel em http://www.terra.com.br/istoe/1718/meidicina/1718 os segredos da obesidade 03.htm [2002 set 02].

Lobo RA. Treatment of the post-menopausal women: basic and clinical aspects. New York, Raven, 1994.

López ML, Valle MO, Sastre Y, Cueto A. Evaluatón de un programa educativo para reducir factores de riesgo cancerigeno em la dieta. Alim Nutr Salud 1997; 4(2):50-8. 
Lottenberg AMP. Influência do grau de saturação dos ácidos graxos da dieta e do estado alimentar sobre a esterificação do colesterol e sua transferência entre lipoproteínas no plasma. São Paulo; 1997. [Tese de Doutorado -Faculdade de Ciências Farmacêuticas da USP].

Lottenberg AMP, Nunes VS, Nakandakare ER, Neves M, Bernik M, Santos JE, Quintão ECR. Eficiência dos ésteres de fitoesteróis alimentares na redução dos lípides plasmáticos em hipercolesterolêmicos moderados. Arq Bras Cardiol 2002; $79(2): 139-42$.

Lotufo PA. As doenças cariovasculares no Brasil: estudo de caso da tendência da mortalidade no Estado de São Paulo, 1970-1989. São Paulo; 1993. [Dissertação de Mestrado - Faculdade de Saúde Pública da USP].

Luz PL, Carvalho MEA, Cardoso RHA, Gallucci SDB, Pileggi F. Incidência de dislipidemias e sua relação com doença arterial coronária em populações brasileiras. Arq Bras Cardiol 1990; 54:257-64.

Manninen $V$, Elo $O$, Frick $H$. Lipid alterations and decline in the incidence of coronary heart disease in the Helsinki Heart Study. JAMA 1998; 260:641-51.

Mansur AP, Mattar AP, Tsubo CE, Simuo DT, Yoshi FR, Caci K. Prescrição e aderência das estatinas em pacientes co doença arterial coronariana e hipercolesterolemia. Arq Bras Cardiol 2001; 76(2):111-8. 
Martin MJ, Hulley SB, Browner WS, Kuller LH, Wentworth D. Serum cholesterol, blood pressure, and mortality: implications from a cohort of 361,662 men. Lancet $1986 ; 2: 933-39$

Martins IS, Marucci MFN, Cervato AM, Okani ET, Mazzili RN, Casajus MI. Doenças cardiovasculares ateroscleróticas, dislipidemias, hipertensão, obesidade e diabetes melito em população da área metropolitana da região Sudeste do Brasil. II Dislipidemias. Rev Saúde Pública 1996; 30:75-84.

Marucci MFN. Aspectos nutricionais e hábitos alimentares de idosos matriculados em ambulatório geriátrico. São Paulo; 1992. [Tese de Doutorado Faculdade de Saúde Pública da USP].

Mattson FH, Erickson BA, Kligman AM. Effect of dietary cholesterol on serum cholesterol in men. Am J Clin Nutr 1972; 25:589-94.

McCance RA, Winddowson EM. The composition of foods. $5^{\text {th }}$ ed. Portland: Book News; 1991.

McCullough ML, Feskanich D, Rimm EB, Giovannucci EL, Ascherio A, Variyam JN, Spiegelman D, Stampfer MJ, Willet WC. Adherence to the dietary guidelines for Americans and risk of major chronic disease in men. Am J Clin Nutr 2000a; 72 : 1223-31.

McCullough ML, Feskanich D, Stampfer MJ, Rosner BA, Hu FB, Hunter DJ, Variyam JN, Colditz GA, Willet WC. Adherence to the dietary guidelines for Americans and risk of major chronic disease in women. Am J Clin Nutr 2000b; 72: 1214-22. 
Mitchell DT, Korslund MK, Brewer BK, Novanscone MA. Development and validation of the Cholesterol-Saturated Fat Index (CSI) Scorecard: a dietary selfmonitoring tool. J Am Diet Assoc 1996; 96(2):132-6.

[MNHW] Minister of National Health and Welfare. Canadian guidelines for healthy weights: Report of an expert group. Otawa; 1988.

Molina V. Guias alimentares para a América Latina. INCAP; 2002.

Molina V, Rodríguez M, Torún B, Menchú MT, Elias L. Lineamentos generales para la elaboración de guias alimentarias. Uma propuesta del INCAP. Guatemala: INCAP; 1995.

Mondini L, Monteiro CA. Mudanças no padrão da alimentação da população urbana brasileira (1962-1988). Rev Saúde Pública 1994; 28: 433-9.

Monteiro CA, Mondini L, Costa RBL Mudanças na composição e adequação nutricional da dieta familiar nas áreas metropolitamas do Brasil (1988-996). Rev Saúde Pública 2000; 34: 251-8.

Monteiro CA, Mondini L, Medeiros de Souza AL, Popkin BM. Da desnutrição para a obesidade: a transição nutricional no Brasil. In: Monteiro CA, organizador. Velhos e novos males da saúde no Brasil: a evolução do país e de suas doenças. São Paulo: Hucitec-Nupens/USP; 1995a: p.247-55.

Monteiro CA, Mondini L, Medeiros de Souza AL, Popkin BM. The nutrition transition in Brazil. Eur J Clin Nutr 1995b; 49: $105-13$. 
Moreira LB, Fuchs FD, Moraes RS, Bredemeier M, Cardozo S, Fuchs SC, Victora CG. Alcoholic beverage consumption and associated factors in Porto Alegre, a southern Brazilian city: a population-based survey. J Stud Alcohol 1996; 57(3):253-9.

Motta DG, Boog MCF. Educação Nutricional. São Paulo: Ibrasa; 1984.

[MS] Ministério da Saúde. Secretaria Nacional de Ações Básicas de Saúde. Divisão Nacional de Epidemiologia. Estatísticas de mortalidade - Brasil, 1980. Brasilia: Centro de documentação do Ministério da Saúde; 1983.

[MS] Ministério da Saúde. Guia alimentar para crianças menores de 2 anos. Brasilia: Editora MS; 2002

[MS] Ministério da Saúde. Secretaria Nacional de Ações Básicas de Saúde. Divisão Nacional de Epidemiologia. Estatísticas de mortalidade - Brasil, 1995. Brasilia: Centro de documentação do Ministério da Saúde; 1998.

Murray RK, Granner DK, Mayes PA, Rodwell WW. Harper: Bioquimica. 9a. ed. São Paulo: Atheneu; 2000.

Nacif MAL. Guia Alimentar para Controle de Colesterol e Gordura no Sangue concordância do sistema de pontos. São Paulo; 2003. [Dissertação de Mestrado - FCF/FEA/FSP da USP - Programa de Pós-Graduação Interunidades em Nutrição Humana Aplicada - PRONUT]. 
Navarro AM, Stedille MS, Unamuro MRDL, Marchini JS. Distribuiçāo da gordura corporal em pacientes com e sem doenças crônicas: uso da relação cintura-quadril e do indice de gordura do braço. Rev Nutr 2001; 14(1):37-41.

[NCEP] National Cholesterol Education Program. Detection, evaluation, and treatment of high blood cholesterol in adults (Adult treatment panel II). Circulation $1994 ; 89(3): 1330-445$.

[NCEP] National Cholesterol Education Program. Executive summary of the third report of the National Cholesterol Education Program (NCEP) expert panel on detection, evaluation, and treatment of high blood cholesterol in adults (Adult treatment panel III). JAMA 2001; 285(19):2486-97.

Nelson DL, Cox MM. Lehninger - Principios de bioquimica. $3^{a}$ ed. São Paulo: Sarvier; 2002.

Neter J, Kutner MH, Nachtsheim CJ, Wasserman W. Applied linear statistical models. $4^{\text {th }}$ ed. Boston: Irwin; 1996.

Neumann AICP, Philippi ST, Cruz ATR, Marimoto JM, Fisberg RM. A pirâmide alimentar na orientação nutricional de individuos portadores de doenças cardiovasculares. Nutrire 2000; 19/20:7-17.

Neves NM. Nutrição e doenças cardiovasculares. Rio de Janeiro. Guanabara; 1997. 
Nicolau JC, Nogueira C, Maia LN, Ramires JAF. Evolução dos niveis de colesterol na população adulta de São José do Rio Preto (1991-1997). Arq Bras Cardiol $1998 ; 71(5): 699-704$.

[NIH] National Institute of Health. National Cholesterol Education Program. Working Group on Lipoprotein Measurement. Recommendation lipoprotein measurement. Bethesda, Maryland; 1995. (NIH publication, 93-3044).

[NRC] National Research Council. Nutrient update. Nutr Today 1998; 33:257-9.

Paschoal SMP. Epidemiologia do envelhecimento. In: Papaléo Neto $M$. Gerontologia. São Paulo: Atheneu; 1996: p. 26-43.

Papaléo Neto M. Envelhecimento: desafio na transição do século. In: Papaléo Neto M. Gerontologia. São Paulo: Atheneu; 1996: p. 3-12.

Peña M, Molina V. Guias Alimentarias y Promoción de la Salud en America

Latina. Washington D. C. Organización Panamericana de la Salud. Instituto de Nutrición de Centroamérica y Panamá (INCAP); 1998.

Pessa RP. Seleção de uma alimentação equilibrada. In: Dutra de Oliveira JE, Marquine JS. Ciências nutricionais. São Paulo: Ed. Savier; 1998: p.19-38.

Philippi, ST. Tabela de composição de alimentos - Suporte para decisão nutricional. Brasilia; 2001.

Pi-Sunyer FX. Medical hazards of obesity. Ann Intern Med 1993; $119: 655$-60. 
Posner BM, DeRusso PA, Norquist SL, Erick MA. Preventive nutrition intervention in coronary heart disease: Risk assessment and formulating dietary goals. J Amer Diet Assoc 1986; 86 (10): 1395-1400.

Pyörala K, Savolainen E, Kaukola J. Plasma insulin as coronary heart disease risk factor: relationship to other risk factors and predictive value during $9 \frac{1}{2}$ years followup of The Helsinki Policemen Study Population. Acta Med Scand 1985; 701(Suppl):38-52.

Quintão E. Hiperlipidemia: Etiologia do colesterol e aterosclerose. Rio de Janeiro: Qualitymark Editora, 1992.

Rabelo LM. Análise comparativa de fatores de risco para doença aterosclerótica entre estudantes de universidades privadas de São Paulo e Salvador. São Paulo; 2000. Tese de Doutorado - Escola Paulista de Medicina da Universidade Federal de São Paulo].

Rabelo LM, Martinez TLR. Dislipidemias. Rev Soc Cardiol 1998; 8(5):908-13.

Ramos de Marins VM, Varnier Almeida RM, Pereira RA, Barros MB. Factors associated with overweight and central body fat in the city of Rio de Janeiro; results of a two-stage random samplimg survey. Public Healthy $2001 ; 115(3): 236-42$.

Ramos LR. A explosão demográfica da terceira idade no Brasil: Uma questão de Saúde Pública. Gerontologia 1993; 1:3-8.

Reaven GM. Syndrome X. Bood Press Suppl 1992; 4:13-6. 
Repetto GA. Síndrome Plurimetabólica, também chamada de Sindrome da "vida boa" ou dos "boas vidas". Diab Metab 1998; 2:56-7.

Richard JL. Les fecteures de risque coronarien. Le paradox français. Arch Melad Coeur 1987; April: 17-21.

Rimm EB, Stampfer MJ, Ascherio A, Giovannucci E, Colditz GA, Willett WC. Vitamin E consumption and the risk of coronary disease in men. N Engl J Medicine 1993; $328(20): 1450-6$.

Robert WJ, French SA. Epidemic obesity in the United States: are fast food and television viewing contributing? Am J Public Health 1998; 88: 277-80.

Rodriguez Herrera N, Gladys Arauz A, Meza Rojas N, Rosello Araya M. Factores aterogenicos de la dieta de la poblacion costarricense, 1991. Arch Latinoam Nutr 1996:46(1):27-32.

Rolls BJ. The role of energy density in the over consumption of fat. J Nutr 2000; 130:268S-71S.

Rouquayriol, MZ. Epidemiologia \& saúde. Boston, Toronto, Litle Brown and Company; 1986.

Santos JE. Terapêutica das hiperlipemias: como e por quê? Rev Bras Hipertens $1999 ; 6(2): 158-62$. 
Sasaki S, Ishikawa T, Yanagibori R, Amano K. Change and 1-year maintenance and food group intakes at a 12-week worksite dietary intervention trial for men at high risk of coronary disease. J Nutr Sci Vitaminol 2000, 46(1):15-22.

[SBC] Sociedade Brasileira de Cardiologia. III Diretrizes brasileiras sobre dislipidemias e diretrizes de prevenção de aterosclerose do Departamento de Aterosclerose da Sociedade Brasileira de Cardiologia. Arq Bras Cardiol 2001; 77(Suplemento III):1-48.

[SBD] Sociedade Brasileira de Diabetes. Diagnóstico e classificação do diabetes mellitus e tratamento do diabetes mellitus tipo 2. Consenso 2002 [on line]. Disponivel em http://www. diabetes.org.br [2003 mai 13].

Schmitz G, Hankowitz J, Kovacs EM. Cellular processes in atherogenesis: potential targets of $\mathrm{Ca}^{2+}$ channel blockers. Atherosclerosis 1991; 88:109-32.

Serra-Majem LI, Barbas LR. Recordatorio de 24 horas. In: Serra-Majem LI, Bartrina JÁ, Verdú MJ. Nutrición y Salud Pública - Métodos, bases científicas y aplicaciones. Barcelona: Masson; 1995.p.113-9.

Sevenhuysen GP. Food composition databases: current problems and solutions. Food Nutr Agric 1994; 12: 21-6.

Shamah LT, Vásquez RC, Cervantes TL, Chávez VA. Guias de alimentación e nutrición. Una propuesta didáctica. Arch Latinoam Nutr 1997; 47(3):256-61. 
Sichieri R. Epidemiologia da obesidade. Rio de Janeiro: EdUERJ (Coleção Saúde \& Sociedade); 1998.

Singh RB, Beegom R, Mehta AS, Mohammad NA, De AK, Mitra KM, Haque M, Satya PV, Dube GK, Siddiqui HM, Wander GS, Janus ED, Haque MS.

Smith SR, Lovejoy JC, Greenway F. Ryan D, deJonge L, de la Bretonne J, Volafova J, Bray GA. Contributions of total body fat, abdominal subcutaneous adipose tissue compartments, and visceral adipose to the metabolic complications of obesity. Metabolism 2001; 50(4):425-35.

Spinelli MGN, Sesoko EH, Holland CV. Avaliação da pirâmide alimentar como instrumento de educação nutricional. In: Anais do Simpósio Sul-Brasileiro de Alimentação e Nutrição: História, Ciência e Arte. Florianópolis; 2000: p.299-303.

[SPSS] Advanced do software par análise estatistica SPSS for Windows [programa de computador]. Versão 10.0. São Paulo: SPSS; 1999.

Stampfer MJ, Hennekens CH, Manson JE, Colditz GA, Rosner B, Willett WC. Vitamin $\mathbf{E}$ consumption and the risk of coronary disease in women. $\mathbf{N}$ Engl $\mathbf{J}$ Medicine 1993; 328(20):1444-9.

[SUA] Sociedad Uruguaya de Ateroesclerosis. 2do. Consenso uruguyo sobre dislipemias. Arch Med Interna 1999; 21(1):23-43.

Sundquist J, Winkleby MA, Pudaric S. Cardiovascular disease risk factors among older black, Mexican-American, and white women and man: an analysis of NHANES 
III, 1988-1994. Third National Health and Nutrition Examination Survey. J Am Geriatr Soc 2001; 49(2):109-16.

Taddei CFG, Ramos LR, Moraes JC, Wajngarten M, Libberman A, Santos SC e col. Estudo multicêntrico de idosos em ambulatórios de cardiologia e geriatria de instituições brasileiras. Arq Brás Cardiol 1997; 69(5):327-33.

Tarasuk VS, Brooker AS. Interpreting epidemiologic studies of diet-disease relationships. J Nutr 1997; 127:1847-52.

[TFR] Task Force Report. Prevention of coronary heart disease in clinical practice. Prepared by Wood D, De Backer G, Faergemann O et al. Europ Heart J 1998; 19:1434-503.

Timlin MT, Shores KV, Reicks M. Behavior change outcomes in na outpatients cardiac rehabilitation program. J Am Diet Assoc 2002; 102(5):664-71.

Toeller M, Buyken AE, Heitkamp G, Scherbaum WA, Krans HM, Fuller JH. Associations of fat and cholesterol intake with serum lipid levels and cardiovascular disease: the EURODIAB IDDM Complications Study. Exp Clin Endocrinol Diabetes 1999; 107(8):512-21.

Torres EAFS. Teor de lipídeos em alimentos e sua importância na nutrição. São Paulo; 2000. [Tese de Livre Docência - Faculdade de Saúde Pública da USP].

Uehara MH. Efeitos metabólicos e hemodinâmicos da metiformina em pacientes com diabetes mellitus tipo 2 e hipertensão arterial essencial. São 
Paulo; 1999. [Tese de Doutorado - Escola Paulista de Medicina da Universidade Federal de São Paulo].

[USDA] United States Department of Agriculture, Center for Nutrition Policy and Promotion CNPP-5. The healthy eating index. Washington D. C.: U.S. Department of Agriculture; 1995.

[USP] Universidade de São Paulo. Faculdade de Saúde Pública. Departamento de Nutrição. Pirâmide alimentar: guia para escolha dos alimentos. São Paulo. Universidade de São Paulo. Faculdade de Saúde Pública. Departamento de Nutrição; 1999.

VandenLangenberg GM, Brady WE, Nebeling LC, Block G, Forman M, Bowen PE, Stacewicz-Sapuntzakis M, Mares-Perlman JA. Influence of using different sources of carotenoid data in epidemiologic studies. J Am Diet Assoc 1996; 96(12):1271-75.

Vannucchi $H$, Menezes EW, Campana AO, Lajolo FM. Aplicações das recomendações nutricionais adaptadas à população brasileira. Ribeirão Preto: Sociedade Brasileira de Alimentação e Nutrição (SBAN); 1990.

Vasconcellos FAG. Avaliação nutricional de coletividades: textos de apoio didático. Florianópolis: UFSC; 1995.

Verschuren WMM, Jacobs DR, Bloemberg BPM. Serum total cholesterol and longterm coronary heart disease mortality in different cultures: twenty-five-years-followup of the Seven Countries Study. JAMA 1995; 274:131-36. 
Viggiano CE. Estudo sobre prevalência de sindrome plurimetabólica em população de área metropolitana da cidade de São Paulo. São Paulo; 2001. [Dissertação de Mestrado - Faculdade de Saúde Pública da USP].

Watts GF, Lewis B, Brunt JN, Lewis ES, Coltart DJ, Smith LD, Mann JI Swan AV. Effects on coronary artery disease of lipid-lowering diet, or diet plus cholestyramine, in the St Thomaz' Atherosclerosis Regression Study (STARS). Lancet 1992; $339(8793): 563-9$

Welsh S, Davis C, Shaw A. Development of the food guide pyramid. Nutr Today $1992 ; 27(6): 12-23$

White HM, Havenstein NA. A perspective view of dieting to lower the blood cholesterol in men. Am J Clin Nutr 1976; 29:784-96.

[WHO] World Health organization. Diet Nutrition and the prevention of chronic diseases. Report. Geneva; 2002

[WHO] World Health Organization. Obesity: preventing and managing the global epidemic. Report. Geneva; 1998.

WHO MONICA Project: risk factores. Int J Epidemiol 1989; 18 (Suppl. 1): S46-S55.

Wilcox S, King AC, Castro $C$, Bortz W. Do changes in physical activity lead to dietary changes in middle and old age? Am J Prev Med 2000; 18(4):276-83

Willett WC. Coma, beba e seja saudável. Rio de Janeiro: Editora Campus; 2002. 
Willett WC. Eat, drink, and be healthy. The Harvard Medical School Guide to Healthy Eating. New York; 2001.

Willett WC. Nutritional epidemiology. $2^{\text {nd }}$ ed. New York: Oxford University Press; 1998.

Yu-Poth S, Etherton TD, Reddy CC, Pearson TA, Reed R, Zhao G, Jonnalagadda S, Wan Y, Kris-Etherton PM. Lowering dietary saturated fat and total fat reduces the oxidative susceptibility of LDL in healthy men and women. J Nutr 2000; 130(9):2228-37.

Zilversmit DB. Cholesterol index in foods. J Am Diet Assoc 1979; 74:562-65. 


\section{ANEXOS}




\section{ANEXO 1}

\section{Dieta Tradicional para portadores de dislipidemias}

\section{ORIENTAÇÃO DIETÉTICA}

\section{ALIMENTOS PROIBIDOS}

-manteiga,coalhada ou iogurte integrais,margarina;

-queijos gordos (mozzarela,requeijão,provolone,catupiry,gorgonzola,cheddar,etc);

-toucinho ou torresmo, bacon,salame,linguiça,presunto,mortadela;

-carne de porco e/ou carne de animais com gordura aparente ou muito macias(gordura entremeada)

-miúdos ou vísceras; côco, leite de côco; sorvete / chocolate

- açúcar, doces em geral que levem açúcar,refrigerante, bebidas alcoólicas

- maionese, creme de leite, chantily;leite condensado,

-sardinha em lata, gordura animal para cozinhar

-bolachas(todas), biscoitos, torradas prontas, pães de forma ou integrais que não

sejam light ou diet

\section{USO MODERADO}

-arroz,milho,aveia,trigo;

-mandioca,batata,batata-doce,mandioquinha,cará,inhame,beterraba,massas em geral(com molho tomate);

-pães(francês/italianao/sírio/light)

-fubá,sagú,farinhas em geral;

-feijão,ervilha,lentilha,soja,tremoço,grão-de-bico;

-frituras com óleo vegetal ou azeite;

-halvarinas(Becel/ Doriana Light), frutos oleaginosos(amendoim,nozes,castanhas); -frutas(03 unidades ao dia)

-carne magra de animais (vaca,frango sem pele,caças) ,peixes; peito de perú,peito de chester ,atum ao natural, $(1 \mathrm{x} / \mathrm{dia})$.

\section{ALIMENTOS PERMITIDOS}

-leite desnatado

-coalhada ou iogurte desnatados;

-ricota, queijo fresco magro,queijo cottage;

-legumes e verduras (todos sem exceção); 


\section{ANEXO 2}

\section{Instrumento para Coleta de Dados}

Nome:

Prontuário n :

Data de nascimento:

Idade: anos

Data da coleta do dado:

Sexo: ( ) masculino ( ) feminino

Escolaridade:

Raça:

Ocupação

Estado civil:

Comorbidades:

( ) obesidade

( ) sobrepeso

( ) hipertensão

( ) DM2

( ) Resistência insulínica

Outros:

Uso de medicamentos:

Telefone contato:

\begin{tabular}{|c|c|c|}
\hline & $1^{\text {a }}$ Consulta & Após 3 meses \\
\hline & Data: $/ 1$ & Data: $\quad / 1$ \\
\hline Peso (kg) & & \\
\hline Altura (m) & & \\
\hline $\operatorname{IMC}\left(\mathrm{kg} / \mathrm{m}^{2}\right)$ & & \\
\hline Cintura $(\mathrm{cm})$ & & \\
\hline Colesterol total $(\mathrm{mg} / \mathrm{dl})$ & & \\
\hline HDL - colesterol $(\mathrm{mg} / \mathrm{dl})$ & & \\
\hline $\mathrm{LDL}$ - colesterol $(\mathrm{mg} / \mathrm{dl})$ & & \\
\hline VLDL - colesterol $(\mathrm{mg} / \mathrm{dl})$ & & \\
\hline Triglicérides (mg/dl) & & \\
\hline Atividade fisica & & \\
\hline
\end{tabular}

Obs.: 


\section{ANEXO 3}

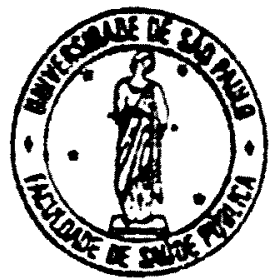

\section{UNIVERSIDADE DE SÃO PAULO} FACULDADE DE SAÚDE PÜBLICA

\section{COMITÉ DE ÉTICA EM PESQUISA-COEP}

Av. Dr. Arnaldo, 715 - Cerqueira César

São Paulo-SP - CEP: 01246-904

Telefone: (0xI11) 3066-7779 - e-mail: mdgracas@asp.br

Of. COEP/067/01

24 de maio de 2011

Pelo presente, informo que o Comitê de Ética em Pesquisa da Faculdade de Saúde Pública da Universidade de São Paulo-COEP, analisou e aprovou "adreferendum", de acordo com os requisitos da Resolução CNS/196/96, o protocolo de Pesquisa n. ${ }^{\circ}$ 454, intitulado: “ INDICE DE COLESTEROL/GORUURA SATURADA EM ALIMENTOS: UMA FERRAMENTA PARA INTERVENÇÕES DIETÉTICAS EM PACIENTES HIPERLIPIDÊMICOS", apresentado pela pesquisadora Edeli Simioni de Abreu.

Atenciosamente,

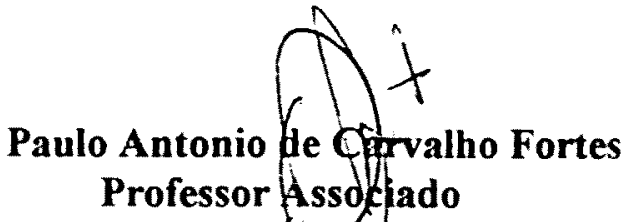

Vice-Coordenador do Comitê de Etica em Pesquisa da FSP-COEP 


\section{ANEXO 4}

\section{Termo de Consentimento Livre e Esclarecido}

Resolução n_ 196 de 10 de outubro de 1996, segundo o Conselho Nacional de Saúde

Concordo em participar da pesquisa:

Título do Protocolo de Pesquisa: Índice de colesterol/gordura saturada em alimentos: uma ferramenta para intervenções dietéticas em indivíduos hiperlipidêmicos.

Objetivo: Elaborar um guia alimentar que sirva como ferramenta para orientar pacientes com colesterol e gordura no sangue e a população em geral, como se alimentar de maneira saudável, diminuindo o consumo de gorduras .

A pesquisa a ser desenvolvida será realizada pelo departamento de nutrição da Faculdade de Saúde Pública da USP, de autoria e responsabilidade da nutricionista Edeli Simioni de Abreu CRN3-1986, sob a orientação da Prof ${ }^{a}$. Assoc. Elizabeth A. F. S. Torres.

Fui esclarecido sobre os procedimentos a serem realizados, e, me submeterei à dieta prescrita durante 3 (três) meses. Permito a coleta de $10 \mathrm{ml}$ de sangue venoso antes e após a realização da dieta. Fui esclarecido de que as amostras de sangue serão usadas para controle do colesterol e suas frações. Estou ciente que esta pesquisa é importante para o estudo de dietas adequadas à prevenção e controle do colesterol e gorduras do sangue.

Fui esclarecido pela pesquisadora que terei:

- Acesso, a qualquer tempo, às informações sobre procedimentos, riscos e benefícios relacionados à pesquisa, inclusive para sanar eventuais dúvidas;

- Liberdade de retirar o consentimento a qualquer momento e de deixar de participar do estudo, sem que isso traga prejuízo à continuidade da assistência;

- Segurança da confidencialidade, sigilo e privacidade dos dados;

Declaro que, após convenientemente esclarecido pelo pesquisador e ter entendido o que me foi explicado, consinto em participar do presente Protocolo de Pesquisa.

Local:

Data:

Nome do paciente:

Assinatura do sujeito da pesquisa

$\overline{\text { Assinatura e carimbo da pesquisadora }}$

Para maiores esclarecimentos contatar a pesquisadora ou a orientadora, na Faculdade de Saúde Pública. Av. Dr. Arnaldo, 715 ou pelo telefone 3066-7771 ou 3066-7701. 


\section{ANEXO 5}

\section{Análise de Resíduos}
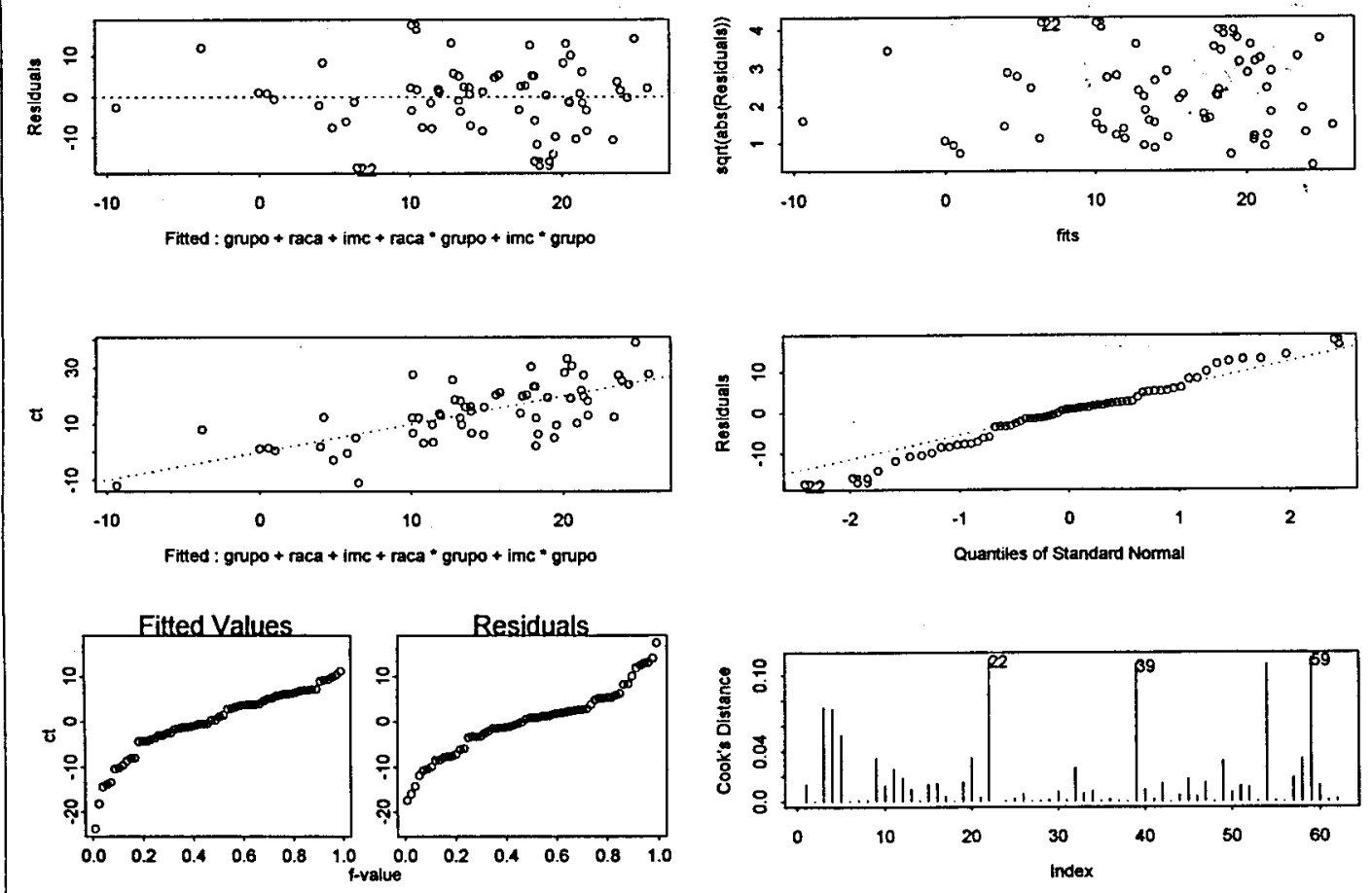